\title{
43. BENTHIC FORAMINIFERAL STABLE ISOTOPE STRATIGRAPHY OF SITE 846: 0-1.8 MA
}

\author{
A.C. Mix ${ }^{2}{ }^{\text {J. Le }},{ }^{3}$ and N.J. Shackleton ${ }^{4}$
}

\begin{abstract}
A stable-isotope stratigraphy at Site 846 (tropical Pacific, $3^{\circ} 06^{\prime} \mathrm{S}, 90^{\circ} 49^{\prime} \mathrm{W}, 3307 \mathrm{~m}$ water depth), based on the benthic foraminifers Cibicides wuellerstorfi and Uvigerina peregrina, yields a high-resolution record of deep-sea $\delta^{18} \mathrm{O}$ and $\delta^{13} \mathrm{C}$ over the past $1.8 \mathrm{Ma}$, with an average sampling interval of $3 \mathrm{k}$.y. Variance in the $\delta^{18} \mathrm{O}$ and $\delta^{13} \mathrm{C}$ records is concentrated in the well-known orbital periods of 100,41 , and $23 \mathrm{k} . \mathrm{y}$. In the 100-k.y. band, both isotopic signals grow from relatively low amplitudes prior to 1.2 $\mathrm{Ma}$, to high amplitudes in the late Quaternary since $0.7 \mathrm{Ma}$. The amplitude of $\delta^{18} \mathrm{O}$ and especially of $\delta^{13} \mathrm{C}$ decreases in the $41-\mathrm{k} . \mathrm{y}$. band as it grows in the 100-k.y. band, consistent with a transfer of energy into an orbitally-paced internal oscillation. A weak 30-k.y. rhythm, present in both $\delta^{18} \mathrm{O}$ and $\delta^{13} \mathrm{C}$, may reflect nonlinear interaction between the 41-k.y. and 100-k.y. bands in the evolving climate system. In the 23-k.y. and 19-k.y. bands associated with orbital precession, $\delta^{18} \mathrm{O}$ and $\delta^{13} \mathrm{C}$ are not coherent with each other on long time scales, and do not evolve like the 100-k.y. and 41-k.y. bands. This suggests that the source of the growing 100-k.y. oscillation is not a nonlinear response to precession, in contrast to predictions of some climate models. Sedimentation rates at this site also vary with a strong 100-k.y. cycle. Unlike the isotope records, the amplitude of 100-k.y. variations in sedimentation rate is relatively constant over the past $1.8 \mathrm{Ma}$, ranging from about 15 to $70 \mathrm{~m} / \mathrm{m}$.y. Prior to $0.9 \mathrm{Ma}$, sedimentation rates co-vary with orbital eccentricity, rather than with global climate as reflected by $\delta^{18} \mathrm{O}$ or $\delta^{13} \mathrm{C}$. A source of this $100-\mathrm{k}$.y. cycle of sedimentation rate in the absence of similar ice volume fluctuations may be precessional heating of equatorial land masses, which in an energy balance climate model drives variations of monsoonal climates with a 100-k.y. rhythm. For the interval younger than $0.9 \mathrm{Ma}$, high sedimentation rates in the 100-k.y. band are consistently associated with glacial stages. This change of pattern suggests that when the amplitude of glacial cycles become large enough, their global effects overpower a local monsoon-driven variation in sedimentation rate at Site 846.
\end{abstract}

\section{INTRODUCTION}

Here, we document and tabulate stable isotope data from benthic foraminifera in the upper $60 \mathrm{~m}$ of ODP Site 846 from the tropical Pacific Ocean ( $3^{\circ} 06^{\prime} \mathrm{S}, 90^{\circ} 49^{\prime} \mathrm{W}, 3307 \mathrm{~m}$ water depth, Fig. 1). This site provides a high-resolution record of $\delta^{18} \mathrm{O}$ and $\delta^{13} \mathrm{C}$ at an openocean site in the Peru Basin. Bottom waters in this basin presently are a mixture of Pacific Deep Water, which spills eastward over the East Pacific Rise at depths of 2500-3000 m, with water from the Antarctic Circumpolar Deep Water, which spreads northward along the South American margin (Lonsdale, 1976). At present, waters near $3300 \mathrm{~m}$ in the Peru Basin are warmer by $\sim 0.2^{\circ} \mathrm{C}$, lower in oxygen by $\sim 13$ $\mu \mathrm{mol} / \mathrm{kg}$ (Lonsdale, 1976), higher in phosphate by $\sim 0.1 \mu \mathrm{mol} / \mathrm{kg}$ (Levitus et al., 1993), and lower in $\delta^{13} \mathrm{C}$ of $\Sigma \mathrm{CO}_{2}$ by about $0.1 \%$ (Kroopnick, 1974) than sites west of the East Pacific Rise. These differences are small, but considered together are significant and are detected here in foraminiferal $\delta^{13} \mathrm{C}$ data.

\section{RESULTS}

\section{Isotopic Data}

Of the benthic foraminiferal stable isotope data presented here, all of the 716 analyses of Cibicides wuellerstorfi and nine analyses of Uvigerina peregrina were determined at the College of Oceanic and Atmospheric Sciences Stable Isotope Laboratory of Oregon State University. The remaining 84 analyses of Uvigerina peregrina presented here were made at the Godwin Laboratory, University of Cambridge. All benthic foraminifers were hand-picked from the $>150$

' Pisias, N.G., Mayer, L.A., Janecek, T.R., Palmer-Julson, A., and van Andel, T.H. (Eds.), 1995. Proc. ODP, Sci. Results, 138: College Station, TX (Ocean Drilling Program) ${ }^{2}$ College of Oceanic and Atmospheric Sciences, Oregon State University, Corvallis, OR 97331-5503, U.S.A.

${ }^{3}$ Department of Geological Sciences, University of South Carolina, Columbia, SC 29208, U.S.A

${ }^{4}$ Godwin Laboratory for Quaternary Research, University of Cambridge, Free School Lane, Cambridge, United Kingdom. $\mu \mathrm{m}$ size fraction. Typical measurements included 5 to 10 benthic foraminifers in a single analysis, but some samples were as small as two specimens.

The instrument at Oregon State University is a Finnigan/MAT 251 gas-source mass spectrometer, equipped with an Autoprep Systems automated carbonate device. Prior to isotopic analysis at OSU, foraminifers were cleaned ultrasonically in alcohol, dried, and then roasted for $1 \mathrm{hr}$ at $400^{\circ} \mathrm{C}$ under high vacuum. Reactions of carbonates occurred on line with the mass spectrometer, under vacuum, in $\sim 100 \%$ orthophosphoric acid at $90^{\circ} \mathrm{C}$. Precision of isotopic analyses of the OSU local carbonate standard (Wiley marble), measured in the same size range as the foraminiferal analyses, was $\pm 0.06 \%$ for $\delta^{18} \mathrm{O}$ and $\pm 0.03 \%$ for $\delta^{13} \mathrm{C}( \pm 1 \sigma, n=578)$. Primary calibration to the PDB standard was through NBS-20, supplied by the U.S. National Institute for Standards and Technology, assuming NBS-20 $\delta^{18} \mathrm{O}=-4.14 \%$ and $\delta^{13} \mathrm{C}=-1.06 \%$. Precision of isotopic analyses of this standard at OSU over the same period as the foraminiferal analyses was $\pm 0.10 \%$ for $\delta^{18} \mathrm{O}$ and $\pm 0.05 \%$ for $\delta^{13} \mathrm{C}(n=31)$. Replicate analyses of $C$. wuellerstorfi were made in 18 samples, yielding a precision estimate within a species of $\pm 0.10 \%$ for $\delta^{18} \mathrm{O}$ and $\pm 0.08 \%$ for $\delta^{13} \mathrm{C}$. We consider this a reasonable estimate of analytical precision for typical small-volume foraminiferal samples.

Mass spectrometry at the University of Cambridge was done on a VG/Isotech Prism instrument. Foraminiferal specimens were cleaned using $10 \%$ hydrogen peroxide in an ultrasonic bath and then reacted on-line under vacuum in $100 \%$ orthophosphoric acid at $90^{\circ} \mathrm{C}$ using a VG Isocarb common acid bath system. Long-term precision for $\delta^{18} \mathrm{O}$ and $\delta^{13} \mathrm{C}$ of carbonate standards at University of Cambridge is about $\pm 0.06 \%$.

The calibration of carbonate isotopic values at Oregon State University and University of Cambridge is highly compatible. Isotopic analyses of the same sample depths from Site 846 at the two laboratories (Uvigerina peregrina at Cambridge, and Cibicides wuellerstorfi at OSU) yield results identical to paired analyses of these genera within each laboratory. This is consistent with earlier comparison of the laboratories by Zahn and Mix (1991), which found no significant offsets between samples of similar age from nearby cores. 


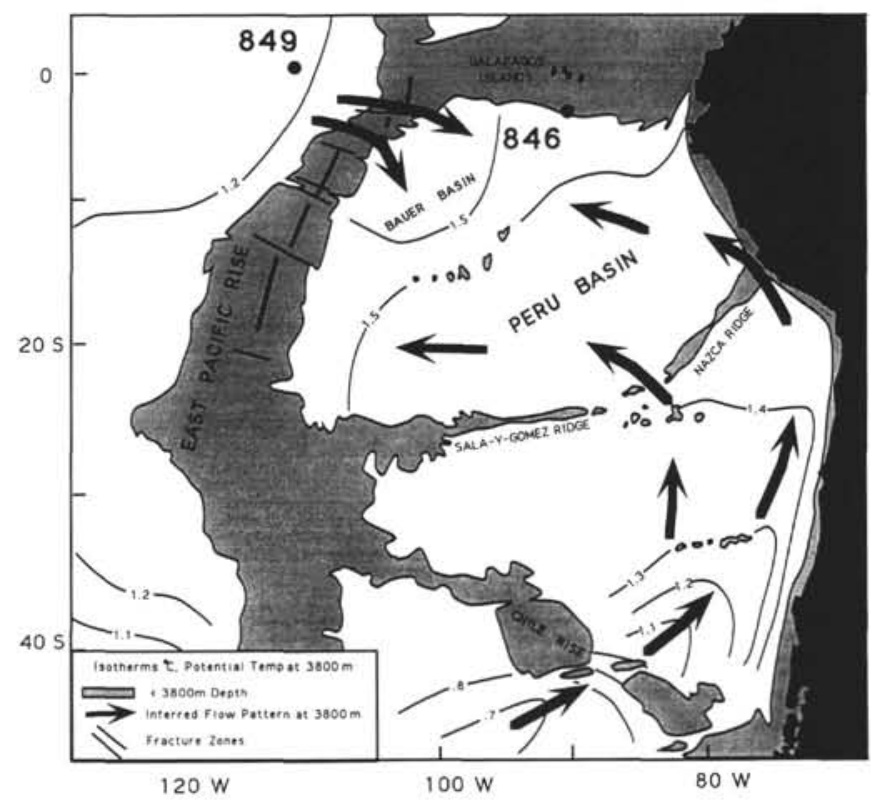

Figure 1. Site 846 monitors deep waters at a depth of $3300 \mathrm{~m}$ in the Peru Basin, east of the East Pacific Rise. Here, deep waters reflect mixing of Antarctic Circumpolar Deep Water spreading northward along the eastern boundary with Pacific Deep Water entering from the west, at 2500 to $3000 \mathrm{~m}$ across the East Pacific Rise. Map of deep-water flow vectors, and potential temperatures at $3800 \mathrm{~m}$, follows Lonsdale (1976). For comparison the location of Site 849 is shown, west of the East Pacific Rise.

To combine the isotopic data from Cibicides with those from Uvigerina, we evaluate the isotopic offsets between these taxa in 75 of the same samples (Fig. 2). Uvigerina yields $\delta^{18} \mathrm{O}$ values $0.58 \pm 0.18 \%$ higher (Fig. 2A), and $\delta^{13} \mathrm{C}$ values $0.93 \pm 0.18 \%$ lower (Fig. 2B) than Cibicides in the same samples from Site 846 . These are statistically identical to conventional values of +0.64 for the $\delta^{18} \mathrm{O}$ offset (Shackleton, 1974) and -0.90 for the $\delta^{13} \mathrm{C}$ offset (Duplessy et al., 1984) of Uvigerina-Cibicides. The standard deviations of the isotopic offsets between species measured here are not significantly different from expected random analytical error on isotopic differences of paired analyses of foraminiferal samples. Thus, we use the previously published values of Shackleton (1974) and Duplessy et al. (1984) (1) to correct $\delta^{18} \mathrm{O}$ of Cibicides to simulate that of Uvigerina and (2) to correct $\delta^{13} \mathrm{C}$ of Uvigerina to simulate that of Cibicides. These corrections are identical to those used for Site 849 by Mix et al. (this volume).

We find no evidence for systematic variation of either $\delta^{18} \mathrm{O}$ or $\delta^{13} \mathrm{C}$ offsets between species through time or with climate state at Site 846. For example, there is no significant correlation between the species offsets for $\delta^{18} \mathrm{O}$ and $\delta^{13} \mathrm{C}(r=0.01, n=75$, Fig. 2C). A single anomalous sample exists in which $\delta^{18} \mathrm{O}$ of Uvigerina is lower than that of Cibicides, but this sample lies on a major isotopic transition from glacial to interglacial conditions. It probably reflects bioturbational mixing of younger (mostly interglacial) Uvigerina into sediments containing older (mostly glacial) Cibicides. As far as we can tell, this is an isolated occurrence within this data set and has no significant bearing on the major results. In Figures 2D and $2 \mathrm{E}$, we illustrate the oxygen and carbon isotopic offsets between species as a function of glacial state (as recorded by $\delta^{18} \mathrm{O}$ in Cibicides), and in Figures $2 \mathrm{~F}$ and $2 \mathrm{G}$, the same offsets are shown as a function of $\delta^{13} \mathrm{C}$ in Cibicides. Lack of strong correlation in all of these cases suggests that isotopic offsets between species are not a function of the state of climate. We conclude that variations in the isotopic offsets are essentially random around their mean values at this site, and combine the data sets from the two species into a single depth series, after making constant offset corrections noted above. Where replicate analyses of the same species, or paired analyses of two species, were made in the same sample, the species-corrected isotope values were averaged prior to time-series analysis. All data are tabulated in Appendix A.

\section{Depth Model}

Because ODP cores are taken in discrete intervals of $\sim 9.5 \mathrm{~m}$, a depth model is required to form a long stratigraphic section. In Figure 3, we illustrate $\delta^{18} \mathrm{O}$ data from Holes $846 \mathrm{~B}, 846 \mathrm{C}$, and $846 \mathrm{D}$, for three depth models. The simplest model is based on advances of the pipe string measured by eye from the drilling floor. This is referred to as meters below seafloor (mbsf). With this model (Fig. 3A), the oxygen isotope data appear to conflict among holes. This confirms that gaps or overlaps must exist between sequential cores.

A second depth scale (referred to as meters composite depth, or mcd) was determined at sea by linearly translating cores up or down, with no stretching or squeezing of depths within each core, to best match variations in GRAPE density, reflectance, and magnetic susceptibility in the three holes (Hagelberg et al., 1992). With this depth scale, the composite $\delta^{18} \mathrm{O}$ record is more nearly continuous, and the match between holes is good (Fig. 3B).

Slight improvements in this record (Fig. 3C) come from a third depth scale, called revised meters composite depth (rmcd). This scale allows for squeezing and/or stretching of core intervals to best match shipboard GRAPE density and reflectance data at all overlapping intervals in the three holes relative to a single spliced reference record. The adjustments to the mcd scale, which create the rmcd scale, are found by correlating continuously measured data from each hole to a corresponding interval of a composite section developed at sea, using a continuous Fourier mapping function (Martinson et al., 1982). The rmcd depth models and correlation methods are documented by Hagelberg et al. (this volume). The stable isotope data, which were not used to define the mcd or rmcd depth models, clearly confirm the necessity of using a composite depth scale to assemble a complete stratigraphic section. For the remainder of this study, we use the rmcd depth scale.

\section{Age Model}

To transform the stable isotope records from Site 846 into an age framework, we correlate the Site $846 \delta^{18} \mathrm{O}$ data on the rmcd scale to a reference $\delta^{18} \mathrm{O}$ curve on an existing age scale. The reference curve for the interval 0 to $0.6 \mathrm{Ma}$ is the SPECMAP planktonic isotope composite record (Imbrie et al., 1984). For the interval 0.6 to $1.8 \mathrm{Ma}$, it is the composite benthic foraminiferal $\delta^{18} \mathrm{O}$ record from Site 677 (Shackleton et al., 1990). We chose the SPECMAP record for the upper portion of the reference curve because the details of the younger interval were not the primary focus at Site 677. For the late Quaternary interval, the SPECMAP record is more complete, better tested, and more widely used as a reference age model (e.g., Pisias et al., 1990; Imbrie et al., 1992, 1993).

We constructed the reference $\delta^{18} \mathrm{O}$ record by transforming the SPECMAP planktonic $\delta^{18} \mathrm{O}$ stack from 0 to $0.6 \mathrm{Ma}$ (which was reported by Imbrie et al., 1984, in standard deviation units, rather than $\delta^{18} \mathrm{O}$ per mil units) to match the mean and standard deviation of the Site 677 benthic $\delta^{18} \mathrm{O}$ data over the same interval. We then spliced the transformed SPECMAP $\delta^{18} \mathrm{O}$ and untransformed Site $677 \delta^{18} \mathrm{O}$ records together at $0.6 \mathrm{Ma}$, where a perfect match of $\delta^{18} \mathrm{O}$ values occurred. Prior to using this composite as a reference curve, we smoothed it with an 18-k.y. Gaussian filter to remove essentially all variations at periods $<9$ k.y., to avoid unrealistic correlation of analytical noise. This filter width was the narrowest that would yield a reasonably gap-free record over the 0 - to $1.8-\mathrm{Ma}$ interval studied here. We then used the technique of Martinson et al. (1982) to correlate the composite $\delta^{18} \mathrm{O}$ record from Site 846 to this reference record continuously, with ages defined at $10-\mathrm{cm}$ intervals. The $\delta^{18} \mathrm{O}$ data from Site 846 are shown on this age model, along with the smoothed reference $\delta^{18} \mathrm{O}$ record, which constrains the ages, in Figure 4. 

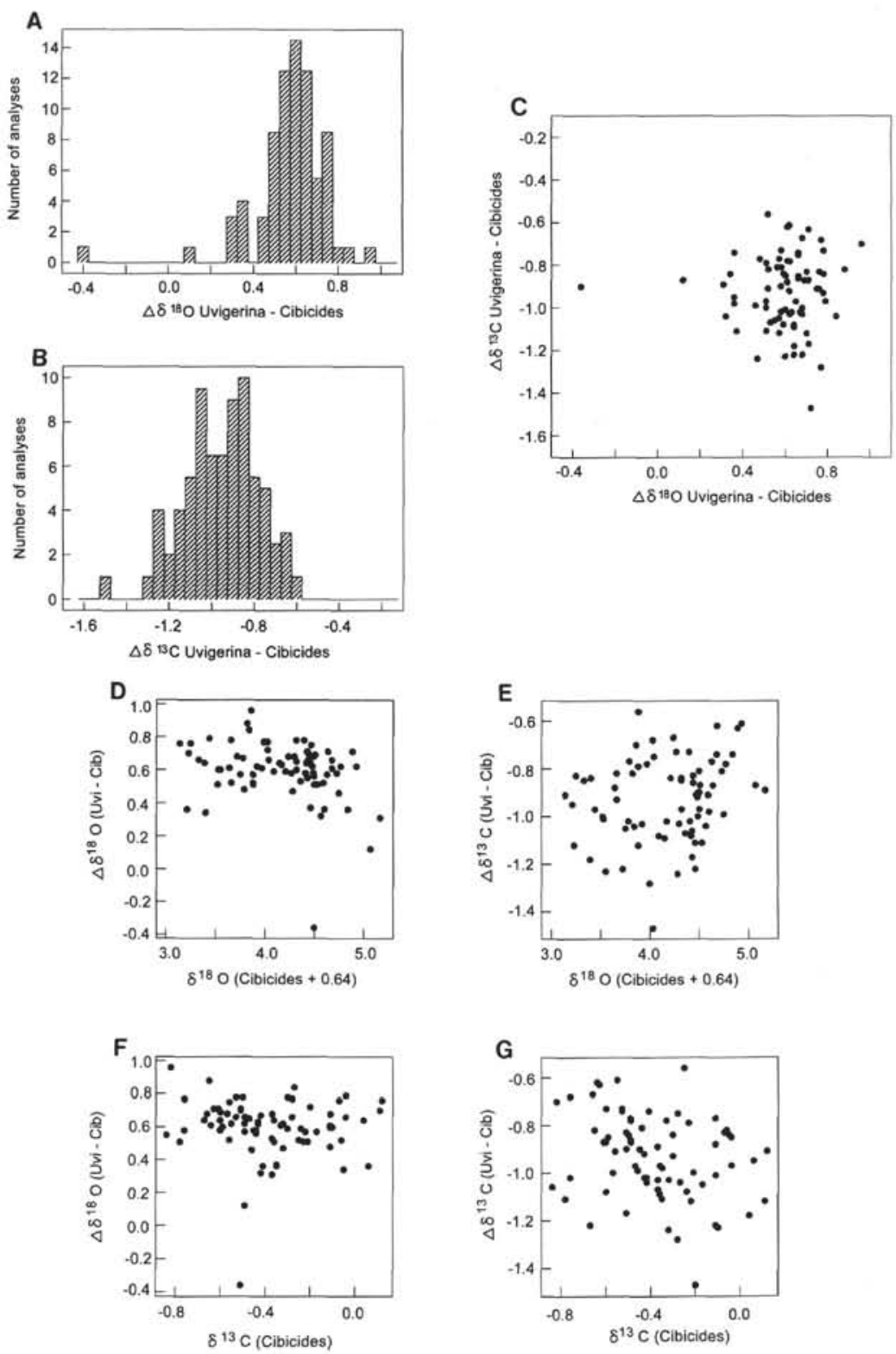

Figure 2. Isotopic offsets between species in the same samples. A. Histogram of $\delta^{18} \mathrm{O}$ offsets between Uvigerina peregrina and Cibicides wuellerstorfi $\left(\Delta \delta^{18} \mathrm{O}\right.$, mean $\left.=0.58 \pm 0.18, n=75\right)$. B. Histogram of $\delta^{13} \mathrm{C}$ offsets between Uvigerina peregrina and Cibicides wuellerstorfi $\left(\Delta \delta^{13} \mathrm{C}\right.$, mean $=-0.93 \pm 0.18, n=75$ ). C. Comparison of $\delta^{18} \mathrm{O}$ and $\delta^{13} \mathrm{C}$ species offsets reveals no correlation between the isotopic offsets. The sample with $\Delta \delta^{18} \mathrm{O}<0$ appears to be an artifact of bioturbation, mixing together two species from different times. D. $\Delta \delta^{18} \mathrm{O}_{\left(U_{v i-C i b}\right)}$ as a function of $\delta^{18} \mathrm{O}$, demonstrates no significant variation of species offsets in oxygen isotopes related to glacial state. E. $\delta^{13} \mathrm{C}_{\left(U_{v i-C i b)}\right.}$ as a function of $\delta^{18} \mathrm{O}$, demonstrates no significant variation of species offsets in carbon isotopes related to glacial state. F. $\Delta \delta^{18} \mathrm{O}_{(U v i-C i b)}$ as a function of $\delta^{13} \mathrm{C}$, demonstrates no significant variation of species offsets in oxygen isotopes related to carbon reservoir changes. G. $\Delta \delta^{13} \mathrm{C}_{(U v i-C i b)}$ as a function of $\delta^{13} \mathrm{C}$, demonstrates no significant variation of species offsets in oxygen isotopes related to carbon reservoir changes. These tests indicate that both $\delta^{18} \mathrm{O}$ and $\delta^{13} \mathrm{C}$ offsets between Uvigerina peregrina and Cibicides wuellerstorfi appear random at Site 846, not significantly different from analytical noise. These results support the use of constant isotopic corrections between species.

To demonstrate consistency with other benthic isotope records in the region, in Figure 5 the benthic $\delta^{18} \mathrm{O}$ and $\delta^{13} \mathrm{C}$ isotope records in Site 846 are compared to those of Site 849 , just west of the East Pacific Rise at $0^{\circ} 11^{\prime} \mathrm{N}, 110^{\circ} 31^{\prime} \mathrm{W}, 3851 \mathrm{~m}$ water depth (Mix et al., this volume). The two sites yield extremely similar variations in both $\delta^{18} \mathrm{O}$ and $\delta^{13} \mathrm{C}$. This confirms that both sites have essentially complete stratigraphic records over the past $1.8 \mathrm{Ma}$ and are well correlated to each other through the reference $\delta^{18} \mathrm{O}$ record of SPECMAP and Site 677 . One exception to the excellent correlation among sites is $\delta^{18} \mathrm{O}$ stage 17 , near $0.7 \mathrm{Ma}$, which appears to be poorly represented in Site 846 compared to Site 849 (Fig. 5A). This interval measured in Section $138-846 \mathrm{D}-3 \mathrm{H}-1$ contains a large vertical burrow visible in the core 

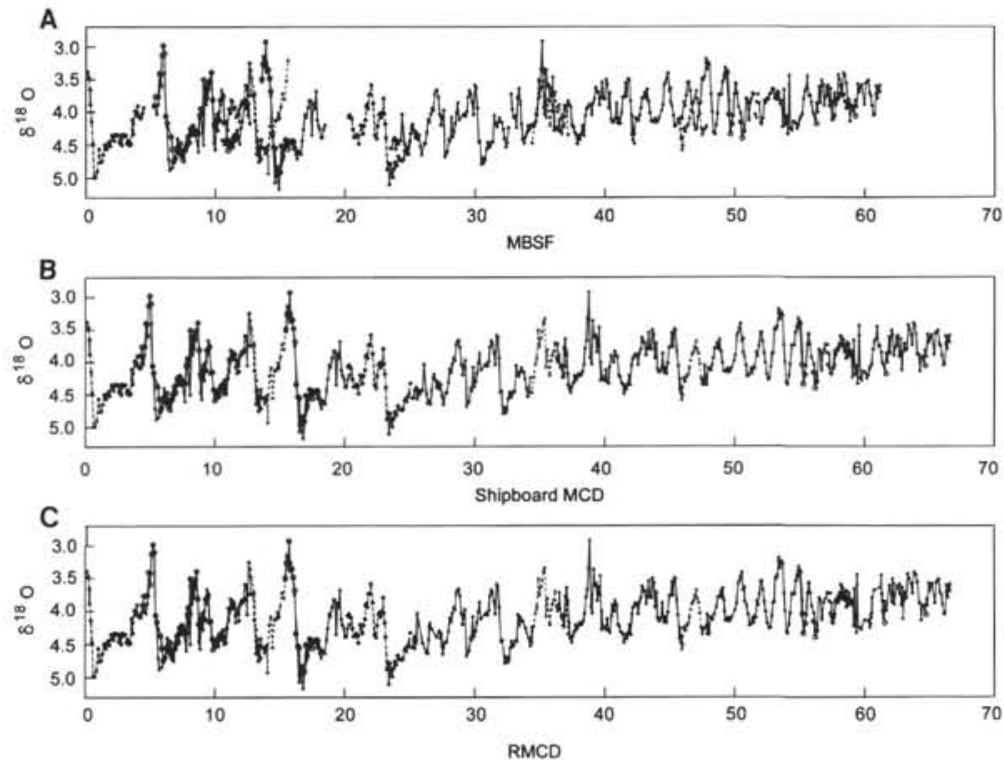

Figure 3. $\delta^{18} \mathrm{O}$ from Site 846 , plotted on three depth scales, documents the need for a composite depth scale. In all cases, data from Hole $846 \mathrm{~B}$ are a dashed line, from Hole $846 \mathrm{C}$, a dotted line, and from Hole $846 \mathrm{D}$, a solid line. Small closed symbols are $\delta^{18} \mathrm{O}$ data from Cibicides wuellerstorf $i+0.64$. Larger open symbols are $\delta^{18} \mathrm{O}$ data from Uvigerina peregrina. The three depth scales are (A) meters below seafloor (mbsf, depths assigned by drillers), (B) meters composite depth (mcd, defined by Hagelberg et al, 1992), (C) revised meters composite depth (rmcd, defined by Hagelberg et al., this volume). The rmcd scale is used here.

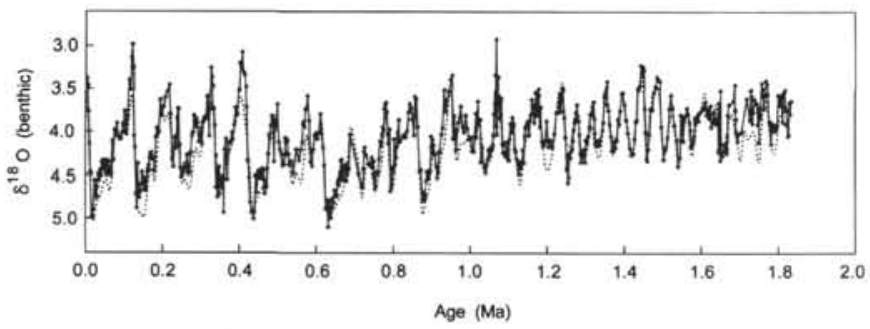

Figure 4. Composite $\delta^{18} \mathrm{O}$ record of Site 846 plotted vs. age (solid line with symbols, replicate analyses averaged) superimposed on the $\delta^{18} \mathrm{O}$ reference record (dashed line, composed of the SPECMAP and Site $677 \delta^{18} \mathrm{O}$ records, smoothed with an 18-k.y. Gaussian filter).

photograph (Mayer, Pisias, Janecek, et al., 1992). This burrow may have obliterated part of stage 17 , and thus the range of isotopic values in this stage are misrepresented in this data set. For purposes of calculating spectra and bandpass-filtered isotope records, we replace this short data gap in Site 846 with the $\delta^{18} \mathrm{O}$ and $\delta^{13} \mathrm{C}$ values from Site 849 documented by Mix et al. (this volume).

Over the past $1.8 \mathrm{Ma}$, the mean $\delta^{18} \mathrm{O}$ values at Site 846 are identical to those at Site 849 . In contrast, $\delta^{13} \mathrm{C}$ values at Site 846 are almost always slightly lower than those at Site 849 (Fig. 5B). This difference, on average $0.1 \%$, is consistent with modern water mass distributions (Kroopnick, 1974; Lonsdale, 1976). Lower $\delta^{13} \mathrm{C}$ of the deep water masses in the Peru Basin may result from both higher nutrient concentrations and lower $\delta^{13} \mathrm{C}$ values of deep waters spilling over the East Pacific at a depth of 2500 to $3000 \mathrm{~m}$, relative to deep waters west of the East Pacific Rise at $3850 \mathrm{~m}$, and oxidation of low- $\delta^{13} \mathrm{C}$ organic matter sinking from the highly productive surface waters along the eastern boundary and South Equatorial Current (Mix et al., this volume).

The continuous age-depth relationship developed here for the interval 0 to $1.8 \mathrm{Ma}$ of the Site 846 , based on the stable isotope record, is compared in Figure 6 with the age model generated from correlating GRAPE density variations to orbital variations at discrete points
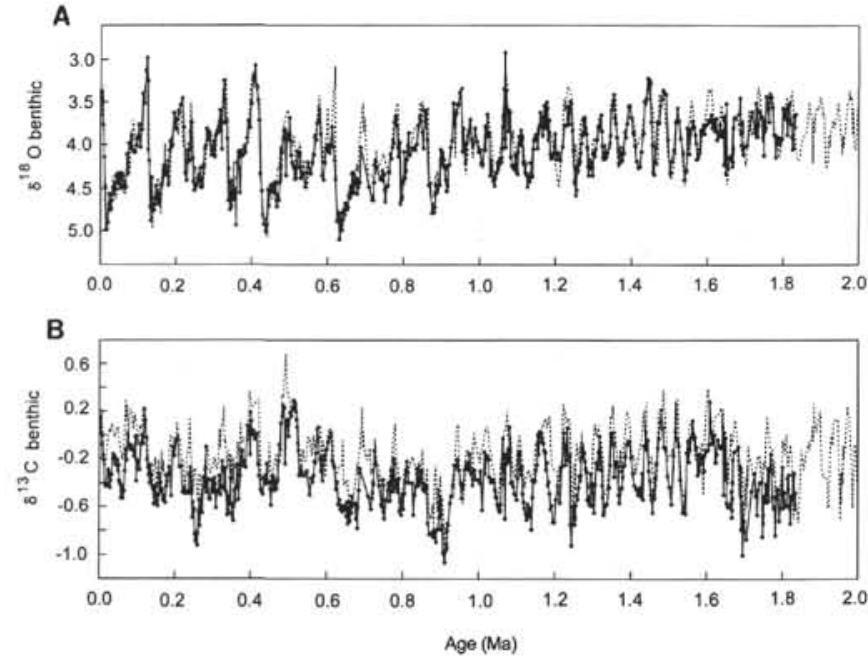

Figure 5. Comparison of $(\mathbf{A}) \delta^{18} \mathrm{O}$ and $(\mathbf{B}) \delta^{13} \mathrm{C}$ records from Site 846 (solid line with symbols) and Site 849 (dashed line, data and age model reported by Mix et al., this volume) vs. age. The $\delta^{18} \mathrm{O}$ records are similar and have the same mean. The $\delta^{13} \mathrm{C}$ values at Site 846 are generally lower than those at Site 849 by about $0.1 \%$, reflecting small difference in the $\delta^{13} \mathrm{C}$ value of deep water masses east and west of the East Pacific Rise.

(Shackleton et al., this volume). In most cases, the two age models are nearly identical. Over the interval 1.3 to $1.7 \mathrm{Ma}$, however, the isotopic age model developed here is about $41 \mathrm{k} . \mathrm{y}$. younger at equivalent depths than the GRAPE age model. In this interval, the stable isotope records are dominated by the 41-k.y. cycle of orbital obliquity; thus, the difference in the two age models implies a jump of one full obliquity cycle between the two age models. The continuous age model generated here (and tabulated in Appendix B) produces a better match of Site 846 with the $\delta^{18} \mathrm{O}$ and $\delta^{13} \mathrm{C}$ records of Site 677 


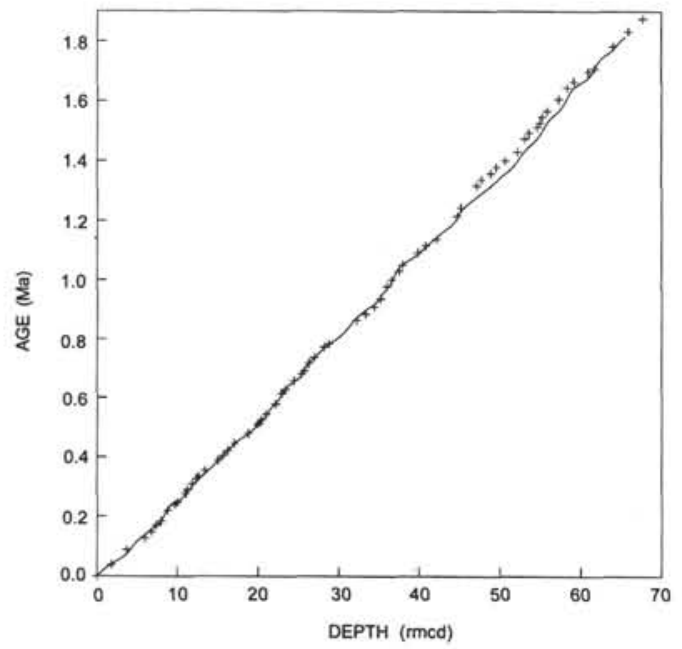

Figure 6. Age vs. depth for Site 846 , based on correlation of $\delta^{18} \mathrm{O}$ records here (solid line), and tuning of GRAPE density variations to orbital variations (discrete points, from Shackleton et al., this volume). Throughout most of the record, the age models are essentially identical. An exception is the interval from $\sim 1.3$ to $\sim 1.7 \mathrm{Ma}$, in which the isotopic age model developed here is on average 41-k.y. younger than the GRAPE age model at equivalent depths.

(Shackleton et al., 1990), and Site 849 (Mix et al., this volume) as illustrated in Figures 4 and 5.

\section{DISCUSSION}

\section{Earth's orbital rhythms in $\delta^{18} \mathrm{O}$ and $\delta^{13} \mathrm{C}$}

We compare the time series of $\delta^{18} \mathrm{O}$ and $\delta^{13} \mathrm{C}$ from Site 846 , to see whether variations in these parameters are coherent with each other, and whether their variance is concentrated in the orbital bands as they are elsewhere (Shackleton et al., 1990; Imbrie et al., 1992; Mix et al., this volume). Power spectra of the two time series (Fig. 7A) reveal that both contain significant concentrations of variance at the periods of orbital eccentricity (100 k.y.) and obliquity (41 k.y.). In these bands, coherence between $\delta^{18} \mathrm{O}$ and $\delta^{13} \mathrm{C}$ (Fig. 7B) is high. Power is significantly concentrated at the periods of orbital precession ( $23 \mathrm{k} . \mathrm{y}$. and 19 k.y.) in the $\delta^{18} \mathrm{O}$ record. Variations in $\delta^{13} \mathrm{C}$ are apparent in the 23-k.y. band, but the coherence with $\delta^{18} \mathrm{O}$ is weak. At the 19-k.y. period, there is no significant concentration of power in $\delta^{13} \mathrm{C}$, and no coherence with $\delta^{18} \mathrm{O}$. This pattern was also detected at Site 849 (Mix et al., this volume).

A weak concentration of coherent power in $\delta^{18} \mathrm{O}$ and $\delta^{13} \mathrm{C}$ is apparent in Figures 7A and 7B at a frequency of $0.033 \mathrm{k.y} .^{-1}$ (period of 30 k.y.). This matches variations that would result from a nonlinear interaction between the 100 - and 41-k.y. periods (i.e., $1 / 30=1 / 100+1 / 41$ ). If this feature is real, it may be evidence for a nonlinear response of both glaciation and the carbon cycle to orbital forcing (Hagelberg et al., 1991).

At the $100-\mathrm{k} . \mathrm{y}$. period, a phase of $-8^{\circ} \pm 10^{\circ}$ indicates that increases in oceanic $\delta^{13} \mathrm{C}$ are either in phase with, or lead interglacial events $\left(-\delta^{18} \mathrm{O}\right)$ by a few thousand years (and similarly decreases in $\delta^{13} \mathrm{C}$ are in phase with or lead glacial events) (Fig. 7C). At shorter periods $\delta^{13} \mathrm{C}$ lags $-\delta^{18} \mathrm{O}$ significantly, with a phase of $12^{\circ} \pm 9^{\circ}$ at the $41-\mathrm{k}$.y. period and a phase of $41^{\circ} \pm 22^{\circ}$ at the 23-k.y. period. Although these are relatively small variations in phase, they are significant, and essentially identical to those found at Site 849 (Mix et al., this volume). Over time intervals shorter than a few hundred thousand years (the steady-state residence time of carbon in the oceans), the mean oceanic $\delta^{13} \mathrm{C}$ value reflects the size of the global organic carbon reservoir relative to inorganic carbon in the oceans (Shackleton, 1977). Under the assumptions that changes in deep Pacific $\delta^{13} \mathrm{C}$ reflect the mean oceanic budget and that the size
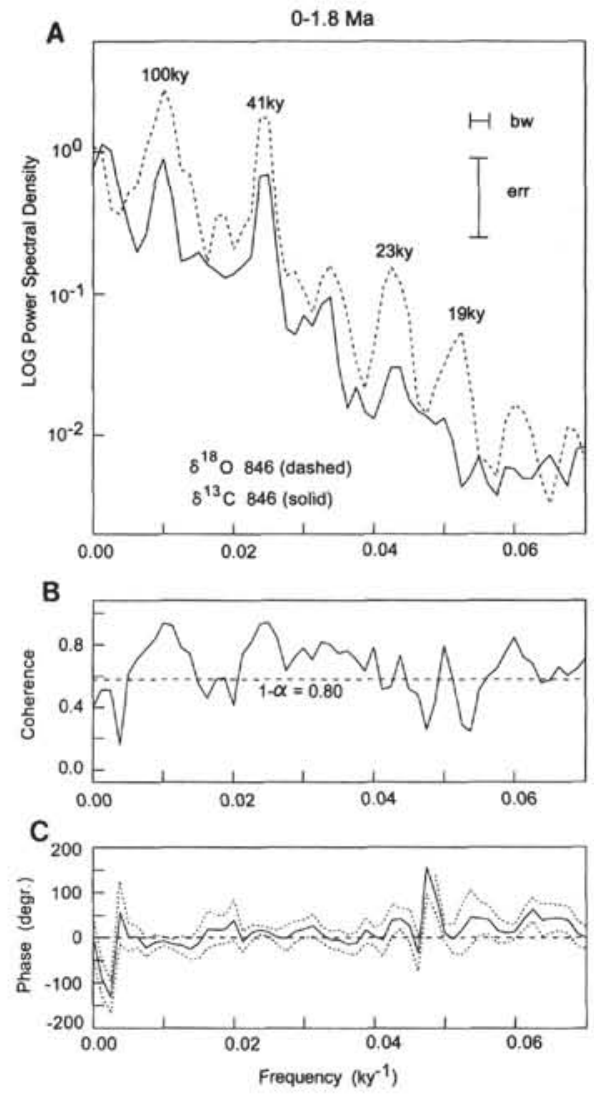

Figure 7. A. Power spectra of $\delta^{18} \mathrm{O}$ (dashed line) and $\delta^{13} \mathrm{C}$ (solid line) indicate significant concentrations of variance at periods of $100 \mathrm{k}$.y. (similar to orbital eccentricity) and 41 k.y. (similar to orbital obliquity) in both isotopes over the interval 0 to $1.8 \mathrm{Ma}$. In addition, both isotopes contain concentrations of power in the 23-k.y. band (similar to orbital precession), and perhaps at a period of 30 k.y. (a possible combination tone of the 100- and 41-k.y. bands). Only $\delta^{18} \mathrm{O}$ concentrates power at the 19-k.y. band. B. Coherency spectrum. The two isotope records are strongly coherent with each other (at $80 \%$ confidence) where power is concentrated only in the 100-, 41-, and 30-k.y. bands. Coherence is weak in the 23-k.y. band and absent in the 19-k.y. band. C. Phase spectrum. In the $100-\mathrm{k} . \mathrm{y}$. band, $\delta^{13} \mathrm{C}$ leads $-\delta^{18} \mathrm{O}$, with phase $=-8^{\circ} \pm 10^{\circ}$ (i.e., highest oceanic $\delta^{13} \mathrm{C}$ occurs at or just prior to interglacial extremes), while at shorter periods $\delta^{13} \mathrm{C}$ lags $-\delta^{18} \mathrm{O}$ (phase $=12^{\circ} \pm 9^{\circ}$ at the $41-\mathrm{k}$.y. period, and $41^{\circ}$ $\pm 22^{\circ}$ at the 23-k.y. period).

of the organic carbon reservoir responds to glacial-to-interglacial climate changes, Mix et al. (this volume) argue that the changing phase of $\delta^{13} \mathrm{C}$ relative to $-\delta^{18} \mathrm{O}$, from low to high frequencies, results from a 1- to 2-k.y. exponential response time for transfer of carbon between the organic and inorganic pools. This time constant is long enough that changes in the budget of soil and/or shallow sedimentary carbon, rather than living biomass (Shackleton, 1977), are the most likely source of mean oceanic $\delta^{13} \mathrm{C}$ change. To confirm this inference, the assumption that the deep Pacific $\delta^{13} \mathrm{C}$ records simulate the global average oceanic record will require long detailed time series of benthic foraminiferal stable isotopes from all major water masses in the global oceans.

\section{Evolution of Climate Variability}

To examine long-term evolution of the isotopic signals in the primary orbital bands, we plot band-pass filtered versions of the $\delta^{18} \mathrm{O}$ and $\delta^{13} \mathrm{C}$ time series (Fig. 8). In Figure 8, the sign of $\delta^{18} \mathrm{O}$ is reversed so that high $\delta^{18} \mathrm{O}$ plots with low $\delta^{13} \mathrm{C}$, and $\delta^{13} \mathrm{C}$ is multiplied by 2 to make 

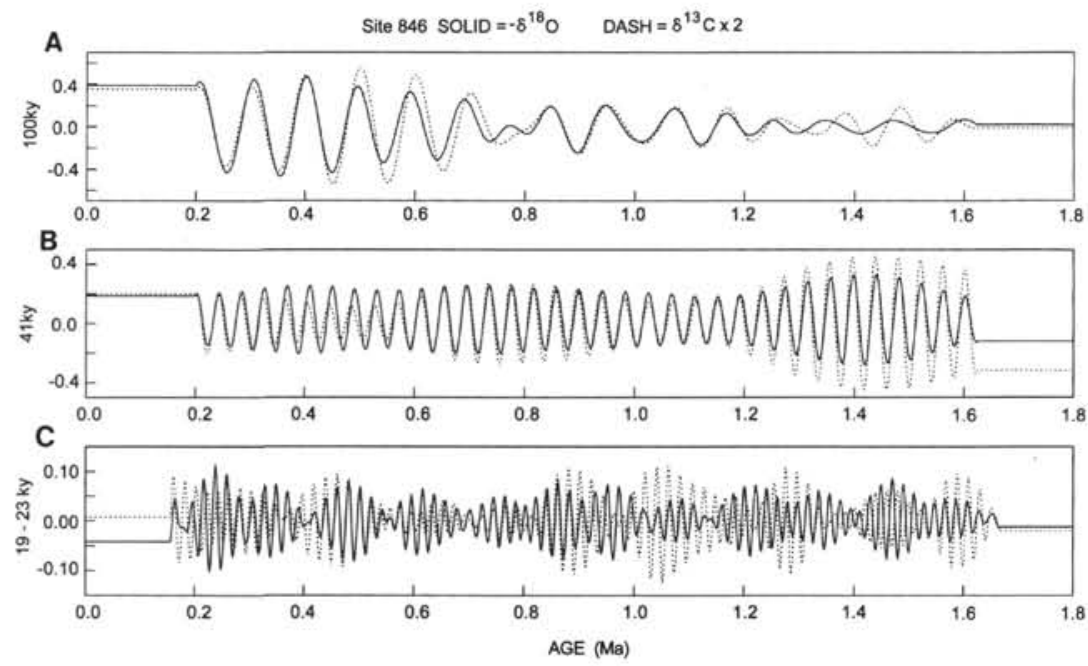

Figure 8 . The $\delta^{18} \mathrm{O}$ (solid line, sign reversed) and $\delta^{13} \mathrm{C}$ (dashed line, multiplied by 2 for scaling) records from Site 846 are filtered in the dominant orbital periods, to assess time-evolution of these signals. A. In the 100-k.y. band, $\delta^{18} \mathrm{O}$ and $\delta^{13} \mathrm{C}$ amplitude increases in the younger record. The two isotopic indices are coherent in this band younger than $1.2 \mathrm{Ma}$. B. In the $41-\mathrm{k} . \mathrm{y}$. band, the amplitude of $\delta^{18} \mathrm{O}$ and $\delta^{13} \mathrm{C}$ decreases in the younger record. C. In the 21.2-k.y. band, which encompasses the dominant precessional periods of 23 and $19 \mathrm{k} . y$. , amplitude modulation of $\delta^{18} \mathrm{O}$ and $\delta^{13} \mathrm{C}$ is not closely linked, and neither evolves similar to the longer periods.

average amplitudes appear equal in the two isotopes. This is a convenience for visualization only. In the 100-k.y. band (Fig. 8A, center frequency $=0.010 \mathrm{k} . \mathrm{y}^{-1}$, bandwidth $\left.=0.010 \mathrm{k} \cdot \mathrm{y}^{-1}\right),-\delta^{18} \mathrm{O}$ and $\delta^{13} \mathrm{C}$ have relatively high amplitudes and co-vary in the interval 0 to 1.2 $\mathrm{Ma}$, with especially strong variations younger than $0.7 \mathrm{Ma}$. Prior to $1.2 \mathrm{Ma}$, both isotope systems had lower amplitude variations and were weakly coupled. This evolution of isotopic amplitudes in the 100-k.y. band confirms earlier studies of other sites (e.g., Pisias and Moore, 1981; Ruddiman et al., 1986; Shackleton et al., 1990; Raymo et al., 1990).

In the 41-k.y. band (Fig. 8B, center frequency $=0.0244$ k.y. ${ }^{-1}$, bandwidth $\left.=0.0100 \mathrm{k} . \mathrm{y}^{-1}\right)$, the amplitude of $\delta^{18} \mathrm{O}$ variations decreases by a factor of two, from high values prior to $1.2 \mathrm{Ma}$. The amplitude of $\delta^{13} \mathrm{C}$ variations in this band decreases by a factor of four, with a similar pattern. This apparent trade-off of variance from the 41-k.y. band to the 100-k.y. band indicates a transfer of energy in the Pleistocene climate system starting around 1.2 Ma. Imbrie et al. (1993) summarized a range of possibilities to explain this based on simple paleoclimate models, and postulated one cause as a nonlinear positive feedback of large ice sheets. Because of the great inertia of large ice sheets, this feedback may channel energy from shorter periods into an orbitally paced internal oscillation near the $100-\mathrm{k}$.y. period. This process may begin when variations at other periods, such as the 41-k.y. obliquity band, become large enough to trigger the oscillation.

Amplitude modulation in the 23-19 k.y. precession band (Fig. 8C, center frequency $=0.0494 \mathrm{k} . \mathrm{y}^{-1}$, bandwidth $\left.=0.0190 \mathrm{k} \cdot \mathrm{y}^{-1}\right)$ is different in the $\delta^{18} \mathrm{O}$ and $\delta^{13} \mathrm{C}$ time series. This is consistent with the relatively low coherency between isotope systems in this band (Fig. 7). Although the amplitudes of both isotope systems vary greatly in this band, there is no obvious long-term drift in the amplitudes similar to that in the 100-k.y. band. Lack of coupling between the evolving 100-k.y. cycle and the amplitude of the 23- to 19-k.y. climate rhythms over long time intervals conflicts with the predictions of some simple climate models, which create a 100-k.y. cycle by a nonlinear response to precession (Imbrie and Imbrie, 1980).

Summarizing, the apparent interplay of the 41 - and 100-k.y. cycles in the evolving climate system point toward feedback involving highlatitude processes, where orbital obliquity dominates insolation change relative to smaller effects of orbital precession (Berger, 1978). The co-variance of $\delta^{18} \mathrm{O}$ and $\delta^{13} \mathrm{C}$ in these bands suggests that relationships between the organic carbon pool and ice sheets are key processes in this transition. The relatively rapid initiation of the 100-k.y. oscillation after 1.2 Ma need not indicate equally rapid changes in boundary conditions, such as rapid uplift of Tibet at this time. Instead, the transition may have been a chance occurrence that could have begun at a number of times, as long as slowly changing boundary conditions were favorable. This view may be consistent with tectonic reconstructions, which seem to require much slower, and older, uplift of mountain systems (Molnar et al., 1993), as well as with hypotheses linking global climatic cooling and enhanced sensitivity of climatic change to plateau uplift (Ruddiman and Kutzbach, 1989; Raymo and Ruddiman, 1992).

\section{Sedimentation Rates}

The sedimentation rate history implied by the $\delta^{18} \mathrm{O}$ age model applied here to Site 846 is illustrated in Figure 9. Sediment accumulation rates are uncorrected for coring distortion and, thus, may be on average $10 \%$ higher than actual rates cause by the lengthening of the sediment depths associated with assembly of the composite depth section (Hagelberg et al., 1992, this volume; Harris et al., this volume). The rates found here vary from $\sim 15$ to $\sim 70 \mathrm{~m} / \mathrm{m}$.y., apparently rhythmically. The dominant period of variation in sedimentation rate is 100 k.y., similar to but not significantly coherent with that of $-\delta^{18} \mathrm{O}$ (Fig. 10).

To assess the reason for this low coherency between sedimentation rate and $-\delta^{18} \mathrm{O}$ in spite of the similarity of their dominant periods, we compare bandpass-filtered versions of the sedimentation-rate curve with those of $\delta^{18} \mathrm{O}, \delta^{13} \mathrm{C}$, and orbital eccentricity (from Berger, 1978) in Figure 11. In this figure, the vertical scale represents deviations from mean sedimentation rate (represented by the solid line) within the 100-k.y. band (frequency $0.010 \mathrm{k.y.} .^{-1}$, bandwidth $0.010 \mathrm{k.y.} .^{-1}$ ). For scaling on the plots, the bandpassed $\delta^{18} \mathrm{O}$ record was multiplied by 30 (Fig. 11A), and the bandpassed $\delta^{13} \mathrm{C}$ record was multiplied by -60 (Fig. 11B). The 100-k.y. bandpassed variations in orbital eccentricity are multiplied by 600 (Fig. 11C). Note that scaling of the 


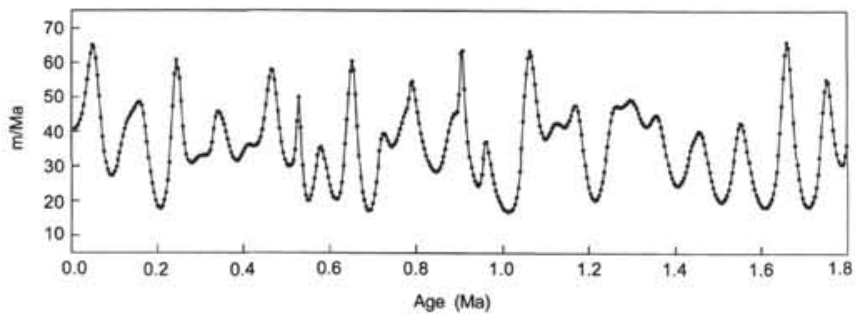

Figure 9. Sedimentation rates at Site 846 , calculated as the first derivative of the age-depth model developed here. The sedimentation rate variations contain a 100-k.y. rhythm throughout the interval 0 to $1.8 \mathrm{Ma}$.

filtered isotope and orbital eccentricity curves is only for convenience of visual comparison with sedimentation rates.

The amplitude of the sedimentation rate variations in the 100-k.y. band is relatively constant through time, in contrast to the growth in amplitude of $\delta^{18} \mathrm{O}$ (Fig. 11A) and $\delta^{13} \mathrm{C}$ (Fig. 11B). In the interval younger than $0.9 \mathrm{Ma}$, high sedimentation rates are clearly linked with glacial events as recorded by $-\delta^{18} \mathrm{O}$, or carbon reservoir shifts recorded by $\delta^{13} \mathrm{C}$. Prior to $0.9 \mathrm{Ma}$, there is no clear link between sedimentation rates and global climate as recorded by either $\delta^{18} \mathrm{O}$ or $\delta^{13} \mathrm{C}$, but there is a strong correlation between high sedimentation rates and high orbital eccentricity in the 100-k.y. band (Fig. 11C). It appears that an older link between variations in sedimentation rate and orbital eccentricity is replaced near $0.9 \mathrm{Ma}$ by a relationship with ice volume, when the amplitude of ice-volume variations becomes large enough to become the dominant influence on global climates.

The existence of a strong 100-k.y. rhythm in sedimentation rate prior to the growth of a strong 100-k.y. cycle of ice volume is puzzling, because direct variations of insolation in this band are very small (Berger, 1978). Most models rely on the existence of ice sheets with long response times (Imbrie et al., 1993), perhaps coupled to the slow isostatic response of Earth's crust (DeBlonde and Peltier, 1991), to create 100-k.y. cycles in climate. The strong 100-k.y. rhythm in sedimentation rates without a link to glaciation or sea level requires a source of 100-k.y. power in the climate or sedimentary systems other than ice sheets. The mechanism does not appear to be deep-ocean circulation, because the amplitude of global scale watermass variations appears to evolve through time, unlike the sedimentation rates calculated here (Raymo et al., 1990; Mix et al., this volume).

Crowley et al. (1992) suggested (based on energy balance model results) that a source of 100-k.y. power in climate, independent of ice, could lie in the tropics, where large continental land masses straddle the equator. Here, maximum sun angle is reached twice each year near the vernal and autumnal equinoxes. With varying precession of the equinoxes, changes in continental heating may drive monsoonal climate systems at either equinox. In their model, this converts shortperiod precessional forcing into a 100-k.y. (and 400-k.y.) rhythmic response that mimics orbital eccentricity.

The mechanisms to transfer continental heating cycles into oceanic sedimentation could be steering of winds, which affects upwelling and local biological productivity, or changes in rainfall on the continent, which could affect local weathering and erosion. The finding that major sediment composition variations are small at Site 846 relative to sedimentation rate changes (Emeis et al., this volume) suggests that both these effects may be important, because accumulation rates of both biogenic and terrigenous components vary. These mechanisms may account for the in-phase relationship between sedimentation rates at Site 846 and eccentricity prior to $0.9 \mathrm{Ma}$. If the tropical continental heating hypothesis of Crowley et al. (1992) proves to be viable as a mechanism to create 100-k.y. climate rhythms, two questions arise: (1) Why is there no strong 400-k.y. cycle of sedimentation rate (Fig. 10), as would be expected from a nonlinear response of monsoons to precession? and (2) Why do ice-volume variations appear to overwhelm this co-variation of sedimentation rates with eccentricity in the interval younger than $0.9 \mathrm{Ma}$ ?

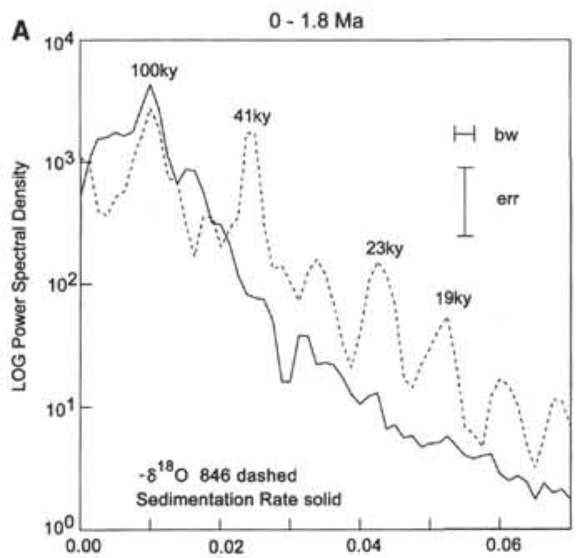

B
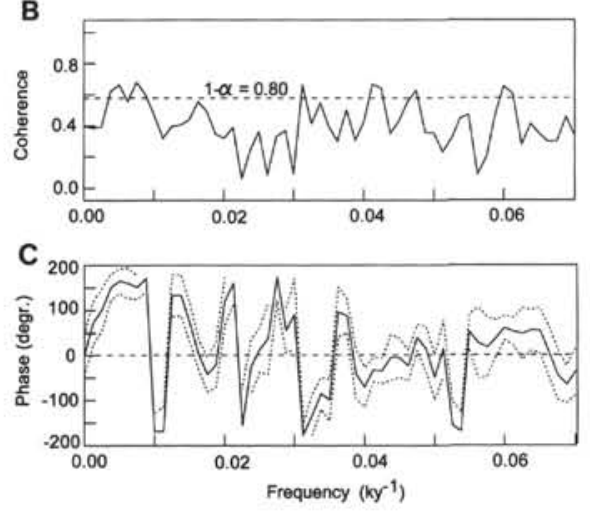

Figure 10. A. Power spectra of $\delta^{18} \mathrm{O}$ (dashed line) and sedimentation rate (solid line) indicate that sedimentation rates vary with a dominant period of 100 k.y. (similar to the dominant period of $\delta^{18} \mathrm{O}$, or the shorter dominant period of orbital eccentricity). B. Coherency spectrum, demonstrates that sedimentation rate is not coherent with $\delta^{18} \mathrm{O}$ in the dominant $100-\mathrm{k} . \mathrm{y}$. band over the interval 0 to 1.8 Ma. C.Phase spectrum. In the 100-k.y. band, phase of sedimentation rate is about $-180^{\circ}$, indicating highest sedimentation rates associated on average with glacial intervals. Low coherency precludes detailed interpretation of phase, however.

\section{SUMMARY AND CONCLUSIONS}

1. A detailed record of $\delta^{18} \mathrm{O}$ and $\delta^{13} \mathrm{C}$ measurements of the benthic foraminifers Cibicides wuellerstorfi and Uvigerina peregrina, over the interval from 0 to $1.8 \mathrm{Ma}$ in Site 846 , confirms the necessity of assembling a composite depth section to match data among holes at ODP sites, with a depth model different from standard drilling depths.

2. We find no evidence for systematic variations in the $\delta^{18} \mathrm{O}$ or $\delta^{13} \mathrm{C}$ isotopic offsets between the two species at this site, outside of normal analytical noise on foraminiferal samples.

3. An age model is documented for Site 846. This model assumes that the SPECMAP $\delta^{18} \mathrm{O}$ age model (Imbrie et al., 1984) applies from 0 to $0.6 \mathrm{Ma}$ and that the Site 677 age model of Shackleton et al. (1990) applies from 0.6 to $1.8 \mathrm{Ma}$. With this age model, Site 846 is well correlated with other records including that of Site 849 (Mix et al., this volume).

4. There is a strong linear relationship between $\delta^{18} \mathrm{O}$ and $\delta^{13} \mathrm{C}$ in the 100- and 41-k.y. bands associated with orbital eccentricity and obliquity. A weak relationship may be present at the 23-k.y. precessional period, but none is detected at the 19-k.y. period. Variations in both isotope systems may be present at periods near 30 k.y., a period expected to result from non-linear interaction between orbital eccentricity and tilt.

5. Varying phase of $\delta^{13} \mathrm{C}$ relative to $-\delta^{18} \mathrm{O}$ at different periods, especially a significant lag at shorter periods, suggests an exponential response time for the organic carbon reservoir of 1 to $2 \mathrm{k}$.y., consistent with that found by Mix et al. (this volume). 

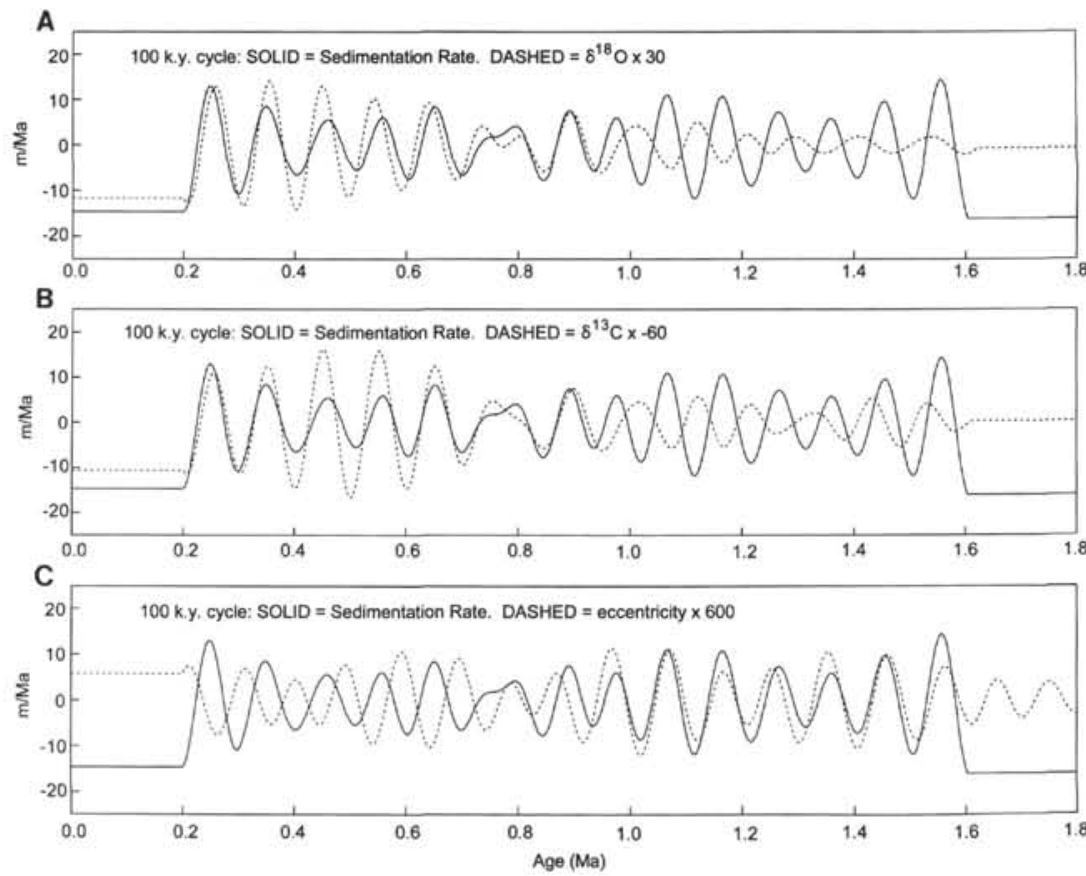

Figure 11. Bandpass-filtered records of sedimentation rates compared to isotopic and orbital signals in the 100-k.y. band (center frequency $0.010 \mathrm{k.y.}{ }^{-1}$, bandwidth $0.010 \mathrm{k.y}{ }^{-1}$ ) indicate a strong link of sedimentation rates to glacial-interglacial climate cycles in the interval 0 to $0.9 \mathrm{Ma}$, but a link to orbital eccentricity (or the amplitude of orbital precession) from 0.9 to $1.8 \mathrm{Ma}$. A. Comparison of filtered sedimentation rate (solid line) and $\delta^{18} \mathrm{O}$ (dashed line, multiplied by 30 for visual scale, up = glacial extreme), demonstrates strong correlation from 0 to $0.9 \mathrm{Ma}$. B. Comparison of filtered sedimentation rate (solid line) and $\delta^{13} \mathrm{C}$ (dashed line, multiplied by -60 for visual scale, up = low oceanic $\delta^{13} \mathrm{C}$ ), demonstrates strong correlation from 0 to $0.9 \mathrm{Ma}$. C. Comparison of filtered sedimentation rate (solid line) and orbital eccentricity (dashed line, multiplied by 600 for visual scale, up $=$ high eccentricity or high amplitude of precession), demonstrates strong correlation from 0.9 to $1.8 \mathrm{Ma}$.

6. The long-term evolution of the orbital climate rhythms is different in each band. The 100-k.y. rhythm grows through time in both $\delta^{18} \mathrm{O}$ and $\delta^{13} \mathrm{C}$, from low amplitudes prior to 1.2 Ma to highest amplitudes in the last few 100 k.y.. In the 41-k.y. band, greatest amplitudes occur prior to 1.2 Ma. Decreasing amplitude in this band is consistent with a transfer of energy from the 41-k.y. period to the growing $100-k . y$. period of climate, as envisioned by the inertial ice feedback of Imbrie et al. (1993). In the precession bands (23- and 19-k.y. periods), amplitude modulation of the $\delta^{18} \mathrm{O}$ and $\delta^{13} \mathrm{C}$ records appears to be at least partially independent of each other and also independent of the long-term evolution of the 100- and 41-k.y. cycles. Thus, the growing $100-\mathrm{k} . \mathrm{y}$. climate cycle is probably not driven by a nonlinear response to precessional forcing.

7. Sedimentation rates at Site 846 vary with a strong $100-\mathrm{k} . \mathrm{y}$. cycle, ranging from about 15 to $70 \mathrm{~m} / \mathrm{m}$.y. Unlike the stable isotope records, the amplitude of sedimentation rate variations in the 100-k.y. band is relatively constant over the past $1.8 \mathrm{Ma}$. Younger than $0.9 \mathrm{Ma}$, high sedimentation rates in this band are associated with glacial stages. Prior to $0.9 \mathrm{Ma}$, there is a strong link between sedimentation rate and orbital eccentricity. A source of 100-k.y. power in deep-sea paleoclimate records, independent of ice volume, may be seasonal solar heating of large equatorial continents. In an energy balance model this produces a $100-k . y$. monsoon cycle in nonlinear response to orbital precession (Crowley et al., 1992). Sedimentation rates at Site 846 thus may reflect monsoonal steering of winds that influence local upwelling and biogenic sedimentation, and/or changes in rainfall that affect local weathering, erosion and sedimentation of terrigenous material.

\section{ACKNOWLEDGMENTS}

We thank the Shipboard Scientific Party and ODP curatorial staff for their efforts in obtaining Leg 138 materials, as well as NSF, USSAC, and NERC for financial support. The laboratory assistance of A. Morey, J. Wilson, B. Rugh, and M. Hall is greatly appreciated. A careful review by W. Prell improved the manuscript.

\section{REFERENCES}

Berger, A., 1978. Long-term variations of caloric insolation resulting from the Earth's orbital elements. Quat. Res., 9:139-167.

Crowley, T.J., Kim, K.-Y., Mengel, J.G., and Short, D.A., 1992. Modeling 100,000-year climate fluctuations in pre-Pleistocene time series. Science, 255:705-707.

DeBlonde, G., and Peltier, W.R., 1991. A one-dimensional model of continental ice volume fluctuations through the Pleistocene: implications for the origin of the mid-Pleistocene transition. J. Clim., 4:318-344.

Duplessy, J.-C., Shackleton, N.J., Matthews, R.K., Prell, W. Ruddiman, W.F., Caralp, M. and Hendy, C.H., $1984 .{ }^{13} \mathrm{C}$ record of benthic foraminifera in the last interglacial ocean: implications for the carbon cycle and the global deep water circulation. Quat. Res., 21:225-243.

Hagelberg, T., Shackleton, N., Pisias, N., and Shipboard Scientific Party, 1992. Development of composite depth sections for Sites 844 through 854 . In

Abbreviations for names of organizations and publications in ODP reference lists follow
the style given in Chemical Abstracts Service Source Index (published by American Chemical Society). 
Mayer, L., Pisias, N., Janecek, T., et al., Proc. ODP, Init. Repts., 138 (Pt. 1): College Station, TX (Ocean Drilling Program), 79-85.

Hagelberg, T.K., Pisias, N.G., and Elgar, S.L., 1991. Linear and nonlinear couplings between orbital forcing and the marine $\delta^{18} \mathrm{O}$ record during the late Neogene. Paleoceanography, 6:729-746.

Imbrie, J., Berger, A., Boyle, E., Clemens, S., Duffy, A., Howard, W., Kukla, G., Kutzbach, J., Martinson, D., McIntyre, A., Mix, A., Molfino, B., Morley, J., Peterson, L., Pisias, N., Prell, W., Raymo, M., Shackleton, N., and Toggweiler, J., 1993. On the structure and origin of major glaciation cycles, 2. The 100,000-year cycle. Paleoceanography, 8:699-735.

Imbrie, J., Boyle, E.A., Clemens, S.C., Duffy, A., Howard, W.R., Kukla, G., Kutzbach, J., Martinson, D.G., McIntyre, A., Mix, A.C., Molfino, B., Morley, J.J., Peterson, L.C., Pisias, N.G., Prell, W.L., Raymo, M.E., Shackleton, N.J., and Toggweiler, J.R., 1992. On the structure and origin of major glaciation cycles, 1 . Linear responses to Milankovitch forcing. Paleoceanography, 7:701-738.

Imbrie, J., Hays, J.D., Martinson, D.G., McIntyre, A., Mix, A.C., Morley, J.J., Pisias, N.G., Prell, W.L., and Shackleton, N.J., 1984. The orbital theory of Pleistocene climate: support from a revised chronology of the marine $\delta^{18} \mathrm{O}$ record. In Berger, A., Imbrie, J., Hays, J., Kukla, G., and Saltzman, B. (Eds.), Milankovitch and Climate (Pt. 1): Dordrecht (D. Reidel), 269-305.

Imbrie, J., and Imbrie, J.Z., 1980. Modeling the climatic response to orbital variations. Science, 207:943-953.

Imbrie, J., Mix, A.C., and Martinson, D.G., 1993. Milankovitch theory viewed from Devils Hole. Nature, 363:531-533.

Kroopnick, P., 1974. The dissolved $\mathrm{O}_{2}-\mathrm{CO}_{2}{ }^{13} \mathrm{C}$ system in the eastern equatorial Pacific. Deep-Sea Res. Part A, 21:211-227.

Levitus, S., Conkright, M.E., Reid, J.L., Najjar, R.G., and Mantyla, N.A., 1993. Distribution of nitrate phosphate, and silicate in the world oceans. Prog. Oceanogr., 31:245-273.

Lonsdale, P., 1976. Abyssal circulation of the southeastern Pacific and some geological implications. J. Geophys. Res., 81:1163-1176.

Martinson, D.G., Menke, W., and Stoffa, P.L., 1982. An inverse approach to signal correlation. J. Geophys. Res., 87:4807-4818.

Mayer, L., Pisias, N., Janecek, T., et al., 1992. Proc. ODP, Init. Repts., 138 (Pts. 1 and 2): College Station, TX (Ocean Drilling Program).

Molnar, P., England, P., and Martinod, J., 1993. Mantle dynamics, uplift of the Tibetan Plateau, and the Indian Monsoon. Rev. Geophys., 31:357-396.
Pisias, N.G., Mix, A.C., and Zahn, R., 1990. Nonlinear response in the global climate system: evidence from benthic oxygen isotopic record in core RC13-110. Paleoceanography, 5:147-160.

Pisias, N.G., and Moore, T.C., Jr., 1981. The evolution of Pleistocene climate: a time series approach. Earth Planet. Sci. Lett., 52:450-458.

Raymo, M.E., and Ruddiman, W.F., 1992. Tectonic forcing of late Cenozoic climate. Nature, 359:117-122.

Raymo, M.E., Ruddiman, W.F., Shackleton, N.J., and Oppo, D.W., 1990. Evolution of global ice volume and Atlantic-Pacific $\delta^{13} \mathrm{C}$ gradients over the last 2.5 m.y. Earth Planet. Sci. Lett., 97:353-368.

Ruddiman, W.F., and Kutzbach, J.E., 1989. Forcing of late Cenozoic northern hemisphere climate by plateau uplift in southern Asia and the American West. J. Geophys. Res., 94:18409-18427.

Ruddiman, W.F., Raymo, M., and McIntyre, A., 1986. Matuyama 41,000-year cycles: North Atlantic Ocean and northern hemisphere ice sheets. Earth Planet. Sci. Lett., 80:117-129.

Shackleton, N.J., 1974. Attainment of isotopic equilibrium between ocean water and the benthonic foraminifera genus Uvigerina: isotopic changes in the ocean during the last glacial. Les Meth. Quant. d'etude Var. Clim. au Cours du Pleist., Coll. Int. C.N.R.S., 219:203-209.

-1977. Carbon-13 in Uvigerina: tropical rainforest history and the equatorial Pacific carbonate dissolution cycles. In Andersen, N.R., and Malahoff, A. (Eds.), The Fate of Fossil Fuel $\mathrm{CO}_{2}$ in the Oceans: New York (Plenum), 401-427.

Shackleton, N.J., Berger, A., and Peltier, W.R., 1990. An alternative astronomical calibration of the lower Pleistocene time scale based on ODP Site 677. Trans. R. Soc. Edinburgh, Earth Sci., 81:251-261.

Zahn, R., and Mix, A.C., 1991. Benthic foraminiferal $\delta^{18} \mathrm{O}$ in the ocean's temperature-salinity-density field: constraints on ice age thermohaline circulation. Paleoceanography, 6:1-20.

Date of initial receipt: 16 November 1993

Date of acceptance: 16 March 1994

Ms 138SR-160 
APPENDIX A

Benthic Foraminifer Stable Isotope Data from Site $\mathbf{8 4 6}$

\begin{tabular}{|c|c|c|c|c|c|c|c|c|c|c|c|c|c|c|}
\hline $\begin{array}{l}\text { Core, section. } \\
\text { interval }(\mathrm{cm})\end{array}$ & Species & Lab. & $\begin{array}{l}\text { Interval } \\
(\mathrm{cm})\end{array}$ & $\begin{array}{l}\text { Depth } \\
\text { (mbsf) }\end{array}$ & $\begin{array}{l}\text { Depth } \\
\text { (med) }\end{array}$ & $\begin{array}{l}\text { Depth } \\
\text { (rmcd) }\end{array}$ & $\delta^{18} \mathrm{O}$ & $\delta^{13} \mathrm{C}$ & $\begin{array}{l}\text { Core, section, } \\
\text { interval }(\mathrm{cm})\end{array}$ & Species & Lab. & $\begin{array}{c}\text { Interval } \\
(\mathrm{cm})\end{array}$ & $\begin{array}{l}\text { Depth } \\
\text { (mbsf) }\end{array}$ & $\begin{array}{l}\text { Depth } \\
\text { (med) }\end{array}$ \\
\hline $846 \mathrm{~B}-1 \mathrm{H}-1$ & C. wuell. & OSU & 12 & 0.12 & 0.12 & 0.12 & 3.38 & 0.14 & $846 \mathrm{D}-1 \mathrm{H}-3$ & U. pereg. & CAM & 68 & 7.68 & 6.68 \\
\hline $846 \mathrm{~B}-1 \mathrm{H}-\mathrm{I}$ & $C$. wuell. & OSU & 23 & 0.23 & 0.23 & 0.23 & 3.46 & 0.01 & $846 \mathrm{D}-1 \mathrm{H}-3$ & U. pereg. & CAM & 78 & 7.78 & 6.78 \\
\hline $846 \mathrm{~B}-1 \mathrm{H}-1$ & C. wuell. & OSU & 33 & 0.33 & 0.33 & 0.33 & 3.65 & -0.10 & 846D-1H-3 & C. wuell. & OSU & 78 & 7.78 & 6.78 \\
\hline $846 \mathrm{~B}-1 \mathrm{H}-1$ & C. wuell. & OSU & 33 & 0.33 & 0.33 & 0.33 & 3.88 & -0.06 & $846 \mathrm{D}-1 \mathrm{H}-3$ & $U$. pereg. & CAM & 88 & 7.88 & 6.88 \\
\hline $846 \mathrm{~B}-1 \mathrm{H}-1$ & C. wuell. & OSU & 43 & 0.43 & 0.43 & 0.43 & 4.14 & -0.17 & $846 \mathrm{D}-1 \mathrm{H}-3$ & C. nuell. & OSU & 88 & 7.88 & 6.88 \\
\hline $846 \mathrm{~B}-1 \mathrm{H}-1$ & C. wuell. & OSU & 53 & 0.53 & 0.53 & 0.53 & 4.47 & -0.21 & $846 \mathrm{D}-1 \mathrm{H}-3$ & $U$. pereg. & CAM & 98 & 7.98 & 6.98 \\
\hline $846 \mathrm{~B}-1 \mathrm{H}-1$ & C. wuell. & OSU & 63 & 0.63 & 0.63 & 0.63 & 4.99 & -0.41 & $846 \mathrm{D}-1 \mathrm{H}-3$ & C. wuell. & OSU & 98 & 7.98 & 6.98 \\
\hline $846 \mathrm{~B}-1 \mathrm{H}-1$ & C. wuell. & OSU & 73 & 0.73 & 0.73 & 0.73 & 4.99 & -0.43 & $846 \mathrm{D}-1 \mathrm{H}-3$ & $U$. pereg. & CAM & 108 & 8.08 & 7.08 \\
\hline $846 \mathrm{~B}-1 \mathrm{H}-\mathrm{I}$ & C. wuell. & OSU & 87 & 0.87 & 0.87 & 0.87 & 4.90 & -0.41 & $846 \mathrm{D}-1 \mathrm{H}-3$ & C. wuell. & OSU & 108 & 8.08 & 7.08 \\
\hline $846 \mathrm{~B}-1 \mathrm{H}-\mathrm{I}$ & C. wuell. & OSU & 100 & 1.00 & 1.00 & 1.00 & 4.56 & -0.29 & $846 \mathrm{D}-1 \mathrm{H}-3$ & $U$. pereg. & CAM & 118 & 8.18 & 7.18 \\
\hline $846 \mathrm{~B}-1 \mathrm{H}-1$ & C. wuell. & OSU & 113 & 1.13 & 1.13 & 1.13 & 4.76 & -0.32 & $846 \mathrm{D}-1 \mathrm{H}-3$ & C. whell. & OSU & 118 & 8.18 & 7.18 \\
\hline $846 \mathrm{~B}-1 \mathrm{H}-1$ & C. wuell. & OSU & 123 & 1.23 & 1.23 & 1.23 & 4.74 & -0.44 & $846 \mathrm{D}-1 \mathrm{H}-3$ & $U$. pereg. & CAM & 128 & 8.28 & 7.28 \\
\hline $846 \mathrm{~B}-1 \mathrm{H}-1$ & C. wuell. & OSU & 1.33 & 1.33 & 1.33 & 1.33 & 4.64 & -0.38 & $846 \mathrm{D}-1 \mathrm{H}-3$ & C. wuell. & OSU & 128 & 8.28 & 7.28 \\
\hline $846 \mathrm{~B}-1 \mathrm{H}-1$ & C. wruell. & OSU & 145 & 1.45 & 1.45 & 1.45 & 4.49 & -0.33 & $846 \mathrm{D}-1 \mathrm{H}-3$ & $U$. pereg. & CAM & 138 & 8.38 & 7.38 \\
\hline $846 \mathrm{~B}-1 \mathrm{H}-2$ & C. wuell. & OSU & 9 & 1.59 & 1.59 & 1.59 & 4.56 & -0.20 & $846 \mathrm{D}-1 \mathrm{H}-3$ & C. wuell. & OSU & 1,38 & 8.38 & 7.38 \\
\hline $846 \mathrm{~B}-1 \mathrm{H}-2$ & C. nuell. & OSU & 19 & 1.69 & 1.69 & 1.69 & 4.48 & -0.16 & $846 \mathrm{D}-1 \mathrm{H}-3$ & $U$. pereg. & CAM & 148 & 8.48 & 7.48 \\
\hline $846 \mathrm{~B}-1 \mathrm{H}-2$ & C. wuell. & OSU & 29 & 1.79 & 1.79 & 1.79 & 4.44 & -0.20 & $846 \mathrm{D}-1 \mathrm{H}-3$ & C. wuell. & OSU & 148 & 8.48 & 7.48 \\
\hline $846 \mathrm{~B}-1 \mathrm{H}-2$ & C. wuell. & OSU & 37 & 1.87 & 1.87 & 1.87 & 4.51 & -0.18 & $846 \mathrm{D}-1 \mathrm{H}-4$ & $U$. pereg, & CAM & 8 & 8.58 & 7.58 \\
\hline $846 \mathrm{~B}-1 \mathrm{H}-2$ & C. wuell. & OSU & 48 & 1.98 & 1.98 & 1.98 & 4.35 & -0.19 & $846 \mathrm{D}-1 \mathrm{H}-4$ & $U$. pereg. & CAM & 18 & 8.68 & 7.68 \\
\hline $846 \mathrm{~B}-1 \mathrm{H}-2$ & C. wuell. & OSU & 57 & 2.07 & 2.07 & 2.07 & 4.37 & -0.24 & $846 \mathrm{D}-1 \mathrm{H}-4$ & C. wuell. & OSU & 18 & 8.68 & 7.68 \\
\hline $846 \mathrm{~B}-1 \mathrm{H}-2$ & C. nuell. & OSU & 68 & 2.18 & 2.18 & 2.18 & 4.43 & -0.23 & $846 \mathrm{D}-\mathrm{IH}-4$ & $U$. pereg. & CAM & 28 & 8.78 & 7.78 \\
\hline $846 \mathrm{~B}-1 \mathrm{H}-2$ & C. wuell. & OSU & 78 & 2.28 & 2.28 & 2.28 & 4.33 & -0.26 & $846 \mathrm{D}-1 \mathrm{H}-4$ & C. wuell. & OSU & 28 & 8.78 & 7.78 \\
\hline $846 \mathrm{~B}-1 \mathrm{H}-2$ & C. wuell. & OSU & 88 & 2.38 & 2.38 & 2.38 & 4.35 & -0.21 & $846 \mathrm{D}-\mathrm{IH}-4$ & $U$. pereg. & CAM & 38 & 8.88 & 7.88 \\
\hline $846 \mathrm{~B}-1 \mathrm{H}-2$ & C. wuell. & OSU & 97 & 2.47 & 2.47 & 2.47 & 4.34 & -0.30 & $846 \mathrm{D}-1 \mathrm{H}-4$ & C. wuell. & OSU & 38 & 8.88 & 7.88 \\
\hline $846 \mathrm{~B}-1 \mathrm{H}-2$ & C. wuell. & OSU & 109 & 2.59 & 2.59 & 2.59 & 4.46 & -0.25 & $846 \mathrm{D}-1 \mathrm{H}-4$ & U. pereg. & CAM & 48 & 8.98 & 7.98 \\
\hline $846 \mathrm{~B}-1 \mathrm{H}-2$ & C. wuell. & OSU & 117 & 2.67 & 2.67 & 2.67 & 4.35 & -0.38 & $846 \mathrm{D}-1 \mathrm{H}-4$ & $U$. pereg. & CAM & 58 & 9.08 & 8.08 \\
\hline $846 \mathrm{~B}-\mathrm{IH}-2$ & C. wuell. & OSU & 128 & 2.78 & 2.78 & 2.78 & 4.50 & -0.40 & $846 \mathrm{D}-1 \mathrm{H}-4$ & C. wuell. & OSU & 58 & 9.08 & 8.08 \\
\hline $846 \mathrm{~B}-1 \mathrm{H}-2$ & C. wuell. & OSU & 137 & 2.87 & 2.87 & 2.87 & 4.33 & -0.41 & $846 \mathrm{D}-1 \mathrm{H}-4$ & $U$. pereg. & CAM & 68 & 9.18 & 8.18 \\
\hline $846 \mathrm{~B}-1 \mathrm{H}-2$ & C. wuell. & OSU & 146 & 2.96 & 2.96 & 2.96 & 4.36 & -0.53 & $846 \mathrm{D}-1 \mathrm{H}-4$ & C. wuell. & $\mathrm{OSU}$ & 68 & 9.18 & 8.18 \\
\hline $846 \mathrm{~B}-1 \mathrm{H}-3$ & C. wuell. & OSU & 9 & 3.09 & 3.09 & 3.09 & 4.35 & -0.43 & $846 \mathrm{D}-1 \mathrm{H}-4$ & $U$. pereg. & CAM & 78 & 9.28 & 8.28 \\
\hline $846 \mathrm{~B}-1 \mathrm{H}-3$ & C. nuell. & OSU & 18 & 3.18 & 3.18 & 3.18 & 4.47 & -0.47 & $846 \mathrm{D}-1 \mathrm{H}-4$ & C. wuell. & OSU & 78 & 9.28 & 8.28 \\
\hline $846 \mathrm{~B}-1 \mathrm{H}-3$ & C. wuell. & OSU & 28 & 3.28 & 3.28 & 3.28 & 4.42 & -0.53 & $846 \mathrm{D}-1 \mathrm{H}-4$ & U. pereg. & CAM & 88 & 9.38 & 8.38 \\
\hline $846 \mathrm{~B}-1 \mathrm{H}-3$ & C. wuell. & OSU & 39 & 3.39 & 3.39 & 3.39 & 4.50 & -0.47 & $846 \mathrm{D}-1 \mathrm{H}-4$ & C. wuell. & OSU & 88 & 9.38 & 8.38 \\
\hline $846 \mathrm{~B}-1 \mathrm{H}-3$ & C. nuell. & OSU & 48 & 3.48 & 3.48 & 3.48 & 4.48 & -0.30 & $846 \mathrm{D}-1 \mathrm{H}-4$ & $U$. pereg. & CAM & 98 & 9.48 & 8.48 \\
\hline $846 \mathrm{~B}-1 \mathrm{H}-3$ & C. nuell. & OSU & 57 & 3.57 & 3.57 & 3.57 & 4.11 & -0.12 & $846 \mathrm{D}-1 \mathrm{H}-4$ & C. wuell. & OSU & 98 & 9.48 & 8.48 \\
\hline $846 \mathrm{~B}-1 \mathrm{H}-3$ & C. wuell. & OSU & 67 & 3.67 & 3.67 & 3.67 & 4.33 & -0.21 & $846 \mathrm{D}-1 \mathrm{H}-4$ & $U$. pereg. & CAM & 108 & 9.58 & 8.58 \\
\hline $846 \mathrm{~B}-1 \mathrm{H}-3$ & C. wuell. & OSU & 78 & 3.78 & 3.78 & 3.78 & 3.98 & 0.01 & $846 \mathrm{D}-1 \mathrm{H}-4$ & C. wuell. & OSU & 108 & 9.58 & 8.58 \\
\hline $846 \mathrm{~B}-1 \mathrm{H}-3$ & C. wuell. & OSU & 88 & 3.88 & 3.88 & 3.88 & 4.04 & -0.08 & $846 \mathrm{D}-1 \mathrm{H}-4$ & $U$. pereg. & CAM & 118 & 9.68 & 8.68 \\
\hline $846 \mathrm{~B}-1 \mathrm{H}-3$ & C. wuell. & OSU & 98 & 3.98 & 3.98 & 3.99 & 3.90 & -0.12 & $846 \mathrm{D}-1 \mathrm{H}-4$ & C. wuell. & OSU & 118 & 9.68 & 8.68 \\
\hline $846 \mathrm{~B}-1 \mathrm{H}-3$ & C. nuell. & OSU & 108 & 4.08 & 4.08 & 4.10 & 4.06 & -0.09 & $846 \mathrm{D}-\mathrm{IH}-4$ & $U$. pereg. & CAM & 128 & 9.78 & 8.78 \\
\hline $846 \mathrm{~B}-1 \mathrm{H}-3$ & C. wuell. & OSU & 118 & 4.18 & 4.18 & 4.20 & 4.09 & -0.13 & $846 \mathrm{D}-\mathrm{IH}-4$ & C. wuell. & OSU & 128 & 9.78 & 8.78 \\
\hline $846 \mathrm{~B}-1 \mathrm{H}-3$ & C. wuell. & OSU & 128 & 4.28 & 4.28 & 4.28 & 4.08 & -0.18 & $846 \mathrm{D}-\mathrm{IH}-4$ & $U$. pereg. & CAM & 138 & 9.88 & 8.88 \\
\hline $846 \mathrm{~B}-\mathrm{IH}-3$ & C. wuell. & OSU & 137 & 4.37 & 4.37 & 4.37 & 4.01 & -0.01 & 846D-IH-4 & C. whell. & $\mathrm{OSU}$ & 138 & 9.88 & 8.88 \\
\hline $846 \mathrm{D}-1 \mathrm{H}-1$ & $U$. pereg. & CAM & 128 & 5.28 & 4.28 & 4.43 & 3.90 & -0.45 & $846 \mathrm{D}-1 \mathrm{H}-4$ & $U$. pereg. & CAM & 148 & 9.98 & 8.98 \\
\hline $846 \mathrm{D}-1 \mathrm{H}-1$ & C. nuell. & OSU & 128 & 5.28 & 4.28 & 4.43 & 3.92 & -0.32 & $846 \mathrm{D}-\mathrm{IH}-4$ & $C$. wuell. & $\mathrm{OSU}$ & 148 & 9.98 & 8.98 \\
\hline $846 \mathrm{~B}-1 \mathrm{H}-3$ & C. wuell. & OSU & 146 & 4.46 & 4.46 & 4.46 & 3.93 & -0.21 & 846 D-1H-5 & $U$. pereg. & CAM & 8 & 10.08 & 9.08 \\
\hline $846 \mathrm{D}-1 \mathrm{H}-1$ & $U$. pereg. & CAM & 138 & 5.38 & 4.38 & 4.55 & 3.76 & -0.23 & $846 \mathrm{D}-1 \mathrm{H}-5$ & C. wwell. & OSU & 8 & 10.08 & 9.08 \\
\hline $846 \mathrm{D}-1 \mathrm{H}-1$ & C. wuell. & OSU & 148 & 5.48 & 4.48 & 4.67 & 4.03 & -0.29 & $846 \mathrm{D}-1 \mathrm{H}-5$ & $U$. pereg. & CAM & 18 & 10.18 & 9.18 \\
\hline $846 \mathrm{D}-1 \mathrm{H}-2$ & $U$. pereg. & CAM & 8 & 5.58 & 4.58 & 4.79 & 3.76 & 0.09 & $846 \mathrm{D}-1 \mathrm{H}-5$ & $C$. whell. & $\mathrm{OSU}$ & 18 & 10.18 & 9.18 \\
\hline $846 \mathrm{D}-1 \mathrm{H}-2$ & C. wuell. & OSU & 8 & 5.58 & 4.58 & 4.79 & 3.88 & -0.25 & 846D-1H-5 & $U$. pereg. & CAM & 28 & 10.28 & 9.28 \\
\hline $846 \mathrm{D}-1 \mathrm{H}-2$ & $U$. pereg. & CAM & 18 & 5.68 & 4.68 & 4.90 & 3.40 & 0.00 & 846D-IH-5 & C. wuell. & OSU & 28 & 10.28 & 9.28 \\
\hline $846 \mathrm{D}-1 \mathrm{H}-2$ & U.pereg. & CAM & 28 & 5.78 & 4.78 & 5.02 & 3.59 & -0.11 & $846 \mathrm{D}-\mathrm{IH}-5$ & $U$. pereg. & CAM & 38 & 10.38 & 9.38 \\
\hline $846 \mathrm{D}-1 \mathrm{H}-2$ & C. wuell. & OSU & 28 & 5.78 & 4.78 & 5.02 & 3.44 & -0.04 & 846D-IH-5 & C. wuell. & OSU & 38 & 10.38 & 9.38 \\
\hline $846 \mathrm{D}-1 \mathrm{H}-2$ & U. pereg. & CAM & 38 & 5.88 & 4.88 & 5.12 & 3.13 & 0.22 & 846D-1H-5 & $U$. pereg. & CAM & 48 & 10.48 & 9.48 \\
\hline $846 \mathrm{D}-1 \mathrm{H}-2$ & $U$. pereg. & CAM & 48 & 5.98 & 4.98 & 5.22 & 2.98 & 0.12 & 846D-IH-5 & C. wuell. & OSU & 48 & 10.48 & 9.48 \\
\hline $846 \mathrm{D}-1 \mathrm{H}-2$ & $U$. pereg. & CAM & 58 & 6.08 & 5.08 & 5.32 & 3.10 & 0.01 & $846 \mathrm{D}-1 \mathrm{H}-5$ & $U$. pereg. & CAM & 58 & 10.58 & 9.58 \\
\hline $846 \mathrm{D}-1 \mathrm{H}-2$ & C. wuell. & OSU & 58 & 6.08 & 5.08 & 5.32 & 3.40 & -0.05 & $846 \mathrm{D}-\mathrm{IH}-5$ & C. wuell. & OSU & 58 & 10.58 & 9.58 \\
\hline $846 \mathrm{D}-1 \mathrm{H}-2$ & $U$. pereg. & CAM & 68 & 6.18 & 5.18 & 5.42 & 4.06 & -0.13 & $846 \mathrm{D}-1 \mathrm{H}-5$ & $U$. pereg. & CAM & 68 & 10.68 & 9.68 \\
\hline $846 \mathrm{D}-1 \mathrm{H}-2$ & C. nuell. & OSU & 68 & 6.18 & 5.18 & 5.42 & 4.04 & -0.28 & $846 \mathrm{D}-1 \mathrm{H}-5$ & C. wuell. & OSU & 68 & 10.68 & 9.68 \\
\hline $846 \mathrm{D}-1 \mathrm{H}-2$ & U. pereg. & CAM & 78 & 6.28 & 5.28 & 5.52 & 4.16 & -0.24 & $846 \mathrm{D}-1 \mathrm{H}-5$ & $U$. pereg. & CAM & 78 & 10.78 & 9.78 \\
\hline $846 \mathrm{D}-1 \mathrm{H}-2$ & C. nuell. & OSU & 78 & 6.28 & 5.28 & 5.52 & 4.21 & -0.30 & $846 \mathrm{D}-1 \mathrm{H}-5$ & C. wuell. & $\mathrm{OSU}$ & 78 & 10.78 & 9.78 \\
\hline $846 \mathrm{D}-1 \mathrm{H}-2$ & C. wuell. & OSU & 88 & 6.38 & 5.38 & 5.62 & 4.71 & -0.33 & 846D-1H-5 & U. pereg. & CAM & 88 & 10.88 & 9.88 \\
\hline $846 \mathrm{D}-1 \mathrm{H}-2$ & C. wuell. & OSU & 98 & 6.48 & 5.48 & 5,72 & 4.88 & -0.40 & $846 \mathrm{D}-\mathrm{IH}-5$ & C. wuell. & OSU & 88 & 10.88 & 9.88 \\
\hline $846 \mathrm{D}-1 \mathrm{H}-2$ & U. pereg. & CAM & 108 & 6.58 & 5.58 & 5.82 & 4.37 & -0.25 & $846 \mathrm{D}-1 \mathrm{H}-5$ & $U$. pereg. & CAM & 98 & 10.98 & 9.98 \\
\hline $846 \mathrm{D}-1 \mathrm{H}-2$ & $U$. pereg. & CAM & 118 & 6.68 & 5.68 & 5.92 & 4.56 & -0.25 & $846 \mathrm{D}-1 \mathrm{H}-5$ & $C$. wuell. & OSU & 98 & 10.98 & 9.98 \\
\hline $846 \mathrm{D}-1 \mathrm{H}-2$ & C. wuell. & OSU & 118 & 6.68 & 5.68 & 5.92 & 4.84 & -0.41 & $846 \mathrm{D}-\mathrm{IH}-5$ & $U$. pereg. & CAM & 108 & 11.08 & 10.08 \\
\hline $846 \mathrm{D}-1 \mathrm{H}-2$ & U. pereg. & CAM & 128 & 6.78 & 5.78 & 6.02 & 4.75 & -0.37 & $846 \mathrm{D}-1 \mathrm{H}-5$ & $C$. whell. & OSU & 108 & 11.08 & 10.08 \\
\hline $846 \mathrm{D}-1 \mathrm{H}-2$ & C. wuell. & OSU & 128 & 6.78 & 5.78 & 6.02 & 4.77 & -0.49 & $846 \mathrm{D}-\mathrm{IH}-5$ & $U$. pereg. & CAM & 118 & 11.18 & 10.18 \\
\hline $846 \mathrm{D}-1 \mathrm{H}-2$ & U. pereg. & CAM & 138 & 6.88 & 5.88 & 6.13 & 4.70 & -0.37 & $846 \mathrm{D}-\mathrm{IH}-5$ & C. wuell. & OSU & 118 & 11.18 & 10.18 \\
\hline $846 \mathrm{D}-1 \mathrm{H}-2$ & C. wuell. & OSU & 138 & 6.88 & 5.88 & 6.13 & 4.68 & -0.53 & $846 \mathrm{D}-1 \mathrm{H}-5$ & $U$. pereg. & CAM & 128 & 11.28 & 10.28 \\
\hline $846 \mathrm{D}-1 \mathrm{H}-2$ & C. wuell. & OSU & 148 & 6.98 & 5.98 & 6.23 & 4.61 & -0.58 & 846D-IH-5 & C. wuell. & OSU & 128 & 11.28 & 10.28 \\
\hline $846 \mathrm{D}-1 \mathrm{H}-3$ & U. pereg. & CAM & 8 & 7.08 & 6.08 & 6.33 & 4.54 & -0.36 & $846 \mathrm{D}-\mathrm{IH}-5$ & $U$. pereg. & CAM & 138 & 11.38 & 10.38 \\
\hline $846 \mathrm{D}-1 \mathrm{H}-3$ & C. wuell. & OSU & 8 & 7.08 & 6.08 & 6.33 & 4.40 & -0.53 & $846 \mathrm{D}-\mathrm{IH}-5$ & C. wuell. & OSU & 138 & 11.38 & 10.38 \\
\hline $846 \mathrm{D}-1 \mathrm{H}-3$ & U. pereg. & CAM & 18 & 7.18 & 6.18 & 6.43 & 4.56 & -0.36 & $846 \mathrm{D}-1 \mathrm{H}-5$ & $U$. pereg. & CAM & 148 & 11.48 & 10.48 \\
\hline $846 \mathrm{D}-1 \mathrm{H}-3$ & C. waell. & OSU & 18 & 7.18 & 6.18 & 6.43 & 4.63 & -0.49 & $846 \mathrm{D}-1 \mathrm{H}-5$ & C. whell. & $\mathrm{OSU}$ & 148 & 11.48 & 10.48 \\
\hline $846 \mathrm{D}-1 \mathrm{H}-3$ & U. pereg. & CAM & 28 & 7.28 & 6.28 & 6.53 & 4.47 & -0.57 & $846 \mathrm{D}-1 \mathrm{H}-6$ & $U$. pereg. & CAM & 8 & 11.58 & 10.58 \\
\hline $846 \mathrm{D}-1 \mathrm{H}-3$ & C. wuell. & OSU & 28 & 7.28 & 6.28 & 6.53 & 4.59 & -0.56 & $846 \mathrm{D}-1 \mathrm{H}-6$ & C. wuell. & OSU & 8 & 11.58 & 10.58 \\
\hline $846 \mathrm{D}-1 \mathrm{H}-3$ & $U$. pereg. & CAM & 38 & 7.38 & 6.38 & 6.63 & 4.65 & -0.36 & $846 \mathrm{~B}-2 \mathrm{H}-3$ & C. wuell. & OSU & 8 & 10.08 & 10.68 \\
\hline $846 \mathrm{D}-\mathrm{IH}-3$ & C. wuell. & OSU & 38 & 7.38 & 6.38 & 6.63 & 4.68 & -0.64 & $846 \mathrm{D}-1 \mathrm{H}-6$ & C. wuell. & OSU & 18 & 11.68 & 10.68 \\
\hline $846 \mathrm{D}-1 \mathrm{H}-3$ & $U$. pereg. & CAM & 48 & 7.48 & 6.48 & 6.72 & 4.71 & -0.58 & $846 \mathrm{~B}-2 \mathrm{H}-3$ & C. wuell. & OSU & 18 & 10.18 & 10.78 \\
\hline $846 \mathrm{D}-1 \mathrm{H}-3$ & C. wuell. & OSU & 48 & 7.48 & 6.48 & 6.72 & 4.64 & -0.61 & $846 \mathrm{D}-1 \mathrm{H}-6$ & C. wuell. & OSU & 28 & 11.78 & 10.78 \\
\hline $846 \mathrm{D}-1 \mathrm{H}-3$ & $U$. pereg. & CAM & 58 & 7.58 & 6.58 & 6.82 & 4.57 & -0.55 & $846 \mathrm{D}-1 \mathrm{H}-6$ & C. wuell. & OSU & 38 & 11.88 & 10.88 \\
\hline $846 \mathrm{D}-1 \mathrm{H}-3$ & C. wuell. & OSU & 58 & 7.58 & 6.58 & 6,82 & 4.75 & -0.46 & $846 \mathrm{~B}-2 \mathrm{H}-3$ & C. wuell. & OSU & 29 & 10.29 & 10.89 \\
\hline
\end{tabular}


APPENDIX A (continued)

\begin{tabular}{|c|c|c|c|c|c|c|c|c|}
\hline $\begin{array}{l}\text { Core, section, } \\
\text { interval }(\mathrm{cm})\end{array}$ & Species & Lab. & $\begin{array}{c}\text { Interval } \\
(\mathrm{cm})\end{array}$ & $\begin{array}{l}\text { Depth } \\
\text { (mbsf) }\end{array}$ & & & $\delta^{18} \mathrm{O}$ & $\delta^{13} \mathrm{C}$ \\
\hline 846D-1H-6 & C. whell. & OSU & 48 & 11.98 & 10.98 & 10.94 & 4.24 & -0.65 \\
\hline $846 \mathrm{~B}-2 \mathrm{H}-3$ & C. wuell. & OSU & 38 & 10.38 & 10.98 & 11.03 & 3.95 & -0.23 \\
\hline $846 \mathrm{D}-1 \mathrm{H}-6$ & C. wuell. & OSU & 58 & 12.08 & 11.08 & 11.04 & 4.14 & -0.48 \\
\hline $846 \mathrm{~B}-2 \mathrm{H}-3$ & C. wuell. & OSU & 48 & 10.48 & 11.08 & 11.12 & 4.01 & -0.44 \\
\hline $846 \mathrm{~B}-2 \mathrm{H}-3$ & C. wuell. & OSU & 58 & 10.58 & 11.18 & 11.20 & 3.81 & -0.28 \\
\hline $846 \mathrm{D}-1 \mathrm{H}-6$ & C. wuell. & OSU & 78 & 12.28 & 11.28 & 11.23 & 3.87 & -0.10 \\
\hline $846 \mathrm{~B}-2 \mathrm{H}-3$ & C. wuell. & OSU & 68 & 10.68 & 11.28 & 11.28 & 3.84 & -0.48 \\
\hline 846D-1H-6 & C. wuell. & OSU & 88 & 12.38 & 11.38 & 11.32 & 3.94 & -0.39 \\
\hline $846 \mathrm{~B}-2 \mathrm{H}-3$ & C. wuell. & OSU & 77 & 10.77 & 11.37 & 11.36 & 3.95 & -0.46 \\
\hline $846 \mathrm{D}-1 \mathrm{H}-6$ & C. wuell. & OSU & 98 & 12.48 & 11.48 & 11.41 & 3.85 & -0.37 \\
\hline $846 \mathrm{~B}-2 \mathrm{H}-3$ & C. wuell. & OSU & 88 & 10.88 & 11.48 & 11.49 & 3.92 & -0.55 \\
\hline $846 \mathrm{D}-1 \mathrm{H}-6$ & C. wuell. & OSU & 108 & 12.58 & 11.58 & 11.50 & 3.87 & -0.51 \\
\hline $846 \mathrm{~B}-2 \mathrm{H}-3$ & C. wuell. & OSU & 96 & 10.96 & 11.56 & 11.59 & 4.07 & -0.53 \\
\hline 846D-1H-6 & C. wuell. & OSU & 118 & 12.68 & 11.68 & 11.59 & 4.17 & -0.55 \\
\hline $846 \mathrm{~B}-1 \mathrm{H}-3$ & C. wuell. & OSU & 108 & 11.08 & 11.68 & 11.71 & 4.03 & -0.38 \\
\hline 846B-1H-3 & C. wuell. & OSU & 118 & 11.18 & 11.78 & 11.80 & 3.96 & -0.47 \\
\hline $846 \mathrm{~B}-1 \mathrm{H}-3$ & C. wuell. & OSU & 128 & 11.28 & 11.88 & 11.87 & 4.14 & -0.48 \\
\hline $846 \mathrm{~B}-1 \mathrm{H}-3$ & C. wuell. & OSU & 137 & 11.37 & 11.97 & 11.94 & 3.90 & -0.36 \\
\hline $846 \mathrm{~B}-1 \mathrm{H}-3$ & C. wuell. & OSU & 147 & 11.47 & 12.07 & 12.03 & 3.87 & -0.41 \\
\hline $846 \mathrm{~B}-2 \mathrm{H}-4$ & C. whell. & OSU & 3 & 11.53 & 12.13 & 12.09 & 3.83 & -0.61 \\
\hline $846 \mathrm{~B}-2 \mathrm{H}-4$ & C. wuell. & OSU & 13 & 11.63 & 12.23 & 12.20 & 3.85 & -0.48 \\
\hline $846 \mathrm{~B}-2 \mathrm{H}-4$ & C. wuell. & OSU & 23 & 11.73 & 12.33 & 12.33 & 3.59 & -0.46 \\
\hline $846 \mathrm{C}-2 \mathrm{H}-1$ & C. wuell. & OSU & 88 & 12.88 & 12.41 & 12.38 & 3.80 & -0.34 \\
\hline $846 \mathrm{C}-2 \mathrm{H}-1$ & C. wuell. & OSU & 98 & 12.98 & 12.51 & 12.43 & 3.82 & -0.33 \\
\hline 846B-2H-4 & C. wuell. & OSU & 31 & 11.81 & 12.41 & 12.43 & 3.63 & -0.44 \\
\hline $846 \mathrm{C}-2 \mathrm{H}-1$ & C. wuell. & OSU & 108 & 13.08 & 12.61 & 12.51 & 4.05 & -0.50 \\
\hline 846B-2H-4 & C. wuell. & OSU & 41 & 11.91 & 12.51 & 12.53 & 3.74 & -0.43 \\
\hline $846 \mathrm{C}-2 \mathrm{H}-1$ & C. wuell. & OSU & 118 & 13.18 & 12.71 & 12.62 & 3.25 & -0.22 \\
\hline $846 \mathrm{~B}-2 \mathrm{H}-4$ & C. wuell. & OSU & 54 & 12.04 & 12.64 & 12.64 & 3.25 & -0.28 \\
\hline $846 \mathrm{~B}-2 \mathrm{H}-4$ & C. wuell. & OSU & 62 & 12.12 & 12.72 & 12.71 & 3.36 & -0.27 \\
\hline $846 \mathrm{C}-2 \mathrm{H}-1$ & C. wuell. & OSU & 128 & 13.28 & 12.81 & 12.79 & 3.47 & -0.30 \\
\hline $846 \mathrm{~B}-2 \mathrm{H}-4$ & C. wuell. & OSU & 73 & 12.23 & 12.83 & 12.81 & 3.74 & -0.45 \\
\hline $846 \mathrm{~B}-2 \mathrm{H}-4$ & C. wuell. & OSU & 87 & 12.37 & 12.97 & 12.97 & 3.73 & -0.28 \\
\hline $846 \mathrm{C}-2 \mathrm{H}-1$ & C. wuell. & OSU & 138 & 13.38 & 12.91 & 13.05 & 3.72 & -0.42 \\
\hline $846 \mathrm{~B}-2 \mathrm{H}-4$ & C. wuell. & OSU & 95 & 12.45 & 13.05 & 13.06 & 4.13 & -0.53 \\
\hline $846 \mathrm{~B}-2 \mathrm{H}-4$ & C. wuell. & OSU & 106 & 12.56 & 13.16 & 13.18 & 4.64 & -0.67 \\
\hline $846 \mathrm{C}-2 \mathrm{H}-1$ & C. wuell. & OSU & 148 & 13.48 & 13.01 & 13.20 & 4.28 & -0.51 \\
\hline $846 \mathrm{C}-2 \mathrm{H}-2$ & C. wuell. & OSU & 8 & 13.58 & 13.11 & 13.27 & 4.63 & -0.63 \\
\hline $846 \mathrm{~B}-2 \mathrm{H}-4$ & C. wuell. & OSU & 117 & 12.67 & 13.27 & 13.29 & 4.43 & -0.51 \\
\hline $846 \mathrm{C}-2 \mathrm{H}-2$ & C. wuell. & OSU & 18 & 13.68 & 13.21 & 13.33 & 4.57 & -0.65 \\
\hline 846B-2H-4 & $C$, wuell. & OSU & 126 & 12.76 & 13.36 & 13.37 & 4.75 & -0.53 \\
\hline $846 \mathrm{C}-2 \mathrm{H}-2$ & C. wuell. & OSU & 28 & 13.78 & 13.31 & 13.39 & 4.61 & -0.52 \\
\hline $846 \mathrm{C}-2 \mathrm{H}-2$ & C. wuell. & OSU & 38 & 13.88 & 13.41 & 13.46 & 4.70 & -0.49 \\
\hline $846 \mathrm{~B}-2 \mathrm{H}-4$ & C. wuell. & OSU & 136 & 12.86 & 13.46 & 13.46 & 4.51 & -0.57 \\
\hline $846 \mathrm{~B}-2 \mathrm{H}-4$ & C. wuell. & OSU & 144 & 12.94 & 13.54 & 13.54 & 4.71 & -0.58 \\
\hline $846 \mathrm{C}-2 \mathrm{H}-2$ & C. wuell. & OSU & 48 & 13.98 & 13.51 & 13.56 & 4.41 & -0.36 \\
\hline $846 \mathrm{C}-2 \mathrm{H}-2$ & C. wuell. & OSU & 58 & 14.08 & 13.61 & 13.67 & 4.55 & -0.58 \\
\hline $846 \mathrm{C}-2 \mathrm{H}-2$ & C. whell. & OSU & 68 & 14.18 & 13.71 & 13.77 & 4.55 & -0.67 \\
\hline $846 \mathrm{C}-2 \mathrm{H}-2$ & C. wuell. & OSU & 78 & 14.28 & 13.81 & 13.85 & 4.63 & -0.69 \\
\hline $846 \mathrm{C}-2 \mathrm{H}-2$ & C. wuell. & OSU & 88 & 14.38 & 13.91 & 13.91 & 4.53 & -0.72 \\
\hline $846 \mathrm{C}-2 \mathrm{H}-2$ & C. wuell. & OSU & 98 & 14.48 & 14.01 & 13.96 & 4.59 & -0.60 \\
\hline $846 \mathrm{C}-2 \mathrm{H}-2$ & C. wuell. & OSU & 108 & 14.58 & 14.11 & 14.02 & 4.52 & -0.46 \\
\hline $846 \mathrm{C}-2 \mathrm{H}-2$ & C. wuell. & OSU & 118 & 14.68 & 14.21 & 14.08 & 4.93 & -0.56 \\
\hline $846 \mathrm{C}-2 \mathrm{H}-2$ & C. wuell. & OSU & 128 & 14.78 & 14.31 & 14.18 & 4.21 & -0.44 \\
\hline $846 \mathrm{C}-2 \mathrm{H}-2$ & C. wuell. & OSU & 138 & 14.88 & 14.41 & 14.32 & 4.08 & -0.25 \\
\hline $846 \mathrm{C}-2 \mathrm{H}-2$ & C. wuell. & OSU & 148 & 14.98 & 14.51 & 14.46 & 4.55 & -0.54 \\
\hline $846 \mathrm{C}-2 \mathrm{H}-3$ & C. wuell. & OSU & 8 & 15.08 & 14.61 & 14.59 & 4.13 & -0.34 \\
\hline $846 \mathrm{C}-2 \mathrm{H}-3$ & C. wuell. & OSU & 18 & 15.18 & 14.71 & 14.69 & 4.13 & -0.19 \\
\hline $846 \mathrm{C}-2 \mathrm{H}-3$ & C. wuell. & OSU & 28 & 15.28 & 14.81 & 14.77 & 4.11 & -0.13 \\
\hline $846 \mathrm{C}-2 \mathrm{H}-3$ & C. wuell. & OSU & 38 & 15.38 & 14.91 & 14.86 & 4.01 & -0.26 \\
\hline $846 \mathrm{C}-2 \mathrm{H}-3$ & C. wuell. & OSU & 48 & 15.48 & 15.01 & 14.95 & 4.09 & -0.22 \\
\hline $846 \mathrm{C}-2 \mathrm{H}-3$ & C. wuell. & OSU & 58 & 15.58 & 15.11 & 15.06 & 3.92 & -0.27 \\
\hline $846 \mathrm{C}-2 \mathrm{H}-3$ & C. wuell. & OSU & 68 & 15.68 & 15.21 & 15.18 & 3.72 & 0.08 \\
\hline $846 \mathrm{C}-2 \mathrm{H}-3$ & C. wuell. & OSU & 78 & 15.78 & 15.31 & 15.33 & 3.80 & 0.04 \\
\hline $846 \mathrm{D}-2 \mathrm{H}-1$ & $U$.pereg. & CAM & 8 & 13.58 & 15.48 & 15.42 & 3.49 & -0.22 \\
\hline $846 \mathrm{D}-2 \mathrm{H}-1$ & C. wuell. & OSU & 8 & 13.58 & 15.48 & 15.42 & 3.53 & -0.11 \\
\hline $846 \mathrm{C}-2 \mathrm{H}-3$ & C. wuell. & OSU & 88 & 15.88 & 15.41 & 15.47 & 3.52 & 0.19 \\
\hline $846 \mathrm{D}-2 \mathrm{H}-1$ & $U$.pereg. & CAM & 18 & 13.68 & 15.58 & 15.52 & 3.26 & 0.11 \\
\hline $846 \mathrm{D}-2 \mathrm{H}-1$ & C. wuell. & OSU & 18 & 13.68 & 15.58 & 15.52 & 3.14 & 0.12 \\
\hline $846 \mathrm{C}-2 \mathrm{H}-3$ & C. wuell. & OSU & 98 & 15.98 & 15.51 & 15.60 & 3.21 & 0.03 \\
\hline $846 \mathrm{D}-2 \mathrm{H}-1$ & $U$.pereg. & CAM & 28 & 13.78 & 15.68 & 15.63 & 3.29 & -0.11 \\
\hline $846 \mathrm{D}-2 \mathrm{H}-1$ & C. wuell. & OSU & 28 & 13.78 & 15.68 & 15.63 & 3.23 & 0.11 \\
\hline $846 \mathrm{D}-2 \mathrm{H}-1$ & $U$.pereg. & CAM & 38 & 13.88 & 15.78 & 15.74 & 2.93 & 0.01 \\
\hline $846 \mathrm{D}-2 \mathrm{H}-1$ & C. wuell. & OSU & 38 & 13.88 & 15.78 & 15.74 & 3.21 & 0.06 \\
\hline $846 \mathrm{D}-2 \mathrm{H}-1$ & $U$.pereg. & CAM & 48 & 13.98 & 15.88 & 15.85 & 3.37 & 0.00 \\
\hline $846 \mathrm{D}-2 \mathrm{H}-1$ & C. wuell. & OSU & 48 & 13.98 & 15.88 & 15.85 & 3.25 & -0.07 \\
\hline $846 \mathrm{D}-2 \mathrm{H}-1$ & $U$.pereg. & CAM & 58 & 14.08 & 15.98 & 15.95 & 3.35 & 0.01 \\
\hline $846 \mathrm{D}-2 \mathrm{H}-1$ & C. wuell. & OSU & 58 & 14.08 & 15.98 & 15.95 & 3.33 & -0.04 \\
\hline $846 \mathrm{D}-2 \mathrm{H}-1$ & $U$.pereg. & CAM & 68 & 14.18 & 16.08 & 16.06 & 3.48 & 0.01 \\
\hline $846 \mathrm{D}-2 \mathrm{H}-1$ & $U$.pereg. & CAM & 78 & 14.28 & 16.18 & 16.17 & 3.68 & -0.32 \\
\hline $846 \mathrm{D}-2 \mathrm{H}-1$ & C. wuell. & OSU & 78 & 14.28 & 16.18 & 16.17 & 3.75 & -0.17 \\
\hline $846 \mathrm{D}-2 \mathrm{H}-1$ & $U$.pereg. & CAM & 88 & 14.38 & 16.28 & 16.27 & 4.34 & -0.34 \\
\hline $846 \mathrm{D}-2 \mathrm{H}-2$ & $U$.pereg. & CAM & 8 & 14.51 & 16.41 & 16.41 & 4.53 & -0.46 \\
\hline $846 \mathrm{D}-2 \mathrm{H}-2$ & $U$. pereg. & CAM & 18 & 14.61 & 16.51 & 16.51 & 4.55 & -0.46 \\
\hline $846 \mathrm{D}-2 \mathrm{H}-2$ & C. wuell. & OSU & 18 & 14.61 & 16.51 & 16.51 & 5.07 & -0.49 \\
\hline 846D-2H-2 & $U$.pereg. & CAM & 28 & 14.71 & 16.61 & 16.61 & 4.96 & -0.36 \\
\hline
\end{tabular}

\begin{tabular}{|c|c|c|c|c|c|c|c|}
\hline $\begin{array}{l}\text { Core, section, } \\
\text { interval }(\mathrm{cm})\end{array}$ & Species & Lab. & $\begin{array}{c}\text { Interval } \\
(\mathrm{cm})\end{array}$ & $\begin{array}{l}\text { Depth } \\
\text { (mbsf }\end{array}$ & $\begin{array}{l}\text { h Depth Depth } \\
\text { f) (mcd) (rmcd) }\end{array}$ & $\delta^{18} \mathrm{O}$ & $\delta^{13} \mathrm{C}$ \\
\hline $846 \mathrm{D}-2 \mathrm{H}-2$ & C. wuell. & OSU & 28 & 14.71 & $16.61 \quad 16.61$ & 4.89 & -0.63 \\
\hline $846 \mathrm{D}-2 \mathrm{H}-2$ & $U$.pereg. & CAM & 38 & 14.81 & $16.71 \quad 16.71$ & 4.92 & -0.36 \\
\hline $846 \mathrm{D}-2 \mathrm{H}-2$ & $U$.pereg. & CAM & 48 & 14.91 & $16.81 \quad 16.82$ & 4.84 & -0.36 \\
\hline $846 \mathrm{D}-2 \mathrm{H}-2$ & C. wuell. & OSU & 48 & 14.91 & $16.81 \quad 16.82$ & 5.17 & -0.37 \\
\hline $846 \mathrm{D}-2 \mathrm{H}-2$ & $U$.pereg. & CAM & 58 & 15.01 & $16.91 \quad 16.92$ & 4.91 & -0.26 \\
\hline $846 \mathrm{D}-2 \mathrm{H}-2$ & C. wuell. & OSU & 58 & 15.01 & $\begin{array}{lll}16.91 & 16.92\end{array}$ & 4.93 & -0.55 \\
\hline $846 \mathrm{D}-2 \mathrm{H}-2$ & $U$.pereg. & CAM & 68 & 15.11 & $17.01 \quad 17.02$ & 4.51 & -0.24 \\
\hline $846 \mathrm{D}-2 \mathrm{H}-2$ & $U$.pereg. & CAM & 78 & 15.21 & $17.11 \quad 17.11$ & 4.67 & -0.35 \\
\hline $846 \mathrm{D}-2 \mathrm{H}-2$ & C. wuell. & OSU & 78 & 15.21 & $17.11 \quad 17.11$ & 4.73 & -0.44 \\
\hline $846 \mathrm{D}-2 \mathrm{H}-2$ & $U$.pereg. & CAM & 98 & 15.41 & $17.31 \quad 17.31$ & 4.42 & -0.35 \\
\hline $846 \mathrm{D}-2 \mathrm{H}-2$ & C. wuell. & OSU & 98 & 15.41 & $\begin{array}{lll}17.31 & 17.31\end{array}$ & 4.50 & -0.44 \\
\hline $846 \mathrm{D}-2 \mathrm{H}-2$ & $U$. pereg. & CAM & 108 & 15.51 & $17.41 \quad 17.41$ & 4.43 & -0.45 \\
\hline $846 \mathrm{D}-2 \mathrm{H}-2$ & C. wuell. & OSU & 108 & 15.51 & $\begin{array}{lll}17.41 & 17.41\end{array}$ & 4.49 & -0.45 \\
\hline $846 \mathrm{D}-2 \mathrm{H}-2$ & $U$.pereg. & CAM & 118 & 15.61 & $17.51 \quad 17.51$ & 4.56 & -0.57 \\
\hline $846 \mathrm{D}-2 \mathrm{H}-2$ & C. wuell. & OSU & 118 & 15.61 & $17.51 \quad 17.51$ & 4.51 & -0.60 \\
\hline $846 \mathrm{D}-2 \mathrm{H}-2$ & C. wuell. & OSU & 128 & 15.71 & $17.61 \quad 17.61$ & 4.44 & -0.49 \\
\hline $846 \mathrm{D}-2 \mathrm{H}-2$ & $U$.pereg. & CAM & 128 & 15.71 & $17.61 \quad 17.61$ & 4.46 & -0.45 \\
\hline $846 \mathrm{D}-2 \mathrm{H}-2$ & C. wuell. & OSU & 128 & 15.71 & $17.61 \quad 17.61$ & 4.48 & -0.43 \\
\hline $846 \mathrm{D}-2 \mathrm{H}-2$ & $U$.pereg. & CAM & 138 & 15.81 & $17.71 \quad 17.71$ & 4.44 & -0.35 \\
\hline $846 \mathrm{D}-2 \mathrm{H}-3$ & $U$.pereg. & CAM & 8 & 16.01 & 17.9117 .90 & 4.43 & -0.35 \\
\hline $846 \mathrm{D}-2 \mathrm{H}-3$ & C. wuell. & OSU & 11 & 16.04 & $17.94 \quad 17.93$ & 4.52 & -0.44 \\
\hline $846 \mathrm{D}-2 \mathrm{H}-3$ & $U$.pereg. & CAM & 18 & 16.11 & $18.01 \quad 18.00$ & 4.55 & -0.46 \\
\hline $846 \mathrm{D}-2 \mathrm{H}-3$ & C. wuell. & OSU & 21 & 16.14 & $18.04 \quad 18.03$ & 4.45 & -0.44 \\
\hline $846 \mathrm{D}-2 \mathrm{H}-3$ & C. wuell. & OSU & 28 & 16.21 & $18.11 \quad 18.10$ & 4.64 & -0.39 \\
\hline $846 \mathrm{D}-2 \mathrm{H}-3$ & C. wuell. & OSU & 38 & 16.31 & $18.21 \quad 18.20$ & 4.71 & -0.42 \\
\hline $846 \mathrm{D}-2 \mathrm{H}-3$ & C. wuell. & OSU & 48 & 16.41 & $18.31 \quad 18.30$ & 4.59 & -0.45 \\
\hline $846 \mathrm{D}-2 \mathrm{H}-3$ & C. wuell. & OSU & 58 & 16.51 & $18.41 \quad 18.41$ & 4.61 & -0.39 \\
\hline $846 \mathrm{D}-2 \mathrm{H}-3$ & C. wuell. & OSU & 68 & 16.61 & $\begin{array}{lll}18.51 & 18.51\end{array}$ & 4.64 & -0.37 \\
\hline $846 \mathrm{D}-2 \mathrm{H}-3$ & C. wuell. & OSU & 78 & 16.71 & $18.61 \quad 18.61$ & 4.43 & -0.22 \\
\hline $846 \mathrm{D}-2 \mathrm{H}-3$ & C. wuell. & OSU & 88 & 16.81 & $\begin{array}{lll}18.71 & 18.71\end{array}$ & 4.26 & -0.08 \\
\hline $846 \mathrm{D}-2 \mathrm{H}-3$ & C. wuell. & OSU & 98 & 16.91 & $\begin{array}{lll}18.81 & 18.81\end{array}$ & 4.04 & -0.12 \\
\hline $846 \mathrm{D}-2 \mathrm{H}-3$ & C. wuell. & OSU & 108 & 17.01 & $18.91 \quad 18.91$ & 4.08 & 0.10 \\
\hline $846 \mathrm{D}-2 \mathrm{H}-4$ & C. wuell. & OSU & 8 & 17.15 & $19.05 \quad 19.05$ & 3.93 & 0.16 \\
\hline $846 \mathrm{D}-2 \mathrm{H}-4$ & C. wuell. & OSU & 18 & 17.25 & 19.1519 .15 & 3.82 & 0.25 \\
\hline $846 \mathrm{D}-2 \mathrm{H}-4$ & C. wuell. & OSU & 28 & 17.35 & $\begin{array}{lll}19.25 & 19.25\end{array}$ & 3.82 & 0.23 \\
\hline $846 \mathrm{D}-2 \mathrm{H}-4$ & C. wuell. & OSU & 38 & 17.45 & $\begin{array}{lll}19.35 & 19.35\end{array}$ & 4.35 & -0.24 \\
\hline $846 \mathrm{D}-2 \mathrm{H}-4$ & C. wuell. & OSU & 48 & 17.55 & $19.45 \quad 19.45$ & 3.87 & 0.11 \\
\hline $846 \mathrm{D}-2 \mathrm{H}-4$ & C. wuell. & OSU & 58 & 17.65 & $19.55 \quad 19.55$ & 3.94 & 0.13 \\
\hline $846 \mathrm{D}-2 \mathrm{H}-4$ & C. wuell. & OSU & 68 & 17.75 & 19.6519 .65 & 3.68 & -0.01 \\
\hline $846 \mathrm{D}-2 \mathrm{H}-4$ & C. wuell. & OSU & 78 & 17.85 & $19.75 \quad 19.75$ & 4.12 & 0.19 \\
\hline $846 \mathrm{D}-2 \mathrm{H}-4$ & C. wuell. & OSU & 88 & 17.95 & $19.85 \quad 19.85$ & 4.21 & 0.16 \\
\hline $846 \mathrm{D}-2 \mathrm{H}-4$ & C. wuell. & OSU & 98 & 18.05 & $19.95 \quad 19.95$ & 4.26 & 0.22 \\
\hline $846 \mathrm{D}-2 \mathrm{H}-4$ & C. wuell. & OSU & 108 & 18.15 & 20.0520 .05 & 4.39 & 0.29 \\
\hline $846 \mathrm{D}-2 \mathrm{H}-4$ & C. wuell. & OSU & 118 & 18.25 & $20.15 \quad 20.15$ & 4.38 & 0.25 \\
\hline $846 \mathrm{D}-2 \mathrm{H}-4$ & C. wuell. & OSU & 128 & 18.35 & $20.25 \quad 20.25$ & 4.26 & 0.20 \\
\hline $846 \mathrm{~B}-3 \mathrm{H}-2$ & C. wuell. & OSU & 8 & 18.08 & $20.13 \quad 20.27$ & 4.07 & 0.13 \\
\hline $846 \mathrm{D}-2 \mathrm{H}-4$ & C. wuell. & OSU & 138 & 18.45 & $20.35 \quad 20.35$ & 4.20 & 0.16 \\
\hline $846 \mathrm{~B}-3 \mathrm{H}-2$ & C. wuell. & OSU & 18 & 18.18 & 20.2320 .35 & 4.04 & -0.02 \\
\hline $846 \mathrm{~B}-3 \mathrm{H}-2$ & C. wuell. & OSU & 27 & 18.27 & $20.32 \quad 20.43$ & 4.08 & -0.07 \\
\hline $846 \mathrm{~B}-3 \mathrm{H}-2$ & C. wuell. & OSU & 37 & 18.37 & 20.4220 .51 & 4.10 & -0.13 \\
\hline $846 \mathrm{~B}-3 \mathrm{H}-2$ & C. wuell. & OSU & 48 & 18.48 & 20.5320 .61 & 4.26 & -0.33 \\
\hline $846 \mathrm{~B}-3 \mathrm{H}-2$ & C. wuell. & OSU & 58 & 18.58 & 20.6320 .70 & 4.38 & -0.34 \\
\hline $846 \mathrm{~B}-3 \mathrm{H}-2$ & C. wuell. & OSU & 69 & 18.69 & 20.7420 .81 & 4.37 & -0.28 \\
\hline $846 \mathrm{~B}-3 \mathrm{H}-2$ & C. wuell. & OSU & 78 & 18.78 & 20.8320 .91 & 4.34 & -0.31 \\
\hline $846 \mathrm{~B}-3 \mathrm{H}-2$ & C. wuell. & OSU & 88 & 18.88 & 20.9321 .06 & 4.48 & -0.34 \\
\hline $846 \mathrm{~B}-3 \mathrm{H}-2$ & C. wuell. & OSU & 98 & 18.98 & 21.0321 .21 & 4.20 & -0.30 \\
\hline $846 \mathrm{~B}-3 \mathrm{H}-2$ & C. wuell. & OSU & 109 & 19.09 & $21.14 \quad 21.37$ & 4.33 & -0.50 \\
\hline $846 \mathrm{~B}-3 \mathrm{H}-2$ & C. wuell. & OSU & 117 & 19.17 & 21.2221 .46 & 4.21 & -0.36 \\
\hline $846 \mathrm{~B}-3 \mathrm{H}-2$ & C. wuell. & OS & 128 & 19.28 & $21.33 \quad 21.56$ & 4.12 & -0.39 \\
\hline $846 \mathrm{~B}-3 \mathrm{H}-2$ & C. wuell. & OSU & 137 & 19.37 & $21.42 \quad 21.62$ & 3.91 & -0.34 \\
\hline $846 \mathrm{~B}-3 \mathrm{H}-2$ & C. wuell. & OSU & 147 & 19.47 & 21.5221 .68 & 3.88 & -0.22 \\
\hline $846 \mathrm{~B}-3 \mathrm{H}-3$ & C. wuell. & OSU & 8 & 19.58 & 21.6321 .76 & 3.94 & -0.23 \\
\hline $846 \mathrm{~B}-3 \mathrm{H}-3$ & C. wuell. & OSU & 18 & 19.68 & $21.73 \quad 21.83$ & 3.74 & -0.15 \\
\hline $846 \mathrm{~B}-3 \mathrm{H}-3$ & C. wuell. & OSI & 27 & 19.77 & $21.82 \quad 21.90$ & 3.72 & 0.05 \\
\hline $846 \mathrm{~B}-3 \mathrm{H}-3$ & C. wuell. & OSU & 36 & 19.86 & 21.9122 .01 & 3.58 & -0.02 \\
\hline $846 \mathrm{~B}-3 \mathrm{H}-3$ & C. wuell. & OSU & 48 & 19.98 & $\begin{array}{lll}22.03 & 22.15\end{array}$ & 3.87 & -0.20 \\
\hline $846 \mathrm{~B}-3 \mathrm{H}-3$ & C. wuell. & OSU & 58 & 20.08 & $22.13 \quad 22.28$ & 4.35 & -0.30 \\
\hline $846 \mathrm{~B}-3 \mathrm{H}-3$ & C. wuell. & & 69 & 20.19 & 22.2422 .41 & 4.40 & -0.38 \\
\hline $846 \mathrm{~B}-3 \mathrm{H}-3$ & C. wuell. & OSU & 77 & 20.27 & $22.32 \quad 22.50$ & 4.21 & -0.17 \\
\hline $846 \mathrm{~B}-3 \mathrm{H}-3$ & C. wuell. & & 88 & 20.38 & $22.43 \quad 22.60$ & 4.04 & -0.21 \\
\hline $846 \mathrm{~B}-3 \mathrm{H}-3$ & C. wuell. & OSU & 99 & 20.49 & $22.54 \quad 22.70$ & 4.01 & -0.12 \\
\hline $846 \mathrm{~B}-3 \mathrm{H}-3$ & C. wuell. & OSU & 108 & 20.58 & 22.6322 .78 & 4.08 & -0.06 \\
\hline $846 \mathrm{~B}-3 \mathrm{H}-3$ & C. wuell. & OSU & 118 & 20.68 & $22.73 \quad 22.87$ & 4.01 & -0.02 \\
\hline $846 \mathrm{~B}-3 \mathrm{H}-3$ & C. wuell. & OSU & 128 & 20.78 & $22.83 \quad 22.95$ & 3.79 & 0.02 \\
\hline $846 \mathrm{~B}-3 \mathrm{H}-3$ & C. wuell. & & 137 & 20.87 & $22.92 \quad 23.01$ & 4.02 & -0.21 \\
\hline $846 \mathrm{~B}-3 \mathrm{H}-3$ & C. wuell. & OSU & 146 & 20.96 & 23.0123 .08 & 4.18 & -0.24 \\
\hline $846 \mathrm{~B}-3 \mathrm{H}-4$ & C. wuell. & OSU & 3 & 21.03 & $23.08 \quad 23.14$ & 4.39 & -0.27 \\
\hline $846 \mathrm{~B}-3 \mathrm{H}-4$ & C. wuell. & OSU & 13 & 21.13 & $23.18 \quad 23.22$ & 4.88 & -0.45 \\
\hline $846 \mathrm{~B}-3 \mathrm{H}-4$ & C. wuell. & OSU & 23 & 21.23 & $23.28 \quad 23.30$ & 4.78 & -0.39 \\
\hline & C. wuell. & OSU & 34 & 21.34 & 23.3923 .39 & 5.10 & -0.58 \\
\hline $846 \mathrm{~B}-3 \mathrm{H}-4$ & C. wuell. & OSU & 44 & 21.44 & 23.4923 .48 & 4.79 & -0.54 \\
\hline $846 \mathrm{~B}-3 \mathrm{H}-4$ & C. wuell. & OSU & 53 & 21.53 & $23.58 \quad 23.56$ & 4.93 & -0.62 \\
\hline $846 \mathrm{~B}-3 \mathrm{H}-4$ & C. wuell. & OSU & 62 & 21.62 & 23.6723 .65 & 4.99 & -0.59 \\
\hline $846 \mathrm{~B}-3 \mathrm{H}-4$ & C. wuell. & OSU & 72 & 21.72 & 23.7723 .76 & 4.86 & -0.60 \\
\hline $846 \mathrm{~B}-3 \mathrm{H}-4$ & C. wuell. & & 79 & 21.79 & $23.84 \quad 23.83$ & 4.76 & -0.64 \\
\hline $846 \mathrm{~B}-3 \mathrm{H}-4$ & C. wuell. & OSU & 92 & 21.92 & $23.97 \quad 23.97$ & 4.81 & -0.59 \\
\hline
\end{tabular}




\begin{tabular}{|c|c|c|c|c|c|c|c|}
\hline $\begin{array}{l}\text { Core, section, } \\
\text { interval }(\mathrm{cm})\end{array}$ & Species & Lab. & $\begin{array}{l}\text { Interval } \\
(\mathrm{cm})\end{array}$ & $\begin{array}{l}\text { Depth } \\
\text { (mbsf) }\end{array}$ & $\begin{array}{l}\text { Depth Depth } \\
\text { (mcd) (rmcd) }\end{array}$ & $\delta^{18} \mathrm{O}$ & $\delta^{13} \mathrm{C}$ \\
\hline $846 \mathrm{~B}-3 \mathrm{H}-4$ & C. wuell. & OSU & 103 & 22.032 & $24.08 \quad 24.08$ & 4.67 & -0.62 \\
\hline $846 \mathrm{~B}-3 \mathrm{H}-4$ & C. wuell. & OSU & 116 & 22.16 & $24.21 \quad 24.21$ & 4.73 & -0.60 \\
\hline $846 \mathrm{~B}-3 \mathrm{H}-4$ & C. wuell. & OSU & 125 & 22.25 & 24.3024 .30 & 4.73 & -0.60 \\
\hline $846 \mathrm{~B}-3 \mathrm{H}-4$ & C. wuell. & OSU & 136 & 22.36 & $24.41 \quad 24.40$ & 4.74 & -0.68 \\
\hline $846 \mathrm{~B}-3 \mathrm{H}-4$ & C. wuell. & OSU & 144 & 22.44 & 24.4924 .48 & 4.72 & -0.56 \\
\hline $846 \mathrm{~B}-3 \mathrm{H}-5$ & C. wuell. & OSU & 7 & 22.572 & $24.62 \quad 24.60$ & 4.59 & -0.74 \\
\hline $846 \mathrm{~B}-3 \mathrm{H}-5$ & C. wuell. & OSU & 18 & 22.68 & $24.73 \quad 24.71$ & 4.55 & -0.65 \\
\hline $846 \mathrm{C}-3 \mathrm{H}-1$ & C. wuell. & OSU & 18 & 21.68 & $24.68 \quad 24.76$ & 4.61 & -0.61 \\
\hline $846 \mathrm{~B}-3 \mathrm{H}-1$ & C. wuell. & OSU & 28 & $21.78 ?$ & $24.78 \quad 24.83$ & 4.54 & -0.64 \\
\hline $846 \mathrm{~B}-3 \mathrm{H}-1$ & C. wuell. & OSU & 38 & 21.88 & $24.88 \quad 24.88$ & 4.51 & -0.72 \\
\hline $846 \mathrm{~B}-3 \mathrm{H}-1$ & C. wuell. & OSU & 48 & $21.98 ?$ & $24.98 \quad 24.94$ & 4.47 & -0.65 \\
\hline $846 \mathrm{~B}-3 \mathrm{H}-1$ & C. wuell. & OSU & 58 & 22.08 & $25.08 \quad 25.01$ & 4.33 & -0.56 \\
\hline $846 \mathrm{D}-3 \mathrm{H}-1$ & C. wuell. & OSU & 48 & $23.48 ?$ & $25.18 \quad 25.07$ & 4.55 & -0.65 \\
\hline $846 \mathrm{~B}-3 \mathrm{H}-1$ & C. wuell. & OSU & 68 & 22.18 & $25.18 \quad 25.09$ & 4.32 & -0.51 \\
\hline $846 \mathrm{D}-3 \mathrm{H}-1$ & C. wuell. & OSU & 58 & 23.58 & $25.28 \quad 25.20$ & 4.55 & -0.58 \\
\hline $846 \mathrm{D}-3 \mathrm{H}-\mathrm{I}$ & C. wuell. & OSU & 68 & $23.68 ?$ & $25.38 \quad 25.30$ & 4,42 & -0.58 \\
\hline $846 \mathrm{D}-3 \mathrm{H}-1$ & C. wuell. & OSU & 78 & 23.78 & $25.48 \quad 25.36$ & 4.38 & -0.57 \\
\hline $846 \mathrm{D}-3 \mathrm{H}-1$ & C. wuell. & OSU & 88 & 23.88 & $25.58 \quad 25.40$ & 4.56 & -0.70 \\
\hline $846 \mathrm{D}-3 \mathrm{H}-1$ & C. wuell. & OSU & 98 & 23.982 & $25.68 \quad 25.43$ & 4.42 & -0.63 \\
\hline $846 \mathrm{D}-3 \mathrm{H}-1$ & C. wuell. & OSU & 108 & 24.082 & $25.78 \quad 25.46$ & 4.49 & -0.78 \\
\hline $846 \mathrm{D}-3 \mathrm{H}-1$ & C. wuell. & OSU & 118 & 24.182 & $25.88 \quad 25.49$ & 4.44 & -0.60 \\
\hline $846 \mathrm{D}-3 \mathrm{H}-1$ & C. wuell. & osu & 128 & 24.28 & $25.98 \quad 25.53$ & 4.43 & -0.46 \\
\hline $846 \mathrm{D}-3 \mathrm{H}-1$ & C. wuell. & OSU & 138 & 24.382 & $26.08 \quad 25.58$ & 4.03 & -0.28 \\
\hline $846 \mathrm{D}-3 \mathrm{H}-2$ & C. wuell. & OSU & 8 & 24.582 & $26.28 \quad 26.00$ & 4.48 & -0.51 \\
\hline $846 \mathrm{D}-3 \mathrm{H}-2$ & C. wuell. & OSU & 18 & 24.682 & $26.38 \quad 26.24$ & 4.63 & -0.62 \\
\hline $846 \mathrm{D}-3 \mathrm{H}-2$ & C. wuell. & OSU & 28 & 24.78 & $26.48 \quad 26.33$ & 4.59 & -0.53 \\
\hline $846 \mathrm{D}-3 \mathrm{H}-2$ & C. wuell. & OSU & 38 & 24.882 & $26.58 \quad 26.39$ & 4.64 & -0.48 \\
\hline $846 \mathrm{D}-3 \mathrm{H}-2$ & C. wuell. & OSU & 48 & 24.98 & 26.6826 .44 & 4.43 & -0.39 \\
\hline $846 \mathrm{D}-3 \mathrm{H}-2$ & C. whell. & OSU & 58 & 25.08 & $26.78 \quad 26.49$ & 4.23 & -0.41 \\
\hline $846 \mathrm{D}-3 \mathrm{H}-2$ & C. wuell. & OSU & 68 & 25.182 & $26.88 \quad 26.57$ & 4.18 & -0.13 \\
\hline $846 \mathrm{D}-3 \mathrm{H}-2$ & C. wuell. & OSU & 78 & 25.28 & $26.98 \quad 26.71$ & 4.27 & -0.24 \\
\hline $846 \mathrm{D}-3 \mathrm{H}-2$ & C. wuell. & OSU & 88 & 25.382 & $27.08 \quad 27.07$ & 4.39 & -0.42 \\
\hline $846 \mathrm{D}-3 \mathrm{H}-2$ & C. wuell. & OSU & 98 & 25.482 & $27.18 \quad 27.28$ & 4.30 & -0.58 \\
\hline $846 \mathrm{D}-3 \mathrm{H}-2$ & C. wuell. & OSU & 108 & 25.58 & $27.28 \quad 27.37$ & 4.41 & -0.60 \\
\hline $846 \mathrm{D}-3 \mathrm{H}-2$ & C. wuell. & OSU & 118 & 25.682 & $27.38 \quad 27.44$ & 4.34 & -0.37 \\
\hline $846 \mathrm{D}-3 \mathrm{H}-2$ & C. wuell. & OSU & 128 & 25.782 & $27.48 \quad 27.49$ & 4.52 & -0.64 \\
\hline $846 \mathrm{D}-3 \mathrm{H}-2$ & C. wuell. & OSU & 138 & 25.88 & $27.58 \quad 27.56$ & 4.65 & -0.70 \\
\hline $846 \mathrm{D}-3 \mathrm{H}-3$ & C. wuell. & OSU & 8 & 26.082 & $27.78 \quad 27.73$ & 4.47 & -0.54 \\
\hline $846 \mathrm{D}-3 \mathrm{H}-3$ & C. wuell. & OSU & 18 & 26.182 & $27.88 \quad 27.85$ & 4.47 & -0.55 \\
\hline $846 \mathrm{D}-3 \mathrm{H}-3$ & C. wuell. & OSU & 28 & 26.282 & $27.98 \quad 27.98$ & 4.31 & -0.40 \\
\hline $846 \mathrm{D}-3 \mathrm{H}-3$ & C. wuell. & OSU & 38 & 26.382 & $28.08 \quad 28.09$ & 4.11 & -0.42 \\
\hline $846 \mathrm{D}-3 \mathrm{H}-3$ & C. wuell. & OSU & 48 & 26.482 & $28.18 \quad 28.19$ & 4.16 & -0.55 \\
\hline $846 \mathrm{D}-3 \mathrm{H}-3$ & C. wuell. & OSU & 58 & 26.582 & $28.28 \quad 28.29$ & 4.03 & -0.29 \\
\hline $846 \mathrm{D}-3 \mathrm{H}-3$ & C. wuell. & OSU & 68 & 26.68 & $28.38 \quad 28.39$ & 3.94 & -0.35 \\
\hline $846 \mathrm{D}-3 \mathrm{H}-3$ & C. wuell. & OSU & 78 & 26.78 & $28.48 \quad 28.48$ & 3.98 & -0.47 \\
\hline $846 \mathrm{D}-3 \mathrm{H}-3$ & C. wuell. & OSU & 88 & 26.88 & $28.58 \quad 28.58$ & 3.73 & -0.20 \\
\hline $846 \mathrm{D}-3 \mathrm{H}-3$ & C. wuell. & OSU & 98 & 26.98 & 28.6828 .68 & 3.68 & -0.24 \\
\hline $846 \mathrm{D}-3 \mathrm{H}-3$ & C. wuell. & OSU & 108 & 27.082 & $28.78 \quad 28.78$ & 3.66 & -0.44 \\
\hline $846 \mathrm{D}-3 \mathrm{H}-3$ & C. wuell. & OSU & 118 & 27.182 & $28.88 \quad 28.89$ & 3.77 & -0.38 \\
\hline $846 \mathrm{D}-3 \mathrm{H}-3$ & C. wuell. & OSU & 128 & 27.28 & $28.98 \quad 28.99$ & 4.03 & -0.42 \\
\hline $846 \mathrm{D}-3 \mathrm{H}-3$ & C. wuell. & OSU & 138 & 27.38 & 29.0829 .08 & 4.20 & -0.58 \\
\hline $846 \mathrm{D}-3 \mathrm{H}-3$ & C. wuell. & OSU & 138 & 27.38 & 29.0829 .08 & 4.07 & -0.37 \\
\hline $846 \mathrm{D}-3 \mathrm{H}-4$ & C. wuell. & OSU & 8 & 27.58 & $29.28 \quad 29.27$ & 3.97 & -0.36 \\
\hline $846 \mathrm{D}-3 \mathrm{H}-4$ & C. wuell. & osu & 18 & 27.682 & $29.38 \quad 29.37$ & 4.68 & -0.64 \\
\hline $846 \mathrm{D}-3 \mathrm{H}-4$ & C. wuell. & OSU & 28 & 27.782 & $29.48 \quad 29.48$ & 4.63 & -0.62 \\
\hline $846 \mathrm{D}-3 \mathrm{H}-4$ & C. wuell. & OSU & 38 & 27.882 & $29.58 \quad 29.59$ & 4.60 & -0.67 \\
\hline $846 \mathrm{D}-3 \mathrm{H}-4$ & C. wuell. & OSU & 48 & 27.982 & 29.6829 .69 & 4.41 & -0.53 \\
\hline $846 \mathrm{D}-3 \mathrm{H}-4$ & C. wuell. & OSU & 58 & 28.08 & $29.78 \quad 29.78$ & 4.44 & -0.49 \\
\hline $846 \mathrm{D}-3 \mathrm{H}-4$ & C. wuell. & OSU & 68 & 28.182 & $29.88 \quad 29.87$ & 4.08 & -0.62 \\
\hline $846 \mathrm{D}-3 \mathrm{H}-4$ & C. wuell. & OSU & 78 & 28.282 & $29.98 \quad 29.97$ & 4.38 & -0.49 \\
\hline $846 \mathrm{D}-3 \mathrm{H}-4$ & C. wuell. & OSU & 88 & 28.383 & $30.08 \quad 30.08$ & 4.30 & -0.39 \\
\hline $846 \mathrm{D}-3 \mathrm{H}-4$ & C. wuell. & OSU & 98 & 28.48 & 30.1830 .18 & 4.17 & -0.30 \\
\hline $846 \mathrm{D}-3 \mathrm{H}-4$ & C. wuell. & OSU & 108 & 28.58 & $30.28 \quad 30.28$ & 4.01 & -0.22 \\
\hline $846 \mathrm{D}-3 \mathrm{H}-4$ & C. wuell. & OSU & 118 & $28.68 \quad 3$ & $30.38 \quad 30.38$ & 3.86 & -0.31 \\
\hline $846 \mathrm{D}-3 \mathrm{H}-4$ & C. wuell. & OSU & 128 & 28.783 & $30.48 \quad 30.47$ & 4.12 & -0.40 \\
\hline $846 \mathrm{D}-3 \mathrm{H}-5$ & C. wuell. & OSU & 8 & 29.083 & $30.78 \quad 30.78$ & 4.05 & -0.40 \\
\hline $846 \mathrm{D}-3 \mathrm{H}-5$ & C. wuell. & OSU & 18 & $29.18 \quad 3$ & $30.88 \quad 30.88$ & 4.03 & -0.67 \\
\hline $846 \mathrm{D}-3 \mathrm{H}-5$ & C. wuell. & OSU & 28 & $29.28 \quad 3$ & $30.98 \quad 30.98$ & 4.06 & -0.50 \\
\hline $846 \mathrm{D}-3 \mathrm{H}-5$ & C. wuell. & OSU & 38 & $29.38 \quad 3$ & $31.08 \quad 31.08$ & 3.99 & -0.43 \\
\hline 846D-3H-5 & C. wuell. & OSU & 48 & $29.48 \quad 3$ & $31.18 \quad 31.18$ & 3.77 & -0.28 \\
\hline $846 \mathrm{D}-3 \mathrm{H}-5$ & C. wuell. & OSU & 58 & 29.583 & $31.28 \quad 31.28$ & 3.67 & -0.42 \\
\hline $846 \mathrm{D}-3 \mathrm{H}-5$ & C. wuell. & OSU & 68 & $29.68 \quad 3$ & $31.38 \quad 31.38$ & 3.72 & -0.39 \\
\hline $846 \mathrm{D}-3 \mathrm{H}-5$ & C. wuell. & OSU & 78 & $29.78 \quad 3$ & $31.48 \quad 31.49$ & 3.85 & -0.30 \\
\hline $846 \mathrm{D}-3 \mathrm{H}-5$ & C. wuell. & OSU & 88 & $29.88 \quad 3$ & $31.58 \quad 31.59$ & 4.04 & -0.45 \\
\hline $846 \mathrm{D}-3 \mathrm{H}-5$ & C. wuell. & OSU & 98 & 29.983 & 31.6831 .68 & 3.59 & -0.40 \\
\hline $846 \mathrm{D}-3 \mathrm{H}-5$ & C. wuell. & OSU & 108 & $30.08 \quad 3$ & $31.78 \quad 31.78$ & 3.62 & -0.47 \\
\hline $846 \mathrm{D}-3 \mathrm{H}-5$ & C. wuell. & OSU & 118 & $30.18 \quad 3$ & $31.88 \quad 31.89$ & 3.94 & -0.43 \\
\hline $846 \mathrm{D}-3 \mathrm{H}-5$ & C. wuell. & OSU & 128 & $30.28 \quad 3$ & $31.98 \quad 32.02$ & 4.46 & -0.74 \\
\hline $846 \mathrm{D}-3 \mathrm{H}-5$ & C. wuell. & OSU & 138 & $30.38 \quad 3$ & 32.0832 .16 & 4.44 & -0.83 \\
\hline $846 \mathrm{D}-3 \mathrm{H}-5$ & C. wuell. & OSU & 148 & $30.48 \quad 3$ & $32.18 \quad 32.32$ & 4.79 & -0.82 \\
\hline 846D-3H-6 & C. wuell. & OSU & 8 & $30.58 \quad 3$ & $32.28 \quad 32.46$ & 4.69 & -0.82 \\
\hline 846D-3H-6 & C. wuell. & OSU & 18 & $30.68 \quad 3$ & $\begin{array}{lll}32.38 & 32.57\end{array}$ & 4.78 & -0.85 \\
\hline $846 \mathrm{D}-3 \mathrm{H}-6$ & C. wuell. & OSU & 28 & $30.78 \quad 3$ & $32.48 \quad 32.66$ & 4.72 & -0.80 \\
\hline $846 \mathrm{D}-3 \mathrm{H}-6$ & C. wuell. & OSU & 38 & $30.88 \quad 3$ & $32.58 \quad 32.74$ & 4.56 & -0.81 \\
\hline $846 \mathrm{D}-3 \mathrm{H}-6$ & C. wuell. & OSU & 48 & $30.98 \quad 3$ & $32.68 \quad 32.82$ & 4.46 & -0.85 \\
\hline $846 \mathrm{D}-3 \mathrm{H}-6$ & C. wuell. & OSU & 58 & 31.083 & 32.7832 .91 & 4.54 & -0.89 \\
\hline
\end{tabular}

\begin{tabular}{|c|c|c|c|c|c|c|c|c|}
\hline $\begin{array}{l}\text { Core, section, } \\
\text { interval }(\mathrm{cm})\end{array}$ & Species & Lab. & $\begin{array}{l}\text { Interval } \\
(\mathrm{cm})\end{array}$ & $\begin{array}{l}\text { Depth } \\
\text { (mbsf) }\end{array}$ & $\begin{array}{l}\text { Depth } \\
\text { (mcd) }\end{array}$ & $\begin{array}{l}\text { h Depth } \\
\text { l) (rmcd) }\end{array}$ & $\delta^{1 x} \mathrm{O}$ & $\delta^{13} \mathrm{C}$ \\
\hline $846 \mathrm{D}-3 \mathrm{H}-6$ & C. wuell. & OSU & 68 & 31.18 & 32.88 & 33.02 & 4.51 & -0.79 \\
\hline $846 \mathrm{D}-3 \mathrm{H}-6$ & C. wuell. & OSU & 78 & 31.28 & 32.98 & 33.15 & 4.45 & -0.79 \\
\hline $846 \mathrm{D}-3 \mathrm{H}-6$ & C. wuell. & OSU & 88 & 31.38 & 33.08 & 33.26 & 4.46 & -0.69 \\
\hline $846 \mathrm{D}-3 \mathrm{H}-6$ & C. wuell. & OSU & 98 & 31.48 & 33.18 & 33.33 & 4.05 & -0.51 \\
\hline $846 \mathrm{D}-3 \mathrm{H}-6$ & C. wuell. & OSU & 108 & 31.58 & 33.28 & 33.39 & 4.17 & -0.57 \\
\hline $846 \mathrm{D}-3 \mathrm{H}-6$ & C. wuell. & OSU & 118 & 31.68 & 33.38 & 33.43 & 4.22 & -0.65 \\
\hline $846 \mathrm{D}-3 \mathrm{H}-6$ & C. wuell. & OSU & 128 & 31.78 & 33.48 & 33.48 & 4.15 & -0.66 \\
\hline $846 \mathrm{D}-3 \mathrm{H}-6$ & C. whell. & OSU & 138 & 31.88 & 33.58 & 33.53 & 4.09 & -0.54 \\
\hline $846 \mathrm{D}-3 \mathrm{H}-6$ & C. wuell. & OSU & 148 & 31.98 & 33.68 & 33.60 & 4.15 & -0.79 \\
\hline $846 \mathrm{D}-3 \mathrm{H}-7$ & C. wuell. & OSU & 8 & 32.08 & 33.78 & 33.70 & 4.15 & -0.76 \\
\hline $846 \mathrm{D}-3 \mathrm{H}-7$ & C. wuell. & OSU & 18 & 32.18 & 33.88 & 33.91 & 4.26 & -0.98 \\
\hline $846 \mathrm{D}-3 \mathrm{H}-7$ & C. wuell. & OSU & 28 & 32.28 & 33.98 & 34.14 & 4.40 & -1.06 \\
\hline $846 \mathrm{D}-3 \mathrm{H}-7$ & C. wuell. & OSU & 38 & 32.38 & 34.08 & 34.27 & 4.53 & -0.96 \\
\hline $846 \mathrm{D}-3 \mathrm{H}-7$ & C. wuell. & OSU & 48 & 32.48 & 34.18 & 34.35 & 4.46 & -0.91 \\
\hline $846 \mathrm{C}-4 \mathrm{H}-1$ & C. wuell. & OSU & 28 & 31.28 & 34.48 & 34.40 & 4.47 & -0.94 \\
\hline $846 \mathrm{D}-3 \mathrm{H}-7$ & C. wuell. & OSU & 58 & 32.58 & 34.28 & 34.43 & 4.24 & -0.80 \\
\hline $846 C-4-1$ & C. wuell. & OSU & 38 & 31.38 & 34.58 & 34.54 & 4.23 & -0.75 \\
\hline $846 C-4-1$ & C. wuell. & OSU & 48 & 31.48 & 34.68 & 34.67 & 4.03 & -0.57 \\
\hline $846 C-4-1$ & C. wuell. & OSU & 58 & 31.58 & 34.78 & 34.77 & 3.95 & -0.51 \\
\hline $846 C-4-1$ & $C$, whell. & OSU & 68 & 31.68 & 34.88 & 34.88 & 3.51 & -0.42 \\
\hline $846 C-4-1$ & C. wuell. & OSU & 78 & 31.78 & 34.98 & 34.98 & 3.76 & -0.25 \\
\hline $846 C-4-1$ & C. wuell. & OSU & 88 & 31.88 & 35.08 & 35.09 & 3.63 & -0.26 \\
\hline $846 C-4-1$ & C. wuell. & OSU & 98 & 31.98 & 35.18 & 35.19 & 3.53 & -0.20 \\
\hline $846 C-4-1$ & C. wuell. & OSU & 108 & 32.08 & 35.28 & 35.29 & 3.39 & -0.29 \\
\hline $846 C-4-1$ & C. wuell. & OSU & 118 & 32.18 & 35.38 & 35.39 & 3.34 & -0.40 \\
\hline $846 C-4-1$ & C. wuell. & OSU & 128 & 32.28 & 35.48 & 35.48 & 4.08 & -0.53 \\
\hline $846 C-4-1$ & C. wuell. & OSU & 138 & 32.38 & 35.58 & 35.58 & 3.81 & -0.43 \\
\hline $846 \mathrm{C}-4 \mathrm{H}-2$ & C. wuell. & OSU & 8 & 32.58 & 35.78 & 35.78 & 4.21 & -0.29 \\
\hline $846 \mathrm{C}-4 \mathrm{H}-2$ & C. wuell. & OSU & 18 & 32.68 & 35.88 & 35.88 & 3.98 & -0.26 \\
\hline $846 \mathrm{C}-4 \mathrm{H}-2$ & C. wuell. & OSU & 28 & 32.78 & 35.98 & 35.98 & 3.89 & -0.23 \\
\hline $846 \mathrm{C}-4 \mathrm{H}-2$ & C. wuell. & OSU & 38 & 32.88 & 36.08 & 36.08 & 3.83 & -0.29 \\
\hline $846 \mathrm{C}-4 \mathrm{H}-2$ & C. wuell. & OSU & 48 & 32.98 & 36.18 & 36.18 & 3.70 & -0.16 \\
\hline $846 \mathrm{C}-4 \mathrm{H}-2$ & C. wuell. & OSU & 58 & 33.08 & 36.28 & 36.28 & 3.94 & -0.32 \\
\hline $846 \mathrm{C}-4 \mathrm{H}-2$ & C. wuell. & OSU & 68 & 33.18 & 36.38 & 36.38 & 4.00 & -0.42 \\
\hline $846 \mathrm{C}-4 \mathrm{H}-2$ & C. wuell. & OSU & 78 & 33.28 & 36.48 & 36.48 & 3.89 & -0.22 \\
\hline $846 \mathrm{D}-4 \mathrm{H}-1$ & C. wuell. & OSU & 28 & 32.78 & 36.38 & 36.49 & 3.72 & -0.36 \\
\hline $846 \mathrm{D}-4 \mathrm{H}-1$ & C. wuell. & OSU & 38 & 32.88 & 36.48 & 36.57 & 3.96 & -0.37 \\
\hline $846 \mathrm{D}-4 \mathrm{H}-1$ & C. wuell. & OSU & 48 & 32.98 & 36.58 & 36.67 & 4.08 & -0.43 \\
\hline $846 \mathrm{C}-4 \mathrm{H}-2$ & C. wuell. & OSU & 98 & 33.48 & 36.68 & 36.68 & 4.09 & -0.32 \\
\hline $846 \mathrm{D}-4 \mathrm{H}-1$ & C. wuell. & OSU & 58 & 33.08 & 36.68 & 36.76 & 4.06 & -0.40 \\
\hline $846 \mathrm{C}-4 \mathrm{H}-2$ & C. wuell. & OSU & 108 & 33.58 & 36.78 . & 36.78 & 4.22 & -0.30 \\
\hline $846 \mathrm{D}-4 \mathrm{H}-1$ & C. wuell. & OSU & 68 & 33.18 & 36.78 & 36.87 & 4.24 & -0.64 \\
\hline $846 \mathrm{C}-4 \mathrm{H}-2$ & C. wuell. & OSU & 118 & 33.68 & 36.88 & 36.88 & 4.22 & -0.62 \\
\hline $846 \mathrm{D}-4 \mathrm{H}-1$ & C. wuell. & OSU & 78 & 33.28 & 36.88 & 36.96 & 3.78 & -0.14 \\
\hline $846 \mathrm{C}-4 \mathrm{H}-2$ & C. wuell. & OSU & 128 & 33.78 & 36.98 & 36.98 & 4.06 & -0.32 \\
\hline $846 \mathrm{D}-4 \mathrm{H}-1$ & C. wuell. & OSU & 88 & 33.38 & 36.98 & 37.06 & 3.64 & -0.20 \\
\hline $846 \mathrm{C}-4 \mathrm{H}-2$ & C. wuell. & OSU & 138 & 33.88 & 37.08 & 37.08 & 3.90 & -0.17 \\
\hline $846 \mathrm{D}-4 \mathrm{H}-1$ & C. wuell. & OSU & 98 & 33.48 & 37.08 ? & 37.16 & 3.83 & -0.09 \\
\hline $846 \mathrm{D}-4 \mathrm{H}-1$ & C. wuell. & OSU & 98 & 33.48 & 37.08 & 37.16 & 3.88 & -0.31 \\
\hline $846 \mathrm{C}-4 \mathrm{H}-2$ & C. wuell. & OSU & 148 & 33.98 & 37.18 & 37.18 & 4.35 & -0.35 \\
\hline $846 \mathrm{D}-4 \mathrm{H}-1$ & C. wuell. & OSU & 108 & 33.58 & 37.18 & 37.26 & 4.18 & -0.39 \\
\hline $846 \mathrm{D}-4 \mathrm{H}-1$ & C. wuell. & OSU & 118 & 33.68 & 37.28 & 37.36 & 4.41 & -0.37 \\
\hline $846 \mathrm{D}-4 \mathrm{H}-1$ & C. wuell. & OSU & 128 & 33.78 & 37.38 & 37.46 & 4.47 & -0.39 \\
\hline $846 \mathrm{D}-4 \mathrm{H}-1$ & C. wuell. & OSU & 138 & 33.88 & 37.48 & 37.55 & 4.38 & -0.46 \\
\hline $846 \mathrm{D}-4 \mathrm{H}-1$ & C. wuell. & OSU & 148 & 33.98 & 37.58 & 37.65 & 4.32 & -0.52 \\
\hline $846 \mathrm{D}-4 \mathrm{H}-2$ & C. wuell. & OSU & 8 & 34.08 & 37.68 & 37.75 & 4.21 & -0.52 \\
\hline $846 \mathrm{D}-4 \mathrm{H}-2$ & C. wuell. & OSU & 18 & 34.18 & 37.78 & 37.85 & 4.28 & -0.58 \\
\hline $846 \mathrm{D}-4 \mathrm{H}-2$ & $C$, wuell. & OSU & 28 & 34.28 & 37.88 ? & 37.94 & 4.23 & -0.61 \\
\hline $846 \mathrm{D}-4 \mathrm{H}-2$ & C. wuell. & OSU & 38 & 34.38 & 37.98 & 38.04 & 4.18 & -0.59 \\
\hline $846 \mathrm{D}-4 \mathrm{H}-2$ & C. wuell. & OSU & 48 & 34.48 & 38.08 & 38.14 & 4.21 & -0.64 \\
\hline $846 \mathrm{D}-4 \mathrm{H}-2$ & C. wuell. & OSU & 58 & 34.58 & 38.18 & 38.24 & 4.20 & -0.63 \\
\hline $846 \mathrm{D}-4 \mathrm{H}-2$ & C. wuell. & OSU & 68 & 34.68 & 38.28 & 38.34 & 4.15 & -0.58 \\
\hline $846 \mathrm{D}-4 \mathrm{H}-2$ & C. wuell. & OSU & 78 & 34.78 & 38.38 & 38.44 & 4.04 & -0.37 \\
\hline $846 \mathrm{D}-4 \mathrm{H}-2$ & C. wuell. & OSU & 88 & 34.88 & 38.48 & 38.54 & 3.79 & -0.27 \\
\hline $846 \mathrm{D}-4 \mathrm{H}-2$ & C. wuell. & OSU & 98 & 34.98 & 38.58 & 38.64 & 3.67 & -0.03 \\
\hline $846 \mathrm{D}-4 \mathrm{H}-2$ & C. wuell. & OSU & 108 & 35.08 & 38.68 & 38.73 & 3.34 & -0.19 \\
\hline $846 \mathrm{D}-4 \mathrm{H}-2$ & C. wuell. & OSU & 118 & 35.18 & 38.78 & 38.83 & 2.92 & -0.29 \\
\hline $846 \mathrm{D}-4 \mathrm{H}-2$ & C. wuell. & OSU & 128 & 35.28 & 38.88 & 38.93 & 3.93 & -0.41 \\
\hline $846 \mathrm{D}-4 \mathrm{H}-2$ & C. wuell. & OSU & 138 & 35.38 & 38.98 & 39.03 & 4.03 & -0.70 \\
\hline $846 \mathrm{D}-4 \mathrm{H}-2$ & C. wuell. & OSU & 148 & 35.48 & 39.08 & 39.14 & 3.36 & -0.16 \\
\hline $846 \mathrm{D}-4 \mathrm{H}-3$ & C. wuell. & OSU & 8 & 35.58 & 39.18 & 39.23 & 3.61 & -0.24 \\
\hline $846 \mathrm{D}-4 \mathrm{H}-3$ & C. wuell. & OSU & 18 & 35.68 & 39.28 & 39.33 & 3.58 & -0.17 \\
\hline $846 \mathrm{D}-4 \mathrm{H}-3$ & C. wuell. & OSU & 28 & 35.78 & 39.38 & 39.44 & 3.84 & -0.12 \\
\hline $846 \mathrm{D}-4 \mathrm{H}-3$ & C. wuell. & OSU & 38 & 35.88 & 39.48 & 39.54 & 3.63 & -0.22 \\
\hline $846 \mathrm{D}-4 \mathrm{H}-3$ & C. wuell. & OSU & 48 & 35.98 & 39.58 & 39.64 & 3.76 & 0.02 \\
\hline $846 \mathrm{D}-4 \mathrm{H}-3$ & C. wuell. & OSU & 48 & 35.98 & 39.58 & 39.65 & 3.46 & 0.12 \\
\hline $846 \mathrm{D}-4 \mathrm{H}-3$ & C. wuell. & OSU & 58 & 36.08 & 39.68 ? & 39.74 & 4.28 & -0.18 \\
\hline $846 \mathrm{D}-4 \mathrm{H}-3$ & C. wuell. & OSU & 58 & 36.08 & 39.68 ? & 39.75 & 4.00 & -0.08 \\
\hline $846 \mathrm{D}-4 \mathrm{H}-3$ & C. wuell. & OSU & 68 & 36.18 & 39.78 ? & 39.85 & 4.24 & -0.40 \\
\hline $846 \mathrm{D}-4 \mathrm{H}-3$ & C. whell. & OSU & 78 & 36.28 & 39.88 & 39.96 & 4.24 & -0.39 \\
\hline $846 \mathrm{D}-4 \mathrm{H}-3$ & C. wuell. & OSU & 88 & 36.38 & 39.98 & 40.07 & 4.28 & -0.43 \\
\hline $846 \mathrm{D}-4 \mathrm{H}-3$ & C. wuell. & OSU & 98 & 36.48 & 40.08 & 40.19 & 4.12 & -0.49 \\
\hline $846 \mathrm{D}-4 \mathrm{H}-3$ & C. wuell. & OSU & 108 & 36.58 & 40.18 & 40.31 & 4.30 & -0.50 \\
\hline $846 \mathrm{D}-4 \mathrm{H}-3$ & C. wuell. & OSU & 118 & 36.68 & 40.28 & 40.41 & 4.33 & -0.54 \\
\hline $846 \mathrm{D}-4 \mathrm{H}-3$ & C. wuell. & OSU & 128 & 36.78 & 40.38 & 40.50 & 4.08 & -0.36 \\
\hline & & & & 36.88 & 40,48 & 40.58 & 3.90 & 016 \\
\hline
\end{tabular}




\begin{tabular}{|c|c|c|c|c|c|c|c|c|c|c|c|}
\hline $\begin{array}{l}\text { Core, section, } \\
\text { interval (cm) }\end{array}$ & Species & Lab. & $\begin{array}{l}\text { Interval } \\
(\mathrm{cm})\end{array}$ & $\begin{array}{l}\text { Depth } \\
\text { (mbsf) }\end{array}$ & $\begin{array}{l}\text { Depth } \\
\text { (med) }\end{array}$ & $\begin{array}{l}\text { h Depth } \\
\text { l) (rmcd) }\end{array}$ & $\delta^{18} \mathrm{O}$ & $8^{13} \mathrm{C}$ & $\begin{array}{l}\text { Core, section, } \\
\text { interval }(\mathrm{cm})\end{array}$ & Species & Lab. \\
\hline $846 \mathrm{D}-4 \mathrm{H}-4$ & C. wuell. & OSU & 8 & 37.08 & 40.68 & 40.72 & 4.00 & -0.14 & $846 \mathrm{D}-5 \mathrm{H}-1$ & C. wuell. & OSU \\
\hline $846 \mathrm{D}-4 \mathrm{H}-4$ & C. wuell. & OSU & 18 & 37.18 & 40.78 & 40.79 & 3.83 & -0.29 & $846 \mathrm{D}-5 \mathrm{H}-1$ & C. wuell. & OSU \\
\hline $846 \mathrm{D}-4 \mathrm{H}-4$ & C. wuell. & OSU & 28 & 37.28 & 40.88 & 40.86 & 3.89 & -0.33 & $846 \mathrm{D}-5 \mathrm{H}-1$ & C. wuell. & OSU \\
\hline $846 \mathrm{D}-4 \mathrm{H}-4$ & C. wuell. & OSU & 38 & 37.38 & 40.98 & 40.93 & 3.92 & -0.26 & $846 \mathrm{D}-5 \mathrm{H}-1$ & C. wuell. & OSU \\
\hline $846 \mathrm{D}-4 \mathrm{H}-4$ & C. wuell. & OSU & 48 & 37.48 & 41.08 & 41.02 & 4.20 & -0.49 & $846 \mathrm{D}-5 \mathrm{H}-\mathrm{I}$ & C. wuell. & OSU \\
\hline $846 \mathrm{D}-4 \mathrm{H}-4$ & C. wuell. & OSU & 58 & 37.58 & 41.18 & 41.12 & 4.23 & -0.56 & $846 \mathrm{D}-5 \mathrm{H}-1$ & C, wuell. & OSU \\
\hline $846 \mathrm{D}-4 \mathrm{H}-4$ & C. wuell. & OSU & 68 & 37.68 & 41.28 & 41.22 & 4.31 & -0.61 & $846 \mathrm{D}-5 \mathrm{H}-2$ & C. wuell. & OSU \\
\hline $846 \mathrm{D}-4 \mathrm{H}-4$ & C. wuell. & OSU & 78 & 37.78 & 41.38 & 41.35 & 4.34 & -0.66 & $846 \mathrm{D}-5 \mathrm{H}-2$ & C. wuell. & OSU \\
\hline $846 \mathrm{D}-4 \mathrm{H}-4$ & C. wuell. & OSU & 88 & 37.88 & 41.48 & 41.47 & 4.48 & -0.71 & $846 \mathrm{D}-5 \mathrm{H}-2$ & C. wuell. & OSU \\
\hline $846 \mathrm{D}-4 \mathrm{H}-4$ & C. wuell. & OSU & 98 & 37.98 & 41.58 & 41.60 & 4.36 & -0.58 & $846 \mathrm{D}-5 \mathrm{H}-2$ & C. wuell. & OSU \\
\hline $846 \mathrm{D}-4 \mathrm{H}-4$ & C. wuell. & OSU & 108 & 38.08 & 41.68 & 41.72 & 4.42 & -0.68 & $846 \mathrm{D}-5 \mathrm{H}-2$ & C. wuell. & OSU \\
\hline $846 \mathrm{D}-4 \mathrm{H}-4$ & C. wuell. & OSU & 118 & 38.18 & 41.78 & 41.82 & 4.34 & -0.65 & $846 \mathrm{D}-5 \mathrm{H}-2$ & C. wuell. & OSU \\
\hline $846 \mathrm{D}-4 \mathrm{H}-4$ & C. wuell. & OSU & 128 & 38.28 & 41.88 & 41.92 & 4.21 & -0.61 & $846 \mathrm{D}-5 \mathrm{H}-2$ & C. wuell. & OSU \\
\hline $846 \mathrm{D}-4 \mathrm{H}-4$ & C. wuell. & OSU & 138 & 38.38 & 41.98 & 42.01 & 4.36 & -0.79 & $846 \mathrm{D}-5 \mathrm{H}-2$ & C. wuell. & OSU \\
\hline $846 \mathrm{D}-4 \mathrm{H}-4$ & C. wuell. & OSU & 148 & 38.48 & 42.08 & 42.11 & 4.05 & -0.52 & $846 \mathrm{D}-5 \mathrm{H}-2$ & C, wuell. & OSU \\
\hline $846 \mathrm{D}-4 \mathrm{H}-5$ & C. wuell. & OSU & 8 & 38.58 & 42.18 & 42.19 & 3.95 & -0.38 & $846 \mathrm{D}-5 \mathrm{H}-2$ & C. wuell. & osu \\
\hline $846 \mathrm{D}-4 \mathrm{H}-5$ & C. wuell. & OSU & 18 & 38.68 & 42.28 & 42.28 & 3.92 & -0.39 & $846 \mathrm{D}-5 \mathrm{H}-2$ & C. wuell. & $\mathrm{OSU}$ \\
\hline $846 \mathrm{D}-4 \mathrm{H}-5$ & C. wuell. & OSU & 28 & 38.78 & 42.38 & 42.38 & 3.88 & -0.38 & $846 \mathrm{D}-5 \mathrm{H}-2$ & C. wuell. & OSU \\
\hline $846 \mathrm{D}-4 \mathrm{H}-5$ & C. wuell. & OSU & 38 & 38.88 & 42.48 & 42.48 & 3.89 & -0.29 & $846 \mathrm{D}-5 \mathrm{H}-2$ & C. wuell. & OSU \\
\hline $846 \mathrm{D}-4 \mathrm{H}-5$ & C. wuell. & OSU & 48 & 38.98 & 42.58 & 42.58 & 4.04 & -0.25 & $846 \mathrm{D}-5 \mathrm{H}-2$ & C. wuell. & OSU \\
\hline 846D-4H-5 & C. wuell. & OSU & 58 & 39.08 & 42.68 & 42.69 & 3.86 & 0.00 & $846 \mathrm{D}-5 \mathrm{H}-3$ & C. wuell. & OSU \\
\hline $846 \mathrm{D}-4 \mathrm{H}-5$ & C. wuell. & OSU & 68 & 39.18 & 42.78 & 42.79 & 3.80 & -0.16 & $846 \mathrm{D}-5 \mathrm{H}-3$ & C. wuell. & OSU \\
\hline $846 \mathrm{D}-4 \mathrm{H}-5$ & C. wuell. & OSU & 78 & 39.28 & 42.88 & 42.90 & 3.62 & 0.03 & $846 \mathrm{D}-5 \mathrm{H}-3$ & C. wuell. & OSU \\
\hline $846 \mathrm{D}-4 \mathrm{H}-5$ & C. wuell. & OSU & 88 & 39.38 & 42.98 & 43.00 & 3.68 & -0.01 & $846 \mathrm{D}-5 \mathrm{H}-3$ & C. wuell. & OSU \\
\hline $846 \mathrm{D}-4 \mathrm{H}-5$ & C. wuell. & OSU & 98 & 39.48 & 43.08 & 43.09 & 3.70 & 0.02 & $846 \mathrm{D}-5 \mathrm{H}-3$ & C. wuell. & OSU \\
\hline $846 \mathrm{D}-4 \mathrm{H}-5$ & C. wuell. & OSU & 108 & 39.58 & 43.18 & 43.19 & 3.89 & -0.02 & $846 \mathrm{D}-5 \mathrm{H}-3$ & C. wuell. & OSU \\
\hline $846 \mathrm{D}-4 \mathrm{H}-5$ & C. wuell. & OSU & 118 & 39.68 & 43.28 & 43.28 & 3.78 & -0.06 & $846 \mathrm{D}-5 \mathrm{H}-3$ & C. wuell. & OSU \\
\hline $846 \mathrm{D}-4 \mathrm{H}-5$ & C. wuell. & OSU & 128 & 39.78 & 43.38 & 43.38 & 3.54 & -0.07 & $846 \mathrm{D}-5 \mathrm{H}-3$ & C. wuell. & OSU \\
\hline $846 \mathrm{D}-4 \mathrm{H}-5$ & C. wuell. & OSU & 138 & 39.88 & 43.48 & 43.48 & 3.79 & -0.13 & $846 \mathrm{D}-5 \mathrm{H}-3$ & C. wuell. & OSU \\
\hline $846 \mathrm{D}-4 \mathrm{H}-5$ & C. wuell. & osu & 148 & 39.98 & 43.58 & 43.58 & 3.80 & -0.15 & $846 \mathrm{D}-5 \mathrm{H}-3$ & C. wuell. & OSU \\
\hline $846 \mathrm{D}-4 \mathrm{H}-6$ & C. wuell. & OSU & 8 & 40.08 & 43.68 & 43.69 & 3.50 & -0.29 & $846 \mathrm{D}-5 \mathrm{H}-3$ & C. wuell. & OSU \\
\hline $846 \mathrm{D}-4 \mathrm{H}-6$ & C. wuell. & OSU & 18 & 40.18 & 43.78 & 43.79 & 3.57 & -0.23 & $846 \mathrm{D}-5 \mathrm{H}-3$ & C. wuell. & OSU \\
\hline $846 \mathrm{D}-4 \mathrm{H}-6$ & C. wuell. & OSU & 28 & 40.28 & 43.88 & 43.89 & 3.94 & -0.42 & $846 \mathrm{D}-5 \mathrm{H}-3$ & C. wuell. & OSU \\
\hline $846 \mathrm{D}-4 \mathrm{H}-6$ & C. wuell. & OSU & 38 & 40.38 & 43.98 & 43.99 & 3.71 & -0.39 & $846 \mathrm{D}-5 \mathrm{H}-3$ & C. wuell. & OSU \\
\hline $846 \mathrm{D}-4 \mathrm{H}-6$ & C. wuell. & OSU & 48 & 40.48 & 44.08 & 44.08 & 4.11 & -0.49 & $846 \mathrm{D}-5 \mathrm{H}-3$ & C. wuell. & OSU \\
\hline $846 \mathrm{D}-4 \mathrm{H}-6$ & C. wuell. & OSU & 58 & 40.58 & 44.18 & 44.17 & 4.16 & -0.62 & $846 \mathrm{D}-5 \mathrm{H}-4$ & C. wuell. & OSU \\
\hline $846 \mathrm{D}-4 \mathrm{H}-6$ & C. wuell. & OSU & 68 & 40.68 & 44.28 & 44.26 & 4.14 & -0.59 & $846 \mathrm{D}-5 \mathrm{H}-4$ & C. wuell. & OSU \\
\hline $846 \mathrm{D}-4 \mathrm{H}-6$ & C. wuell. & OSU & 78 & 40.78 & 44.38 & 44.35 & 4.10 & -0.73 & $846 \mathrm{D}-5 \mathrm{H}-4$ & C. wuell. & OSU \\
\hline $846 \mathrm{D}-4 \mathrm{H}-6$ & C. wuell. & OSU & 88 & 40.88 & 44.48 & 44.45 & 3.87 & -0.73 & $846 \mathrm{D}-5 \mathrm{H}-4$ & C. wuell. & OS \\
\hline $846 \mathrm{D}-4 \mathrm{H}-6$ & C. wuell. & OSU & 98 & 40.98 & 44.58 & 44.55 & 4.17 & -0.54 & $846 \mathrm{D}-5 \mathrm{H}-4$ & C. wuell. & OSU \\
\hline $846 \mathrm{D}-4 \mathrm{H}-6$ & C. wuell. & OSU & 107 & 41.07 & 44.67. & 44.65 & 4.09 & -0.42 & $846 \mathrm{D}-5 \mathrm{H}-4$ & C. wuell. & OSU \\
\hline $846 \mathrm{D}-4 \mathrm{H}-6$ & C. wuell. & OSU & 118 & 41.18 & 44.78 & 44.77 & 4.18 & -0.57 & $846 \mathrm{D}-5 \mathrm{H}-4$ & C. wuell. & OSU \\
\hline $846 \mathrm{D}-4 \mathrm{H}-6$ & C. wuell. & OSU & 128 & 41.28 & 44.88 & 44.88 & 4.02 & -0.26 & $846 \mathrm{D}-5 \mathrm{H}-4$ & C. wuell. & OS \\
\hline $846 \mathrm{D}-4 \mathrm{H}-6$ & C. wuell. & OSU & 137 & 41.37 & 44.97 & 44.98 & 3.77 & 0.02 & $846 \mathrm{D}-5 \mathrm{H}-4$ & C. wuell. & OSU \\
\hline $846 \mathrm{D}-4 \mathrm{H}-6$ & C. wuell. & OSU & 148 & 41.48 & 45.08 & 45.09 & 3.77 & -0.25 & $846 \mathrm{D}-5 \mathrm{H}-4$ & C. wuell. & OSU \\
\hline $846 \mathrm{D}-4 \mathrm{H}-7$ & C. wuell. & osu & 8 & 41.58 & 45.18 & 45.18 & 3.55 & 0.06 & $846 \mathrm{D}-5 \mathrm{H}-4$ & C. wuell. & OSU \\
\hline $846 \mathrm{D}-4 \mathrm{H}-7$ & C. wuell. & OSU & 18 & 41.68 & 45.28 & 45.27 & 3.76 & -0.21 & $846 \mathrm{D}-5 \mathrm{H}-4$ & C. wuell. & OSU \\
\hline $846 \mathrm{D}-4 \mathrm{H}-7$ & C. wuell. & osu & 28 & 41.78 & 45.38 & 45.36 & 3.49 & -0.17 & $846 \mathrm{D}-5 \mathrm{H}-4$ & C. wuell. & OSU \\
\hline $846 \mathrm{D}-4 \mathrm{H}-7$ & C. wuell. & OSU & 38 & 41.88 & 45.48. & 45.45 & 3.51 & -0.75 & $846 \mathrm{D}-5 \mathrm{H}-4$ & C. wuell. & OSU \\
\hline $846 \mathrm{D}-4 \mathrm{H}-7$ & C. wuell. & OSU & 48 & 41.98 & 45.58 & 45.55 & 3.83 & -0.92 & $846 \mathrm{D}-5 \mathrm{H}-4$ & C. wuell. & OSU \\
\hline $846 \mathrm{D}-4 \mathrm{H}-7$ & C. wuell. & OSU & 58 & 42.08 & 45.68 & 45.66 & 4.06 & -0.60 & $846 \mathrm{D}-5 \mathrm{H}-4$ & C. wuell. & os \\
\hline $846 \mathrm{D}-4 \mathrm{H}-7$ & C. wuell. & OSU & 68 & 42.18 & 45.78 & 45.77 & 4.42 & -0.60 & $846 \mathrm{D}-5 \mathrm{H}-5$ & C. wuell. & OSU \\
\hline $846 \mathrm{C}-5 \mathrm{H}-1$ & C. wuell. & OSU & 108 & 41.58 & 45.63 & 45.83 & 4.27 & -0.59 & $846 \mathrm{D}-5 \mathrm{H}-5$ & C. wuell. & OSU \\
\hline $846 \mathrm{C}-5 \mathrm{H}-\mathrm{I}$ & C. wuell. & OSU & 118 & 41.68 & 45.73 & 45.87 & 4.42 & -0.6 & $846 \mathrm{D}-5 \mathrm{H}-5$ & C. wuell. & OS \\
\hline $846 \mathrm{D}-4 \mathrm{H}-7$ & C. wuell. & OSU & 78 & 42.28 & 45.88 & 45.88 & 4.48 & -0.84 & $846 \mathrm{D}-5 \mathrm{H}-5$ & C. wuell. & Os \\
\hline $846 \mathrm{C}-5 \mathrm{H}-1$ & C. wuell. & osu & 128 & 41.78 & 45.83 & 45.90 & 4.38 & -0.68 & $846 \mathrm{D}-5 \mathrm{H}-5$ & C. wuell. & OSU \\
\hline $846 \mathrm{C}-5 \mathrm{H}-1$ & C. wuell. & OSU & 138 & 41.88 & 45.93 & 45.94 & 4.58 & -0.70 & $846 \mathrm{D}-5 \mathrm{H}-5$ & C. wuell. & OSU \\
\hline $846 \mathrm{C}-5 \mathrm{H}-\mathrm{I}$ & C. wuell. & OSU & 148 & 41.98 & 46.03 & 46.01 & 4.52 & & & C. wue & os \\
\hline $846 \mathrm{C}-5 \mathrm{H}-2$ & C. wuell. & OSU & 8 & 42.08 & 46.13 & 46.11 & 4.25 & -0.50 & $846 \mathrm{D}-5 \mathrm{H}-5$ & C. wuell. & Osu \\
\hline $846 \mathrm{C}-5 \mathrm{H}-2$ & C. wuell. & OSU & 18 & 42.18 & 46.23 & 46.22 & 4.30 & -0.54 & $846 \mathrm{D}-5 \mathrm{H}-5$ & C. wuell. & OSU \\
\hline $846 \mathrm{C}-5 \mathrm{H}-2$ & C. wuell. & OSU & 28 & 42.28 & 46.33 & 46.34 & 4.22 & -0.4 & $846 \mathrm{D}-5 \mathrm{H}-5$ & C. whe & os \\
\hline $846 \mathrm{C}-5 \mathrm{H}-2$ & C. wuell. & OSU & 38 & 42.38 & 46.43 & 46.43 & 4.19 & -0.3 & $846 \mathrm{D}-5 \mathrm{H}-5$ & C. wue & os \\
\hline $846 \mathrm{C}-5 \mathrm{H}-2$ & C. whell. & OSU & 48 & 42.48 & 46.53 & 46.53 & 4.10 & -0.38 & $846 \mathrm{D}-5 \mathrm{H}-5$ & C. wuell. & OSU \\
\hline $846 \mathrm{C}-5 \mathrm{H}-2$ & C. wuell. & osu & 58 & 42.58 & 46.63 & 46.63 & 3.98 & -0.34 & $846 \mathrm{D}-5 \mathrm{H}-5$ & C. wuell. & OS \\
\hline $846 \mathrm{C}-5 \mathrm{H}-2$ & C. wuell. & OS & 68 & 42.68 & 46.73 & 46.73 & 3.89 & -0.14 & $846 \mathrm{D}-5 \mathrm{H}-5$ & C. wut & os \\
\hline $846 \mathrm{C}-5 \mathrm{H}-2$ & C. wuell. & OSU & 78 & 42.78 & 46.83 & 46.83 & 3.85 & -0.1 & $846 \mathrm{D}-5 \mathrm{H}-5$ & C. wu & ost \\
\hline $846 \mathrm{C}-5 \mathrm{H}-2$ & C. wuell. & & 88 & 42.88 & 46.93 & 46.94 & 3.77 & -0.19 & $846 \mathrm{D}-5 \mathrm{H}-5$ & C. wue & os \\
\hline $846 \mathrm{C}-5 \mathrm{H}-2$ & C. wue & os & 98 & 42.98 & 47.03 & 47.04 & 3.68 & -0.1 & $846 \mathrm{D}-5 \mathrm{H}$ & U.per & os \\
\hline $846 \mathrm{C}-5 \mathrm{H}-2$ & C. wuell. & OS & 108 & 43.08 & 47.13 & 47.13 & 3.81 & -0.22 & $846 \mathrm{D}-5 \mathrm{H}-5$ & C. wut & OS \\
\hline $846 \mathrm{C}-5 \mathrm{H}-2$ & C. wuell. & OSU & 118 & 43.18 & 47.23 & 47.23 & 3.87 & -0.28 & $846 \mathrm{D}-5 \mathrm{H}-6$ & U.per & os \\
\hline & C. whel & OSU & 128 & 43.28 & 47.33 & 47.33 & 4.03 & -0.3 & $846 \mathrm{D}-5 \mathrm{H}-6$ & C. wu & os \\
\hline $846 \mathrm{C}-5 \mathrm{H}-2$ & C. wue & os & 138 & 43.38 & 47.43 & 47.43 & 4.25 & -0 . & $846 \mathrm{D}-5 \mathrm{H}-6$ & C. wue & \\
\hline $846 \mathrm{C}-5 \mathrm{H}-2$ & C. wuel & OS & 148 & 43.48 & 47.53 & 47.53 & 4.35 & -0.5 & $846 \mathrm{D}-5 \mathrm{H}-6$ & U.per & OSI \\
\hline $846 \mathrm{C}-5 \mathrm{H}-3$ & C. wuell. & OSU & 8 & 43.58 & 47.63 & 47.63 & 4.28 & -0.5 & $846 \mathrm{D}-5 \mathrm{H}-6$ & & ost \\
\hline & & & 18 & 43.68 & 47. & 47.73 & 4.26 & -0.5 & $846 \mathrm{D}-5 \mathrm{H}-6$ & C. wu & \\
\hline $846 \mathrm{C}-5 \mathrm{H}-3$ & C. whe & & 28 & 43 . & 47.8 & 47.83 & 4.22 & -0 . & $846 \mathrm{D}-5 \mathrm{H}-6$ & C. wut & \\
\hline $846 \mathrm{D}-5 \mathrm{H}-1$ & C. wuell. & OS & 8 & 42.08 & 47.68 & 47.90 & 4.05 & -0.20 & $846 \mathrm{D}-5 \mathrm{H}-6$ & C. wuell. & OSU \\
\hline $846 \mathrm{D}-5 \mathrm{H}-1$ & C. wuell. & OSU & 8 & 42.08 & 47.6 & 47.91 & 4.35 & -0.45 & $846 \mathrm{D}-5 \mathrm{H}-6$ & & OSU \\
\hline & & & 18 & 42.18 & 47.78 & 48.00 & 4.26 & -0 . & $846 \mathrm{D}-5 \mathrm{H}-6$ & C. wue & \\
\hline & C. wuet & & 28 & 42.28 & 47.8 & 48.06 & 4.35 & -0.4 & $846 \mathrm{D}-5 \mathrm{H}-6$ & C. wut & \\
\hline $846 \mathrm{D}-5 \mathrm{H}-1$ & C. wuell. & osu & 38 & 42.38 & 47.98 & 48.13 & 4.09 & -0.48 & $846 \mathrm{D}-5 \mathrm{H}-6$ & C. wuell. & osu \\
\hline $846 \mathrm{D}-5 \mathrm{H}-1$ & C. wuell. & OSU & 48 & 42.48 & 48.08 & 48.20 & 4.11 & -0.5 & $846 \mathrm{D}-5 \mathrm{H}-6$ & $U$.pereg. & OSU \\
\hline & & & 58 & 42.58 & 48.1 & 48.31 & 4. & -0 . & & & \\
\hline $846 \mathrm{D}-5 \mathrm{H}-1$ & C. wue & OS & 68 & 42,68 & 48.2 & 48.43 & 4.05 & -0.41 & $846 \mathrm{D}-5 \mathrm{H}-6$ & $U$. pereg. & OSU \\
\hline $846 \mathrm{D}-5 \mathrm{H}-1$ & C. wuell. & OSU & 78 & 42.78 & 48.38 & 48.58 & 3.94 & -0.23 & $846 \mathrm{D}-5 \mathrm{H}-6$ & C. wuell. & OSU \\
\hline $846 \mathrm{D}-5 \mathrm{H}-1$ & C. wuell. & osu & 88 & 42.88 & 48.48 & 48.73 & 3.79 & -0.28 & $846 \mathrm{D}-5 \mathrm{H}-6$ & C. wuell. & OSU \\
\hline
\end{tabular}


APPENDIX A (continued)

\begin{tabular}{|c|c|c|c|c|c|c|c|}
\hline $\begin{array}{l}\text { Core, section, } \\
\text { interval }(\mathrm{cm})\end{array}$ & Species & Lab. & $\begin{array}{c}\text { Interval } \\
(\mathrm{cm})\end{array}$ & $\begin{array}{l}\text { Depth } \\
\text { (mbsf) }\end{array}$ & $\begin{array}{l}\text { h Depth Depth } \\
\text { f) (mcd) (rmcd) }\end{array}$ & $\delta^{18} \mathrm{O}$ & $\delta^{13} \mathrm{C}$ \\
\hline $846 \mathrm{D}-5 \mathrm{H}-6$ & C. wuell. & OSU & 148 & 50.98 & $56.58 \quad 56.59$ & 3.83 & -0.05 \\
\hline $846 \mathrm{D}-5 \mathrm{H}-7$ & C. wuell. & OSU & 8 & 51.08 & 56.6856 .71 & 4.08 & -0.22 \\
\hline $846 \mathrm{D}-5 \mathrm{H}-7$ & C. wuell. & OSU & 8 & 51.08 & $56.68 \quad 56.71$ & 4.13 & -0.23 \\
\hline $846 \mathrm{D}-5 \mathrm{H}-7$ & C. wuell. & OSU & 18 & 51.18 & 56.7856 .84 & 3.87 & -0.12 \\
\hline $846 \mathrm{D}-5 \mathrm{H}-7$ & C. wuell. & OSU & 28 & 51.28 & 56.8856 .98 & 3.81 & -0.02 \\
\hline $846 \mathrm{D}-5 \mathrm{H}-7$ & $C$. wuell. & OSU & 38 & 51.38 & $56.98 \quad 57.12$ & 3.72 & 0.12 \\
\hline $846 \mathrm{D}-6 \mathrm{H}-1$ & C. wuell. & OSU & 18 & 51.68 & $57.08 \quad 57.24$ & 3.85 & 0.00 \\
\hline $846 \mathrm{D}-5 \mathrm{H}-7$ & C. wuell. & OSU & 48 & 51.48 & $57.08 \quad 57.25$ & 3.73 & 0.02 \\
\hline $846 \mathrm{D}-5 \mathrm{H}-7$ & C. wuell. & OSU & 58 & 51.58 & $57.18 \quad 57.36$ & 4.04 & -0.04 \\
\hline $846 \mathrm{D}-6 \mathrm{H}-\mathrm{I}$ & C. wuell. & OSU & 28 & 51.78 & $57.18 \quad 57.37$ & 3.73 & 0.00 \\
\hline $846 \mathrm{D}-6 \mathrm{H}-\mathrm{I}$ & C. wuell. & OSU & 38 & 51.88 & $57.28 \quad 57.43$ & 3.87 & -0.13 \\
\hline $846 \mathrm{D}-5 \mathrm{H}-7$ & C. wuell. & OSU & 68 & 51.68 & $57.28 \quad 57.43$ & 4.09 & -0.12 \\
\hline $846 \mathrm{D}-6 \mathrm{H}-1$ & C. wuell. & OSU & 48 & 51.98 & $57.38 \quad 57.48$ & 4.17 & -0.10 \\
\hline $846 \mathrm{D}-6 \mathrm{H}-1$ & C. wuell. & OSU & 58 & 52.08 & $57.48 \quad 57.58$ & 4.19 & -0.30 \\
\hline $846 \mathrm{~B}-6 \mathrm{H}-5$ & C. wrell. & OSU & 8 & 51.08 & $57.58 \quad 57.58$ & 4.10 & -0.37 \\
\hline $846 \mathrm{D}-6 \mathrm{H}-1$ & C. wuell. & OSU & 68 & 52.18 & $57.58 \quad 57.65$ & 4.10 & -0.30 \\
\hline $846 \mathrm{~B}-6 \mathrm{H}-5$ & C. wuell. & OSU & 18 & 51.18 & $57.68 \quad 57.68$ & 4.05 & -0.16 \\
\hline $846 \mathrm{D}-6 \mathrm{H}-1$ & C. wuell. & OSU & 78 & 52.28 & $57.68 \quad 57.76$ & 3.83 & -0.24 \\
\hline $846 \mathrm{~B}-6 \mathrm{H}-5$ & $C$, whell. & OSU & 28 & 51.28 & 57.7857 .78 & 3.88 & -0.19 \\
\hline $846 \mathrm{~B}-6 \mathrm{H}-5$ & C. wuell. & OSU & 42 & 51.42 & 57.9257 .92 & 3.81 & -0.20 \\
\hline $846 \mathrm{D}-6 \mathrm{H}-1$ & C. wuell. & OSU & 88 & 52.38 & $57.78 \quad 57.97$ & 3.87 & -0.30 \\
\hline $846 \mathrm{~B}-6 \mathrm{H}-5$ & C. wuell. & OSU & 49 & 51.49 & 57.9957 .99 & 3.78 & -0.17 \\
\hline $846 \mathrm{~B}-6 \mathrm{H}-5$ & C. wuell. & OSU & 58 & 51.58 & $58.08 \quad 58.08$ & 3.72 & -0.11 \\
\hline $846 \mathrm{D}-6 \mathrm{H}-1$ & C. wuell. & OSU & 98 & 52.48 & 57.8858 .09 & 3.80 & -0.16 \\
\hline $846 \mathrm{D}-6 \mathrm{H}-1$ & C. wuell. & OSU & 108 & 52.58 & $57.98 \quad 58.18$ & 3.82 & -0.24 \\
\hline $846 \mathrm{~B}-6 \mathrm{H}-5$ & C. wuell. & OSU & 68 & 51.68 & $58.18 \quad 58.18$ & 3.60 & -0.01 \\
\hline $846 \mathrm{D}-6 \mathrm{H}-1$ & C. wuell. & OSU & 118 & 52.68 & $58.08 \quad 58.21$ & 3.73 & -0.08 \\
\hline $846 \mathrm{D}-6 \mathrm{H}-1$ & C. whell. & OSU & 128 & 52.78 & $58.18 \quad 58.25$ & 3.72 & 0.28 \\
\hline $846 \mathrm{D}-6 \mathrm{H}-1$ & C. wuell. & OSU & 138 & 52.88 & $58.28 \quad 58.28$ & 3.65 & 0.15 \\
\hline $846 \mathrm{~B}-6 \mathrm{H}-5$ & C. wuell. & OSU & 78 & 51.78 & $58.28 \quad 58.28$ & 3.75 & 0.08 \\
\hline $846 \mathrm{D}-6 \mathrm{H}-1$ & C. wuell. & OSU & 148 & 52.98 & $58.38 \quad 58.31$ & 3.65 & 0.02 \\
\hline $846 \mathrm{D}-6 \mathrm{H}-2$ & C. wuell. & OSU & 8 & 53.08 & $58.48 \quad 58.36$ & 3.80 & -0.07 \\
\hline $846 \mathrm{~B}-6 \mathrm{H}-5$ & C. wuell. & OSU & 88 & 51.88 & $58.38 \quad 58.38$ & 3.73 & -0.03 \\
\hline $846 \mathrm{D}-6 \mathrm{H}-2$ & C. wuell. & OSU & 18 & 53.18 & $58.58 \quad 58.43$ & 3.74 & -0.07 \\
\hline $846 \mathrm{~B}-6 \mathrm{H}-5$ & C. wuell. & OSU & 98 & 51.98 & $58.48 \quad 58.48$ & 3.84 & 0.00 \\
\hline $846 \mathrm{D}-6 \mathrm{H}-2$ & C. wuell. & OSU & 28 & 53.28 & $58.68 \quad 58.53$ & 3.82 & -0.23 \\
\hline $846 \mathrm{D}-6 \mathrm{H}-2$ & $C$, wuell. & OSU & 28 & 53.28 & $58.68 \quad 58.56$ & 3.69 & -0.23 \\
\hline $846 \mathrm{~B}-6 \mathrm{H}-5$ & C. wuell. & OSU & 109 & 52.09 & 58.5958 .59 & 3.94 & -0.16 \\
\hline $846 \mathrm{~B}-6 \mathrm{H}-5$ & C. wuell. & OSU & 118 & 52.18 & $58.68 \quad 58.68$ & 3.88 & -0.04 \\
\hline $846 \mathrm{D}-6 \mathrm{H}-2$ & C. wuell. & OSU & 38 & 53.38 & $58.78 \quad 58.78$ & 3.72 & -0.09 \\
\hline $846 \mathrm{~B}-6 \mathrm{H}-5$ & C. wuell. & OSU & 128 & 52.28 & 58.7858 .78 & 3.81 & -0.11 \\
\hline $846 \mathrm{~B}-6 \mathrm{H}-5$ & C. wuell. & OSU & 138 & 52.38 & $58.88 \quad 58.88$ & 3.90 & -0.11 \\
\hline $846 \mathrm{D}-6 \mathrm{H}-2$ & C. wuell. & OSU & 48 & 53.48 & $58.88 \quad 58.97$ & 3,88 & -0.22 \\
\hline $846 \mathrm{~B}-6 \mathrm{H}-5$ & C. wuell. & OSU & 147 & 52.47 & 58.9758 .97 & 3.89 & 0.04 \\
\hline $846 \mathrm{D}-6 \mathrm{H}-2$ & C. wuell. & OSU & 58 & 53.58 & $58.98 \quad 59.07$ & 3.83 & 0.07 \\
\hline $846 \mathrm{D}-6 \mathrm{H}-2$ & C. wuell. & OSU & 68 & 53.68 & $59.08 \quad 59.14$ & 4.23 & -0.50 \\
\hline 846D-6H-2 & C. wuell. & OSU & 78 & 53.78 & $59.18 \quad 59.20$ & 3.66 & 0.02 \\
\hline $846 \mathrm{D}-6 \mathrm{H}-2$ & C. wuell. & OSU & 88 & 53.88 & $59.28 \quad 59.24$ & 4.19 & -0.30 \\
\hline 846D-6H-2 & C. wuell. & OSU & 98 & 53.98 & $59.38 \quad 59.29$ & 4.06 & -0.37 \\
\hline $846 \mathrm{D}-6 \mathrm{H}-2$ & C. wuell. & OSU & 108 & 54.08 & $59.48 \quad 59.35$ & 4,33 & -0.34 \\
\hline $846 \mathrm{D}-6 \mathrm{H}-2$ & C. wuell. & OSU & 118 & 54.18 & $59.58 \quad 59.41$ & 3.59 & -0.02 \\
\hline $846 \mathrm{D}-6 \mathrm{H}-2$ & C. wuell. & OSU & 118 & 54.18 & $59.58 \quad 59.42$ & 3.44 & -0.03 \\
\hline $846 \mathrm{D}-6 \mathrm{H}-2$ & C. wuell. & OSU & 128 & 54.28 & 59.6859 .53 & 4.25 & -0.57 \\
\hline $846 \mathrm{D}-6 \mathrm{H}-2$ & C. wuell. & OSU & 138 & 54.38 & $59.78 \quad 59.70$ & 4.28 & -0.60 \\
\hline $846 \mathrm{D}-6 \mathrm{H}-2$ & C. wuell. & OSU & 148 & 54.48 & $\begin{array}{l}59.88 \quad 59.98 \\
50.98\end{array}$ & 4.14 & -0.60 \\
\hline $846 \mathrm{D}-6 \mathrm{H}-3$ & C. wuell. & $\mathrm{OSU}$ & 8 & 54.58 & $59.98 \quad 60.29$ & 4.15 & -0.57 \\
\hline $846 \mathrm{D}-6 \mathrm{H}-3$ & C. wuell. & OSU & 18 & 54.68 & $60.08 \quad 60.37$ & 4.17 & -0.47 \\
\hline $846 \mathrm{D}-6 \mathrm{H}-3$ & C. wuell. & $\mathrm{OSU}$ & 28 & 54.78 & 60.1860 .41 & 4.25 & -0.69 \\
\hline $846 \mathrm{D}-6 \mathrm{H}-3$ & C. wuell. & OSU & 38 & 54.88 & 60.2860 .44 & 4.20 & -0.63 \\
\hline $846 \mathrm{D}-6 \mathrm{H}-3$ & C. whell. & OSU & 48 & 54.98 & 60.3860 .46 & 4.11 & -0.53 \\
\hline $846 \mathrm{D}-6 \mathrm{H}-3$ & C. wuell. & OSU & 58 & 55.08 & $60.48 \quad 60.49$ & 4.06 & -0.39 \\
\hline $846 \mathrm{D}-6 \mathrm{H}-3$ & C. wuell. & OSU & 68 & 55.18 & $60.58 \quad 60.52$ & 4.03 & -0.40 \\
\hline $846 \mathrm{D}-6 \mathrm{H}-3$ & C. whell. & OSU & 78 & 55.28 & 60.6860 .57 & 3.80 & -0.21 \\
\hline $846 \mathrm{D}-6 \mathrm{H}-3$ & C. wuell. & OSU & 88 & 55.38 & 60.7860 .75 & 3.68 & -0.14 \\
\hline $846 \mathrm{D}-6 \mathrm{H}-3$ & C. wuell. & OSU & 98 & 55.48 & 60.8861 .20 & 3.64 & -0.10 \\
\hline
\end{tabular}

\begin{tabular}{|c|c|c|c|c|c|c|c|}
\hline $\begin{array}{l}\text { Core, section, } \\
\text { interval }(\mathrm{cm})\end{array}$ & Species & Lab. & $\begin{array}{l}\text { Interval } \\
(\mathrm{cm})\end{array}$ & $\begin{array}{l}\text { Depth } \\
\text { (mbsf) }\end{array}$ & $\begin{array}{l}\text { Depth Depth } \\
\text { (med) (rmcd) }\end{array}$ & $\delta^{18} \mathrm{O}$ & $\delta^{13} \mathrm{C}$ \\
\hline $846 \mathrm{D}-6 \mathrm{H}-3$ & C. wuell. & OSU & 108 & $55.58 \quad 6$ & $60.98 \quad 61.28$ & 3.45 & -0.26 \\
\hline $846 \mathrm{D}-6 \mathrm{H}-3$ & C. wuell. & OSU & 118 & 55.68 & $61.08 \quad 61.31$ & 3.75 & -0.41 \\
\hline $846 \mathrm{D}-6 \mathrm{H}-3$ & C. wuell. & OSU & 128 & 55.78 & $61.18 \quad 61.33$ & 3.74 & -0.29 \\
\hline $846 \mathrm{D}-6 \mathrm{H}-3$ & C. wuell. & OSU & 138 & 55.88 & $61.28 \quad 61.36$ & 3.85 & -0.51 \\
\hline $846 \mathrm{D}-6 \mathrm{H}-3$ & C. wuell. & OSU & 148 & 55.98 & $61.38 \quad 61.38$ & 4.00 & -0.79 \\
\hline $846 D-6 h-4$ & C. wuell. & OSU & 8 & 56.08 & $61.48 \quad 61.43$ & 4.05 & -0.57 \\
\hline $846 \mathrm{D}-6 \mathrm{~h}-4$ & C. wuell. & OSU & 18 & 56.18 & $61.58 \quad 61.47$ & 4.11 & -1.00 \\
\hline $846 \mathrm{D}-6 \mathrm{~h}-4$ & C. witell. & OSU & 28 & 56.28 & 61.6861 .54 & 3.86 & $=0.82$ \\
\hline $846 \mathrm{D}-6 \mathrm{~h}-4$ & $U$. pereg. & OSU & 28 & 56.28 & 61.6861 .54 & 4.18 & -0.62 \\
\hline $846 \mathrm{D}-6 \mathrm{~h}-4$ & C. wuell. & OSU & 38 & 56.38 & 61.7861 .67 & 4.00 & -0.87 \\
\hline $846 \mathrm{D}-6 \mathrm{~h}-4$ & C. wuell. & OSU & 48 & 56.48 & $61.88 \quad 61.92$ & 3.61 & -0.47 \\
\hline $846 \mathrm{D}-6 \mathrm{~h}-4$ & C. wuell. & OSU & 58 & 56.58 & 61.9862 .09 & 3.86 & -0.32 \\
\hline $846 \mathrm{D}-6 \mathrm{~h}-4$ & C. wuell. & OSU & 68 & 56.68 & 62.0862 .16 & 3.51 & -0.51 \\
\hline $846 \mathrm{D}-6 \mathrm{~h}-4$ & C. wuell. & OSU & 78 & 56.78 & $62.18 \quad 62.22$ & 3.58 & -0.50 \\
\hline $846 \mathrm{D}-6 \mathrm{~h}-4$ & C. wuell. & OSU & 88 & 56.88 & 62.2862 .26 & 3.90 & -0.67 \\
\hline $846 \mathrm{D}-6 \mathrm{~h}-4$ & C. wuell. & OSU & 98 & 56.98 & 62.3862 .32 & 3.77 & -0.46 \\
\hline $846 \mathrm{D}-6 \mathrm{~h}-4$ & C. wuell. & OSU & 108 & 57.08 & 62.4862 .48 & 3.62 & -0.40 \\
\hline $846 \mathrm{D}-6 \mathrm{~h}-4$ & C. wuell. & OSU & 118 & 57.18 & 62.5862 .70 & 3.59 & -0.56 \\
\hline $846 \mathrm{D}-6 \mathrm{~h}-4$ & C. wuell. & OSU & 118 & 57.18 & $62.58 \quad 62.71$ & 3.74 & -0.22 \\
\hline $846 \mathrm{D}-6 \mathrm{~h}-4$ & C. wuell. & OSU & 128 & 57.28 & $62.68 \quad 62.83$ & 3.91 & -0.85 \\
\hline $846 \mathrm{D}-6 \mathrm{~h}-4$ & C. wuell. & $\mathrm{OSU}$ & 138 & 57.38 & 62.7862 .91 & 3.88 & -0.69 \\
\hline $846 \mathrm{D}-6 \mathrm{~h}-4$ & C. wuell. & OSU & 138 & 57.38 & 62.7862 .92 & 3.64 & -0.66 \\
\hline $846 \mathrm{D}-6 \mathrm{~h}-4$ & C. wuell. & OSU & 148 & 57.48 & 62.8862 .95 & 4.12 & -0.74 \\
\hline $846 \mathrm{D}-6 \mathrm{H}-5$ & C. whell. & OSU & 8 & 57.58 & 62.9863 .03 & 3.84 & -0.52 \\
\hline $846 \mathrm{D}-6 \mathrm{H}-5$ & C. wuell. & OSU & 18 & 57.68 & $63.08 \quad 63.08$ & 3.71 & -0.56 \\
\hline $846 \mathrm{D}-6 \mathrm{H}-5$ & C. whell. & OSU & 28 & 57.78 & 63.1863 .14 & 3.81 & -0.51 \\
\hline $846 \mathrm{D}-6 \mathrm{H}-5$ & C. whell. & OSU & 38 & 57.88 & $63.28 \quad 63.22$ & 3.79 & -0.53 \\
\hline $846 \mathrm{D}-6 \mathrm{H}-5$ & C. wuell. & OSU & 48 & 57.98 & $63.38 \quad 63.32$ & 3.43 & -0.41 \\
\hline $846 \mathrm{D}-6 \mathrm{H}-5$ & C. wuell. & OSU & 58 & 58.08 & $63.48 \quad 63.44$ & 3.50 & -0.56 \\
\hline $846 \mathrm{D}-6 \mathrm{H}-5$ & C. wuell. & OSU & 68 & 58.18 & 63.5863 .58 & 3.58 & -0.28 \\
\hline $846 \mathrm{D}-6 \mathrm{H}-5$ & C. wuell. & OSU & 78 & 58.28 & 63.6863 .70 & 3.73 & -0.55 \\
\hline $846 \mathrm{D}-6 \mathrm{H}-5$ & C. wuell. & OSU & 88 & 58.38 & $63.78 \quad 63.82$ & 3.40 & -0.29 \\
\hline $846 \mathrm{D}-6 \mathrm{H}-5$ & C. wuell. & OSU & 98 & 58.48 & $63.88 \quad 63.96$ & 3.44 & -0.16 \\
\hline $846 \mathrm{D}-6 \mathrm{H}-5$ & C. wuell. & OSU & 108 & 58.58 & $63.98 \quad 64.08$ & 3.56 & -0.52 \\
\hline $846 \mathrm{D}-6 \mathrm{H}-5$ & C. wuell. & OSU & 118 & 58.68 & $64.08 \quad 64.19$ & 3.88 & -0.61 \\
\hline $846 \mathrm{D}-6 \mathrm{H}-5$ & C. wuell. & OSU & 128 & 58.78 & $64.18 \quad 64.28$ & 3.88 & -0.60 \\
\hline $846 \mathrm{D}-6 \mathrm{H}-5$ & C. wuell. & OSU & 138 & 58.88 & $64.28 \quad 64.35$ & 4.14 & -0.84 \\
\hline $846 \mathrm{D}-6 \mathrm{H}-5$ & C. wuell. & OSU & 148 & 58.98 & $64.38 \quad 64.42$ & 3.94 & -0.52 \\
\hline $846 \mathrm{D}-6 \mathrm{H}-6$ & C. wuell. & OSU & 8 & 59.08 & $64.48 \quad 64.54$ & 3.91 & -0.45 \\
\hline $846 \mathrm{D}-6 \mathrm{H}-6$ & C. wuell. & OSU & 18 & 59.18 & 64.5864 .65 & 3.99 & -0.72 \\
\hline $846 \mathrm{D}-6 \mathrm{H}-6$ & $U$. pereg. & OSU & 28 & 59.28 & $64.68 \quad 64.76$ & 4.06 & -0.57 \\
\hline $846 \mathrm{D}-6 \mathrm{H}-6$ & C. wuell. & OSU & 28 & 59.28 & 64.6864 .76 & 3.82 & -0.65 \\
\hline $846 \mathrm{D}-6 \mathrm{H}-6$ & C. wuell. & OSU & 38 & 59.38 & $64.78 \quad 64.85$ & 3.92 & -0.49 \\
\hline $846 \mathrm{D}-6 \mathrm{H}-6$ & C. wuell. & OSU & 48 & 59.48 & 64.8864 .94 & 3.57 & -0.27 \\
\hline $846 \mathrm{D}-6 \mathrm{H}-6$ & C. wuell. & OSU & 58 & 59.58 & $64.98 \quad 65.04$ & 3.69 & -0.61 \\
\hline $846 \mathrm{D}-6 \mathrm{H}-6$ & C. wuell. & OSU & 68 & 59.68 & 65.0865 .13 & 3.62 & -0.48 \\
\hline $846 \mathrm{D}-6 \mathrm{H}-6$ & C. wuell. & OSU & 78 & 59.78 & 65.1865 .23 & 3.58 & -0.59 \\
\hline $846 \mathrm{D}-6 \mathrm{H}-6$ & C. wuell. & OSU & 98 & 59.98 & $65.38 \quad 65.42$ & 3.88 & -0.59 \\
\hline $846 \mathrm{D}-6 \mathrm{H}-6$ & C. wuell. & OSU & 108 & 60.08 & $65.48 \quad 65.52$ & 3.56 & -0.36 \\
\hline $846 \mathrm{D}-6 \mathrm{H}-6$ & C. wuell. & OSU & 118 & 60.18 & $65.58 \quad 65.62$ & 3.54 & -0.45 \\
\hline $846 \mathrm{D}-6 \mathrm{H}-6$ & C. wuell. & OSU & 128 & 60.28 & $65.68 \quad 65.72$ & 3.51 & -0.33 \\
\hline $846 \mathrm{D}-6 \mathrm{H}-6$ & C. wuell. & OSU & 138 & 60.38 & $65.78 \quad 65.82$ & 3.71 & -0.61 \\
\hline $846 \mathrm{D}-6 \mathrm{H}-6$ & C. wuell. & OSU & 148 & 60.48 & $65.88 \quad 65.92$ & 3.75 & -0.74 \\
\hline $846 \mathrm{D}-6 \mathrm{H}-7$ & C. wuell. & OSU & 8 & 60.58 & 65.9866 .03 & 3.90 & -0.55 \\
\hline $846 \mathrm{D}-6 \mathrm{H}-7$ & C. wuell. & OSU & 18 & 60.68 & $66.08 \quad 66.12$ & 4.05 & -0.51 \\
\hline $846 \mathrm{D}-6 \mathrm{H}-7$ & C. wuell. & OSU & 28 & 60.78 & $66.18 \quad 66.22$ & 4.03 & -0.53 \\
\hline $846 \mathrm{D}-6 \mathrm{H}-7$ & C. wuell. & OSU & 38 & 60.88 & $66.28 \quad 66.32$ & 3.60 & -0.52 \\
\hline $846 \mathrm{D}-6 \mathrm{H}-7$ & C. wuell. & OSU & 38 & 60.88 & $66.28 \quad 66.32$ & 3.72 & -0.17 \\
\hline $846 \mathrm{D}-6 \mathrm{H}-7$ & $C$. wuell. & OSU & 48 & 60.98 & 66.3866 .42 & 3.79 & -0.32 \\
\hline $846 \mathrm{D}-6 \mathrm{H}-7$ & C. wuell. & OSU & 58 & 61.08 & 66.4866 .51 & 3.64 & -0.62 \\
\hline $846 \mathrm{D}-6 \mathrm{H}-7$ & C. wuell. & OSU & 67 & 61.17 & 66.5766 .60 & 3.69 & -0.47 \\
\hline $846 \mathrm{D}-6 \mathrm{H}-7$ & C, whell. & OSU & 67 & 61.176 & $66.57 \quad 66.60$ & 3.59 & -0.50 \\
\hline
\end{tabular}

Notes: Tabulated isotope data are relative to PDB standard, with species corrections as follows: Cibicides wuellerstorfi $\delta^{18} \mathrm{O}=$ measured +0.64 and Uvigerina peregrina $\delta^{13} \mathrm{C}$ $=$ measured +0.90 . OSU $=$ Oregon State University: $\mathrm{CAM}=$ University of Cambridge. 
APPENDIX B

Age Model and Sedimentation Rates for Site $\mathbf{8 4 6}$

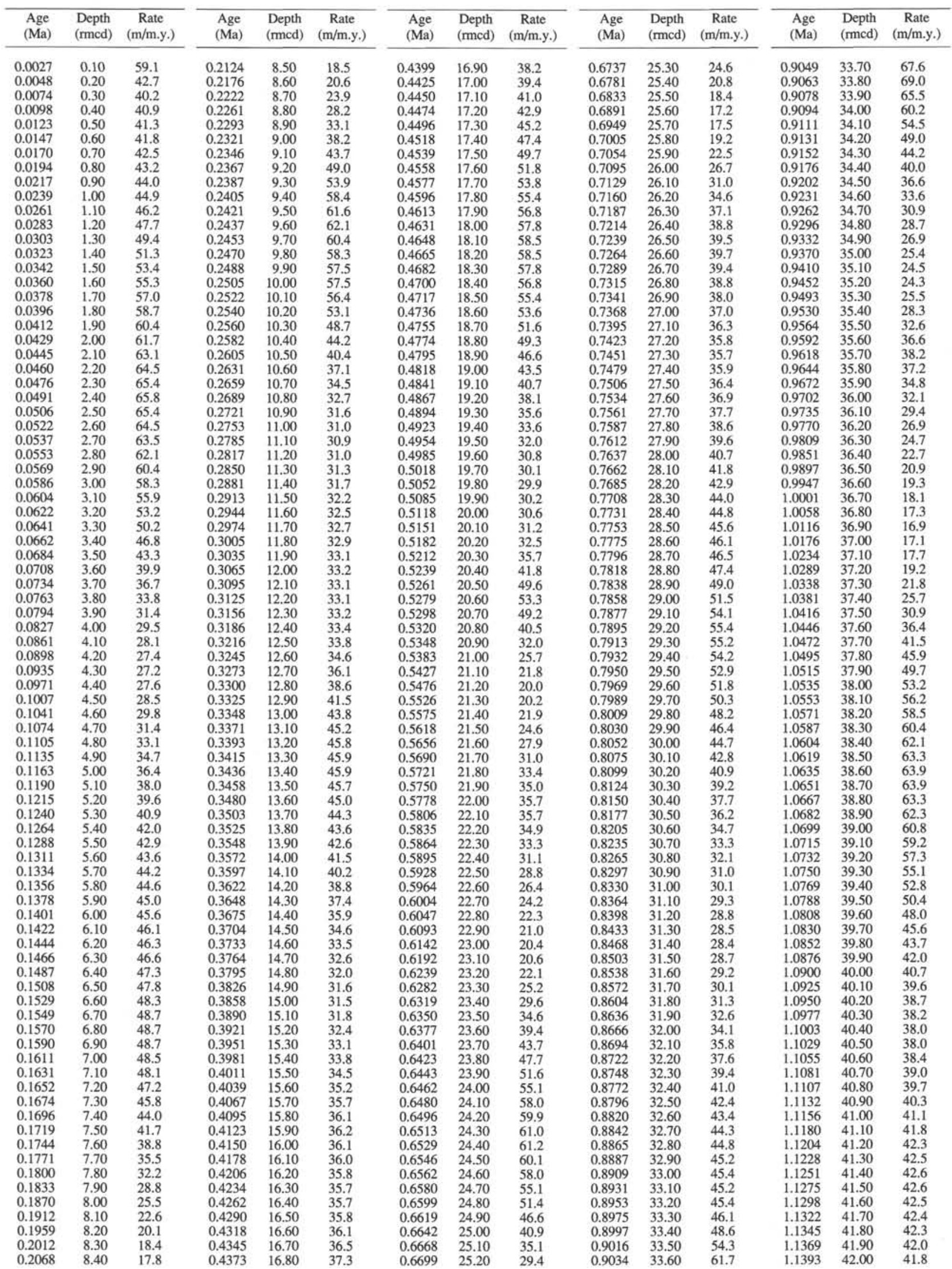


APPENDIX B (continued)

\begin{tabular}{|c|c|c|c|c|c|c|c|c|}
\hline $\begin{array}{l}\text { Age } \\
\text { (Ma) }\end{array}$ & $\begin{array}{l}\text { Depth } \\
\text { (rmcd) }\end{array}$ & $\begin{array}{c}\text { Rate } \\
(\mathrm{m} / \mathrm{m} . \mathrm{y} .)\end{array}$ & $\begin{array}{l}\text { Age } \\
\text { (Ma) }\end{array}$ & $\begin{array}{l}\text { Depth } \\
\text { (rmcd) }\end{array}$ & $\begin{array}{l}\text { Rate } \\
(\mathrm{m} / \mathrm{m} . \mathrm{y} .)\end{array}$ & $\begin{array}{l}\text { Age } \\
\text { (Ma) }\end{array}$ & $\begin{array}{l}\text { Depth } \\
\text { (rmcd) }\end{array}$ & $\begin{array}{c}\text { Rate } \\
(\mathrm{m} / \mathrm{m} . \mathrm{y} .)\end{array}$ \\
\hline 1.1417 & 42.10 & 41.6 & 1.3396 & 49.90 & 41.9 & 1.5814 & 57.70 & 25.1 \\
\hline 1.1441 & 42.20 & 41.4 & 1.3420 & 50.00 & 42.2 & 1.5855 & 57.80 & 23.0 \\
\hline 1.1465 & 42.30 & 41.3 & 1.3443 & 50.10 & 42.6 & 1.5901 & 57.90 & 21.2 \\
\hline 1.1489 & 42.40 & 41.6 & 1.3467 & 50.20 & 43.3 & 1.5950 & 58.00 & 19.8 \\
\hline 1.1513 & 42.50 & 42.2 & 1.3490 & 50.30 & 44.0 & 1.6002 & 58.10 & 18.8 \\
\hline 1.1537 & 42.60 & 42.8 & 1.3512 & 50.40 & 44.3 & 1.6056 & 58.20 & 18.3 \\
\hline 1.1560 & 42.70 & 43.5 & 1.3535 & 50.50 & 44.7 & 1.6111 & 58.30 & 18.3 \\
\hline 1.1583 & 42.80 & 44.3 & 1.3557 & 50.60 & 44.9 & 1.6165 & 58.40 & 18.8 \\
\hline 1.1605 & 42.90 & 45.0 & 1.3579 & 50.70 & 44.8 & 1.6217 & 58.50 & 20.0 \\
\hline 1.1627 & 43.00 & 46.1 & 1.3601 & 50.80 & 44.7 & 1.6266 & 58.60 & 21.8 \\
\hline 1.1649 & 43.10 & 46.9 & 1.3624 & 50.90 & 44.3 & 1.6309 & 58.70 & 24.2 \\
\hline 1.1670 & 43.20 & 47.5 & 1.3647 & 51.00 & 43.4 & 1.6348 & 58.80 & 27.4 \\
\hline 1.1691 & 43.30 & 47.8 & 1.3670 & 51.10 & 42.2 & 1.6383 & 58.90 & 31.1 \\
\hline 1.1712 & 43.40 & 47.8 & 1.3694 & 51.20 & 40.7 & 1.6413 & 59.00 & 35.2 \\
\hline 1.1733 & 43.50 & 47.5 & 1.3719 & 51.30 & 39.0 & 1.6440 & 59.10 & 39.7 \\
\hline 1.1754 & 43.60 & 46.6 & 1.3745 & 51.40 & 37.3 & 1.6464 & 59.20 & 44.2 \\
\hline 1.1776 & 43.70 & 45.4 & 1.3773 & 51.50 & 35.2 & 1.6485 & 59.30 & 48.5 \\
\hline 1.1798 & 43.80 & 43.7 & 1.3802 & 51.60 & 33.1 & 1.6505 & 59.40 & 52.9 \\
\hline 1.1821 & 43.90 & 41.5 & 1.3833 & 51.70 & 31.1 & 1.6523 & 59.50 & 56.7 \\
\hline 1.1846 & 44.00 & 38.8 & 1.3866 & 51.80 & 29.2 & 1.6540 & 59.60 & 59.9 \\
\hline 1.1873 & 44.10 & 35.6 & 1.3902 & 51.90 & 27.5 & 1.6557 & 59.70 & 62.3 \\
\hline 1.1902 & 44.20 & 32.2 & 1.3939 & 52.00 & 26.2 & 1.6572 & 59.80 & 64.3 \\
\hline 1.1935 & 44.30 & 29.0 & 1.3978 & 52.10 & 25.2 & 1.6588 & 59.90 & 66.0 \\
\hline 1.1972 & 44.40 & 26.0 & 1.4019 & 52.20 & 24.6 & 1.6603 & 60.00 & 66.9 \\
\hline 1.2012 & 44.50 & 23.5 & 1.4060 & 52.30 & 24.4 & 1.6618 & 60.10 & 66.9 \\
\hline 1.2057 & 44.60 & 21.6 & 1.4101 & 52.40 & 24.7 & 1.6632 & 60.20 & 65.8 \\
\hline 1.2105 & 44.70 & 20.5 & 1.4141 & 52.50 & 25.4 & 1.6648 & 60.30 & 63.9 \\
\hline 1.2155 & 44.80 & 20.2 & 1.4179 & 52.60 & 26.3 & 1.6664 & 60.40 & 61.8 \\
\hline 1.2204 & 44.90 & 20.7 & 1.4217 & 52.70 & 27.6 & 1.6680 & 60.50 & 58.7 \\
\hline 1.2251 & 45.00 & 22.0 & 1.4252 & 52.80 & 29.0 & 1.6698 & 60.60 & 55.0 \\
\hline 1.2295 & 45.10 & 24.0 & 1.4286 & 52.90 & 30.7 & 1.6717 & 60.70 & 51.2 \\
\hline 1.2335 & 45.20 & 26.5 & 1.4317 & 53.00 & 32.4 & 1.6737 & 60.80 & 47.2 \\
\hline 1.2371 & 45.30 & 29.4 & 1.4347 & 53.10 & 34.1 & 1.6759 & 60.90 & 42.9 \\
\hline 1.2403 & 45.40 & 32.4 & 1.4376 & 53.20 & 35.5 & 1.6784 & 61.00 & 38.6 \\
\hline 1.2433 & 45.50 & 35.3 & 1.4404 & 53.30 & 36.5 & 1.6811 & 61.10 & 34.3 \\
\hline 1.2460 & 45.60 & 37.9 & 1.4431 & 53.40 & 37.2 & 1.6842 & 61.20 & 30.3 \\
\hline 1.2486 & 45.70 & 40.4 & 1.4457 & 53.50 & 37.9 & 1.6878 & 61.30 & 26.5 \\
\hline 1.2510 & 45.80 & 42.6 & 1.4484 & 53.60 & 38.5 & 1.6918 & 61.40 & 23.4 \\
\hline 1.2532 & 45.90 & 44.3 & 1.4509 & 53.70 & 39.3 & 1.6963 & 61.50 & 21.0 \\
\hline 1.2555 & 46.00 & 45.6 & 1.4534 & 53.80 & 39.9 & 1.7013 & 61.60 & 19.3 \\
\hline 1.2576 & 46.10 & 46.4 & 1.4559 & 53.90 & 40.2 & 1.7067 & 61.70 & 18.5 \\
\hline 1.2598 & 46.20 & 47.1 & 1.4584 & 54.00 & 40.2 & 1.7122 & 61.80 & 18.4 \\
\hline 1.2619 & 46.30 & 47.4 & 1.4609 & 54.10 & 39.8 & 1.7176 & 61.90 & 19.3 \\
\hline 1.2640 & 46.40 & 47.5 & 1.4634 & 54.20 & 39.1 & 1.7226 & 62.00 & 20.9 \\
\hline 1.2661 & 46.50 & 47.6 & 1.4660 & 54.30 & 37.9 & 1.7271 & 62.10 & 23.5 \\
\hline 1.2682 & 46.60 & 47.5 & 1.4687 & 54.40 & 36.3 & 1.7311 & 62.20 & 26.8 \\
\hline 1.2703 & 46.70 & 47.3 & 1.4715 & 54.50 & 34.3 & 1.7346 & 62.30 & 30.6 \\
\hline 1.2724 & 46.80 & 47.1 & 1.4746 & 54.60 & 32.2 & 1.7377 & 62.40 & 35.0 \\
\hline 1.2746 & 46.90 & 47.1 & 1.4778 & 54.70 & 29.9 & 1.7404 & 62.50 & 39.5 \\
\hline 1.2767 & 47.00 & 47.3 & 1.4812 & 54.80 & 27.6 & 1.7428 & 62.60 & 43.8 \\
\hline 1.2788 & 47.10 & 47.4 & 1.4850 & 54.90 & 25.5 & 1.7450 & 62.70 & 47.6 \\
\hline 1.2809 & 47.20 & 47.5 & 1.4891 & 55.00 & 23.5 & 1.7470 & 62.80 & 50.7 \\
\hline 1.2830 & 47.30 & 47.7 & 1.4935 & 55.10 & 21.8 & 1.7489 & 62.90 & 53.4 \\
\hline 1.2851 & 47.40 & 47.8 & 1.4983 & 55.20 & 20.6 & 1.7507 & 63.00 & 55.1 \\
\hline 1.2872 & 47.50 & 48.0 & 1.5033 & 55.30 & 19.9 & 1.7525 & 63.10 & 55.9 \\
\hline 1.2893 & 47.60 & 48.4 & 1.5084 & 55.40 & 19.8 & 1.7543 & 63.20 & 55.7 \\
\hline 1.2913 & 47.70 & 48.8 & 1.5134 & 55.50 & 20.3 & 1.7561 & 63.30 & 54.7 \\
\hline 1.2934 & 47.80 & 49.0 & 1.5182 & 55.60 & 21.3 & 1.7580 & 63.40 & 53.1 \\
\hline 1.2954 & 47.90 & 49.4 & 1.5228 & 55.70 & 22.9 & 1.7599 & 63.50 & 50.9 \\
\hline 1.2974 & 48.00 & 49.5 & 1.5270 & 55.80 & 25.0 & 1.7619 & 63.60 & 48.5 \\
\hline 1.2994 & 48.10 & 49.4 & 1.5308 & 55.90 & 27.5 & 1.7640 & 63.70 & 45.7 \\
\hline 1.3015 & 48.20 & 49.1 & 1.5342 & 56.00 & 30.3 & 1.7663 & 63.80 & 42.8 \\
\hline 1.3035 & 48.30 & 48.9 & 1.5374 & 56.10 & 32.9 & 1.7687 & 63.90 & 40.0 \\
\hline 1.3055 & 48.40 & 48.5 & 1.5403 & 56.20 & 35.4 & 1.7713 & 64.00 & 37.4 \\
\hline 1.3076 & 48.50 & 48.1 & 1.5431 & 56.30 & 37.8 & 1.7741 & 64.10 & 35.0 \\
\hline 1.3097 & 48.60 & 47.6 & 1.5456 & 56.40 & 39.8 & 1.7770 & 64.20 & 33.1 \\
\hline 1.3118 & 48.70 & 47.1 & 1.5481 & 56.50 & 41.3 & 1.7801 & 64.30 & 31.6 \\
\hline 1.3140 & 48.80 & 46.3 & 1.5505 & 56.60 & 42.5 & 1.7833 & 64.40 & 30.7 \\
\hline 1.3161 & 48.90 & 45.5 & 1.5528 & 56.70 & 42.8 & 1.7866 & 64.50 & 30.5 \\
\hline 1.3184 & 49.00 & 44.6 & 1.5551 & 56.80 & 42.6 & 1.7899 & 64.60 & 30.8 \\
\hline 1.3206 & 49.10 & 43.9 & 1.5575 & 56.90 & 41.8 & 1.7931 & 64.70 & 31.8 \\
\hline 1.3229 & 49.20 & 43.2 & 1.5599 & 57.00 & 40.7 & 1.7962 & 64.80 & 33.3 \\
\hline 1.3253 & 49.30 & 42.6 & 1.5624 & 57.10 & 39.1 & 1.7991 & 64.90 & 35.4 \\
\hline 1.3276 & 49.40 & 42.1 & 1.5650 & 57.20 & 37.0 & 1.8019 & 65.00 & 37.8 \\
\hline 1.3300 & 49.50 & 41.8 & 1.5678 & 57.30 & 34.7 & 1.8044 & 65.10 & 40.5 \\
\hline 1.3324 & 49.60 & 41.7 & 1.5708 & 57.40 & 32.3 & 1.8068 & 65.20 & 43.2 \\
\hline 1.3348 & 49.70 & 41.7 & 1.5740 & 57.50 & 29.8 & 1.8091 & 65.30 & 46.2 \\
\hline 1.3372 & 49.80 & 41.8 & 1.5775 & 57.60 & 27.4 & 1.8111 & 65.40 & 49.2 \\
\hline
\end{tabular}

